Florida International University FIU Digital Commons

$8-28-2015$

\title{
Long-term Trends in Magnitude and Frequency of Extreme Rainfall Events in Florida
}

Tasnuva Mahjabin

tmahj001@fiu.edu

DOI: $10.25148 /$ etd.FIDC000168

Follow this and additional works at: https://digitalcommons.fiu.edu/etd

Part of the Civil Engineering Commons

\section{Recommended Citation}

Mahjabin, Tasnuva, "Long-term Trends in Magnitude and Frequency of Extreme Rainfall Events in Florida" (2015). FIU Electronic Theses and Dissertations. 2257.

https://digitalcommons.fiu.edu/etd/2257

This work is brought to you for free and open access by the University Graduate School at FIU Digital Commons. It has been accepted for inclusion in FIU Electronic Theses and Dissertations by an authorized administrator of FIU Digital Commons. For more information, please contact dcc@fiu.edu. 


\section{FLORIDA INTERNATIONAL UNIVERSITY}

Miami, Florida

\section{LONG-TERM TRENDS IN MAGNITUDE AND FREQUENCY OF EXTREME RAINFALL EVENTS IN FLORIDA}

A thesis submitted in partial fulfillment of

the requirements for the degree of

MASTER OF SCIENCE

in

CIVIL ENGINEERING

by

Tasnuva Mahjabin 
To: Interim Dean Ranu Jung

College of Engineering and Computing

This thesis, written by Tasnuva Mahjabin, and entitled Long-term Trends in Magnitude and Frequency of Extreme Rainfall Events in Florida, having been approved in respect to style and intellectual content, is referred to you for judgment.

We have read this thesis and recommend that it be approved.

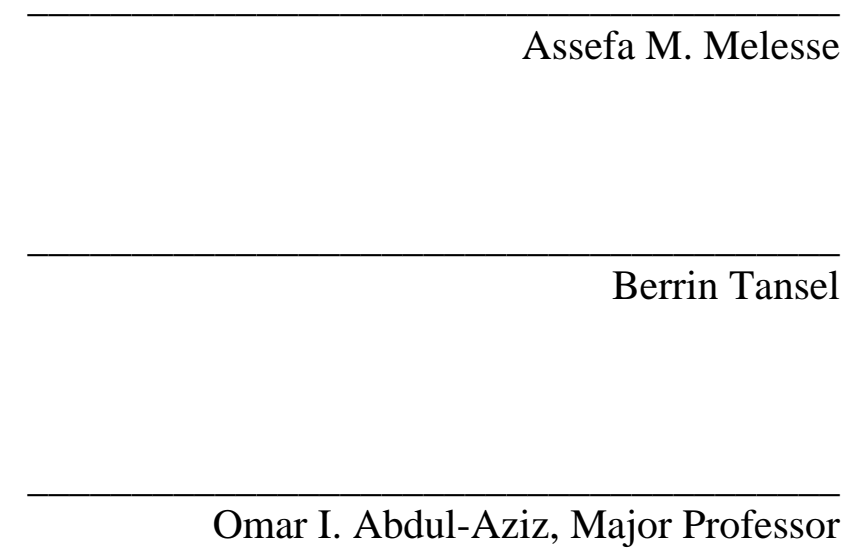

Date of Defense: August 28, 2015

The thesis of Tasnuva Mahjabin is approved.

Interim Dean Ranu Jung
College of Engineering and Computing

Florida International University, 2015 


\section{ACKNOWLEDGEMENTS}

I would like to thank Dr. Omar I. Abdul-Aziz for his mentoring, advice and constant support throughout my study at FIU. I count myself very blessed to have had the opportunity to work with him. I also express sincere gratitude to my committee members Dr. Berrin Tansel and Dr. Assefa M. Melesse for their assistance in completing this manuscript.

This thesis would be incomplete without mentioning the support from my entire family. I would especially thank my husband for his undying support and encouragement during this arduous process.

Financial support of this research has been provided by the State of Florida Office of Insurance Regulations through the "Florida Public Hurricane Loss Model Enhancements" project. 


\section{ABSTRACT OF THE THESIS \\ LONG-TERM TRENDS IN MAGNITUDE AND FREQUENCY OF EXTREME \\ RAINFALL EVENTS IN FLORIDA}

by

Tasnuva Mahjabin

Florida International University, 2015

Miami, Florida

\section{Professor Omar I. Abdul-Aziz, Major Professor}

This study computed trends in extreme precipitation events of Florida for 1950-2010. Hourly aggregated rainfall data from 24 stations of the National Climatic Data Centre were analyzed to derive time-series of extreme rainfalls for 12 durations, ranging from 1 hour to 7 day. Non-parametric Mann-Kendall test and Theil-Sen Approach were applied to detect the significance of trends in annual maximum rainfalls, number of above threshold events and average magnitude of above threshold events for four common analysis periods. Trend Free Pre-Whitening (TFPW) approach was applied to remove the serial correlations and bootstrap resampling approach was used to detect the field significance of trends. The results for annual maximum rainfall revealed dominant increasing trends at the statistical significance level of 0.10, especially for hourly events in longer period and daily events in recent period. The number of above threshold events exhibited strong decreasing trends for hourly durations in all time periods. 


\section{TABLE OF CONTENTS}

CHAPTER

PAGE

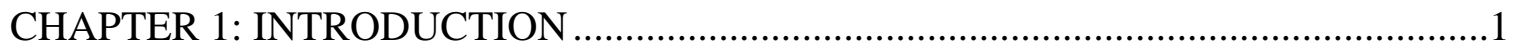

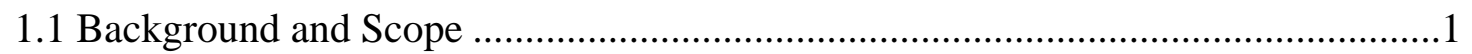

1.2 Objectives of the Study ....................................................................................

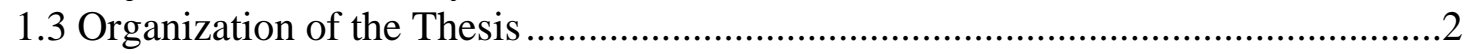

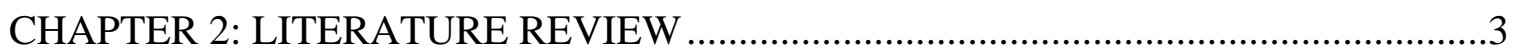

CHAPTER 3: MATERIALS AND METHODS …………...........................................

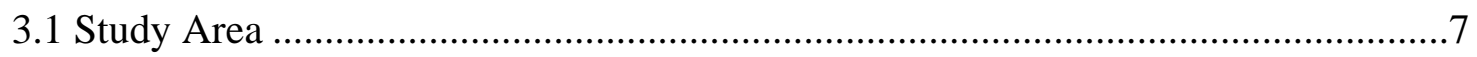

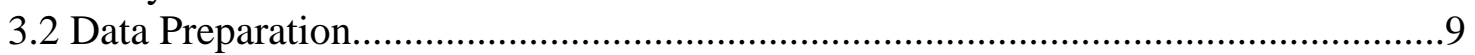

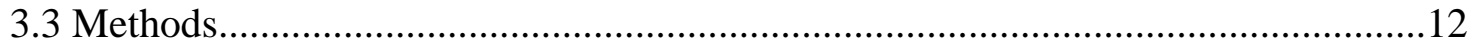

3.3.1 Mann-Kendall Non-Parametric Test .............................................................12

3.3.2 Theil-Sen Approach (TSA) for Trend Slope ..................................................14

3.3.3 Trend Free Pre-Whitening (TFPW) Approach ..................................................15

3.3.4 Bootstrap Resampling Approach ....................................................................16

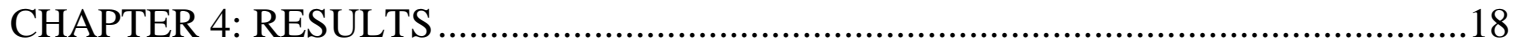

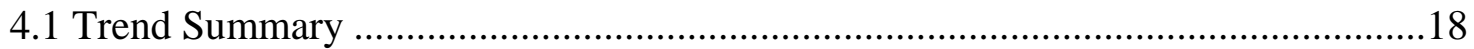

4.1.1 Annual Maximum Rainfall Events ................................................................18

4.1.2 Number of Above Threshold Events ..........................................................20

4.1.3 Average Magnitude of the Above Threshold Events........................................21

4.2 Trend Slopes ……….........................................................................................23

4.2.1 Trend Slopes for the Annual Maximum Rainfall Events...................................23

4.2.2 Trend Slopes for the Number of Above Threshold Events.................................25

4.2.3 Trend Slopes for the Average Magnitude of the Above Threshold Events......26

4.3 Spatial Patterns of Trends for Annual Maximum Events ..........................................27

4.3.1 One Hour Event ..........................................................................................2

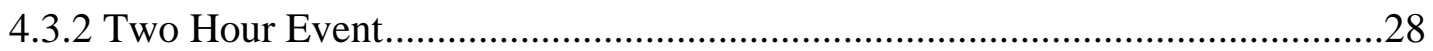

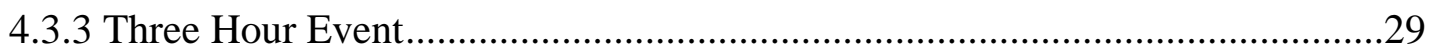

4.3.4 Six Hour Event...........................................................................................

4.3.5 Twelve Hour Event ......................................................................................31

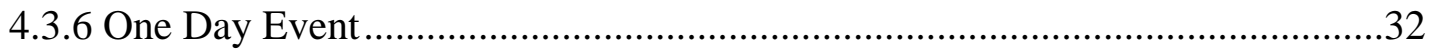

4.3.7 Two Day Event ……………………..........................................................33

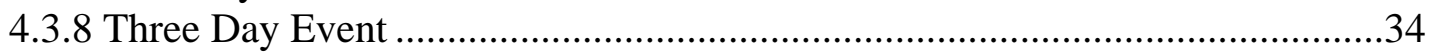

4.3.9 Four Day Event .............................................................................................35

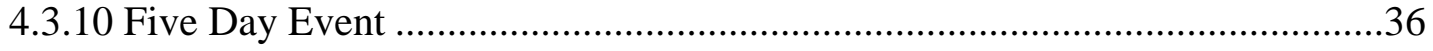

4.3.11 Six Day Event ...........................................................................................

4.3.12 Seven Day Event...............................................................................................38

4.4 Spatial Patterns of Trends for Number of Above Threshold Events ........................39

4.4.1 Hourly Events ...............................................................................................39

4.4.2 Daily Events...............................................................................................42 
CHAPTER 5: DISCUSSION AND CONCLUSIONS

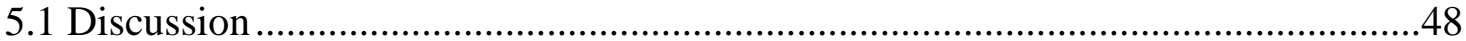

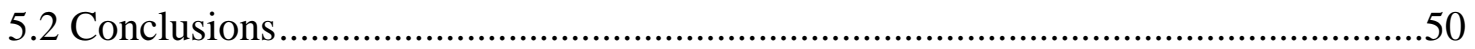

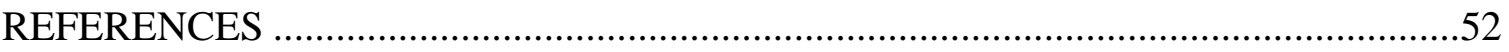

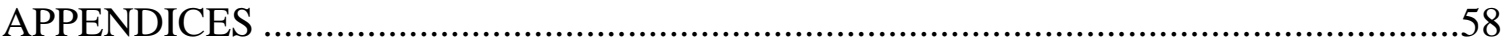




\section{LIST OF FIGURES}

FIGURE

PAGE

Figure 1 Study area map indicating major cities/towns and five water management districts of Florida.................................

Figure 2 Map indicating the stations used for long-term precipitation trend analysis. Number below the station indicates the COOP ID..........

Figure 3 Box-and-whisker plots of trend slopes (mm/year) for the magnitude of the annual maximum rainfall events for (a) 1950-2010, (b) 19602010, (c) 1970-2010 and (d) 1980-2010 analysis periods

Figure 4 Box-and-whisker plots of trend slopes (number/year) for the number of above threshold events for (a) 1950-2010, (b) 1960-2010, (c) 19702010 and (d) 1980-2010 analysis periods

Figure 5 Box-and-whisker plots of trend slopes (mm/year) for the average magnitude of the above threshold events for (a) 1950-2010, (b) 19602010, (c) 1970-2010 and (d) 1980-2010 analysis periods.

Figure 6 Spatial pattern of the trend results for the annual maximum rainfall event for one hour duration for the 1950-2010 (left) and 1980-2010 (right) analysis periods. The slope value (mm/year) for significant trend is also indicated.

Figure 7 Spatial pattern of the trend results for the annual maximum rainfall event for two hour duration for the 1950-2010 (left) and 1980-2010 (right) analysis periods. The slope value (mm/year) for significant trend is also indicated

Figure 8 Spatial pattern of the trend results for the annual maximum rainfall event for three hour duration for the 1950-2010 (left) and 1980-2010 (right) analysis periods. The slope value (mm/year) for significant trend is also indicated.

Figure 9 Spatial pattern of the trend results for the annual maximum rainfall event for six hour duration for the 1950-2010 (left) and 1980-2010 (right) analysis periods. The slope value (mm/year) for significant trend is also indicated.

Figure 10 Spatial pattern of the trend results for the annual maximum rainfall event for twelve hour duration for the 1950-2010 (left) and 1980-2010 
(right) analysis periods. The slope value (mm/year) for significant

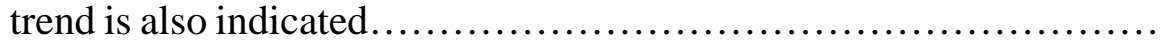

Figure 11 Spatial pattern of the trend results for the annual maximum rainfall event for one day duration for the 1950-2010 (left) and 1980-2010 (right) analysis periods. The slope value (mm/year) for significant trend is also indicated.

Figure 12 Spatial pattern of the trend results for the annual maximum rainfall event for two day duration for the 1950-2010 (left) and 1980-2010 (right) analysis periods. The slope value (mm/year) for significant trend is also indicated.

Figure 13 Spatial pattern of the trend results for the annual maximum rainfall event for three day duration for the 1950-2010 (left) and 1980-2010 (right) analysis periods. The slope value (mm/year) for significant trend is also indicated.

Figure 14 Spatial pattern of the trend results for the annual maximum rainfall event for four day duration for the 1950-2010 (left) and 1980-2010 (right) analysis periods. The slope value (mm/year) for significant trend is also indicated.

Figure 15 Spatial pattern of the trend results for the annual maximum rainfall event for five day duration for the 1950-2010 (left) and 1980-2010 (right) analysis periods. The slope value (mm/year) for significant trend is also indicated.

Figure 16 Spatial pattern of the trend results for the annual maximum rainfall event for six day duration for the 1950-2010 (left) and 1980-2010 (right) analysis periods. The slope value (mm/year) for significant trend is also indicated.

Figure 17 Spatial pattern of the trend results for the annual maximum rainfall event for seven day duration for the 1950-2010 (left) and 1980-2010 (right) analysis periods. The slope value (mm/year) for significant trend is also indicated.

Figure 18 Spatial pattern of the trend results for the number of above threshold events for one hour duration for the 1950-2010 (left) and 1980-2010 (right) analysis periods. The slope value (no. of events/year) for significant trend is also indicated.

Figure 19 Spatial pattern of the trend results for the number of above threshold events for two hour duration for the 1950-2010 (left) and 1980-2010 
(right) analysis periods. The slope value (no. of events/year) for significant trend is also indicated..................................

Figure 20 Spatial pattern of the trend results for the number of above threshold events for three hour duration for the 1950-2010 (left) and 1980-2010 (right) analysis periods. The slope value (no. of events/year) for significant trend is also indicated....

Figure 21 Spatial pattern of the trend results for the number of above threshold events for six hour duration for the 1950-2010 (left) and 1980-2010 (right) analysis periods. The slope value (no. of events/year) for significant trend is also indicated.................................

Figure 22 Spatial pattern of the trend results for the number of above threshold events for twelve hour duration for the 1950-2010 (left) and 19802010 (right) analysis periods. The slope value (no. of events/year) for significant trend is also indicated....................................

Figure 23 Spatial pattern of the trend results for the number of above threshold events for one day duration for the 1950-2010 (left) and 1980-2010 (right) analysis periods. The slope value (no. of events/year) for significant trend is also indicated.................................

Figure 24 Spatial pattern of the trend results for the number of above threshold events for two day duration for the 1950-2010 (left) and 1980-2010 (right) analysis periods. The slope value (no. of events/year) for significant trend is also indicated................................

Figure 25 Spatial pattern of the trend results for the number of above threshold events for three day duration for the 1950-2010 (left) and 1980-2010 (right) analysis periods. The slope value (no. of events/year) for significant trend is also indicated................................

Figure 26 Spatial pattern of the trend results for the number of above threshold events for four day duration for the 1950-2010 (left) and 1980-2010 (right) analysis periods. The slope value (no. of events/year) for significant trend is also indicated...............................

Figure 27 Spatial pattern of the trend results for the number of above threshold events for five day duration for the 1950-2010 (left) and 1980-2010 (right) analysis periods. The slope value (no. of events/year) for significant trend is also indicated...............................

Figure 28 Spatial pattern of the trend results for the number of above threshold events for six day duration for the 1950-2010 (left) and 1980-2010 
(right) analysis periods. The slope value (no. of events/year) for

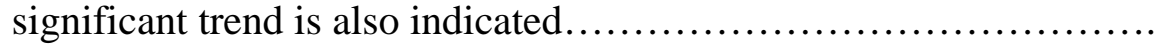

Figure 29 Spatial pattern of the trend results for the number of above threshold events for seven day duration for the 1950-2010 (left) and 1980-2010 (right) analysis periods. The slope value (no. of events/year) for significant trend is also indicated...................................... 


\section{CHAPTER 1 \\ INTRODUCTION}

\subsection{Background and Scope}

Precipitation is one of the most important climatic parameters because any changes in precipitation patterns, intensity or extremes can affect the overall hydrological and environmental processes. The Fourth Assessment Report (AR4) of the Intergovernmental Panel on Climate Change (IPCC) indicates that the increase in intensity and frequency of extreme rainfall events is one of the crucial reasons for climate change vulnerability (Parry et al. 2007). Some experimentations through global climate modeling also predict that increase in extreme precipitation will be higher than increase in mean precipitation (Meehl et al. 2007; Bates et al. 2008; Mailhot et al. 2011). Similarly, increase in heavy precipitation will also raise the risk of flash floods and urban flooding (Bates et al. 2008; Willems et al. 2009; Mailhot et al. 2010). A thorough investigation of trends and variability in the longterm extreme precipitation data can provide a valuable understanding and insights into climate change and its anticipated impacts. It is therefore imperative to understand and analyze the magnitude and frequency of extreme rainfall events, especially for a region like Florida, where large spatial and temporal changes in rainfall are observed.

\subsection{Objectives of the Study}

The overall goal of this research is to provide a comprehensive understanding of the temporal and spatial patterns of trends in precipitation extremes over the last several decades in Florida. The study used hourly rainfall data from 24 rain gauge stations uniformly located throughout the state of Florida. The non-parametric Mann-Kendall test was applied to detect the significance of trend and the Theil-Sen Approach (TSA) was used 
to quantify the trend magnitude. The analyses were conducted for the four separate study periods of 61 (1950-2010), 51 (1960-2010), 41 (1970-2010) and 31 (1980-2010) year, respectively. A Trend Free Pre-Whitening (TFPW) approach was used to remove any serial correlations from the time series data. A bootstrap resampling approach was also applied to estimate the global or field significance of the trend results.

The specific objectives of the study are as below.

- To quantify the long-term trends in the magnitude of the annual maximum rainfall of 12 durations ranging from 1 hour to 7 day.

- To detect trends for the number of above threshold events and the average magnitude of the above threshold events considering the $99^{\text {th }}$ percentile rainfall magnitude as the threshold value.

- To perform a comparative study between the magnitude and frequency of extreme precipitation in terms of both spatial and temporal scales.

\subsection{Organization of the Thesis}

This thesis is comprised of five distinct chapters. The current chapter provides a brief introduction and scope of the study along with the objectives and organization of the thesis. Chapter 2 reviews the detailed literature related to the investigation on precipitation trends in the U.S. and across the globe. Chapter 3 describes the study area, preparation of rainfall data and detailed methodology used for these research. Chapter 4 describes the results obtained from trend analysis and their spatial variability along the state. Chapter 5 consists of a discussion where comparison between the results from this work and other previous studies has been illustrated, and conclusions where important findings from the current research have been established. 


\section{CHAPTER 2}

\section{LITERATURE REVIEW}

Many studies have been conducted to detect precipitation trends in United States. Lettenmaier et al. (1994) examined monthly precipitation trends for the continental United States during 1948-88 and identified increases in precipitation from September through December especially for the central part of the country. Karl and Knight (1998) also described that annual precipitation had increased about $10 \%$ over the U.S. for duration 1910-1996. Large increase in fall precipitation was observed in the eastern U.S. (Small et al. 2006) and in the central and southern U.S. (Wang et al. 2009) during the last several decades. Over the past century in Central Plains/northwestern Midwest, more positive than negative long-term trends in annual total precipitation was estimated by Pryor et al. (2009). Sayemuzzaman and Jha (2014) performed a spatial and temporal analysis of precipitation trend for the state of North Carolina for a period of 1950-2009. They found a notable increasing trend for winter and decreasing trend for fall precipitation. Annual, spring and summer precipitation showed mixed (increasing/decreasing) trend in their study.

Several prior studies have found it pivotal to identify and analyze trends in precipitation extremes so that the research outcomes can be used to implement a range of adaptation options to manage the heavy downpours. For example, Frich et al. (2002) used a global dataset to investigate the severity of climate change due to extreme events over the second half of the $20^{\text {th }}$ century. The study observed significant increases in the extreme amount derived from wet spells and number of heavy rainfall events. Kunkel et al. (2003) examined extreme precipitation events (1, 5, 10 and 30 day durations and 1,5 and 20 year return periods) in the United States for 1895-2000. In their study, heavy precipitation frequencies 
were relatively high during the late 19th/early 20th Centuries, then decreasing to a minimum in the 1920s and 30s, again followed by a general increase into the 1990s. In another study (Kunkel et al. 2007), they used U.S. Cooperative Observer Network (COOP) data to assess the uncertainty in heavy precipitation frequency. Peterson et al. (2008) concluded that, heavy precipitation had been increasing over the last half century in North America and the average amount of precipitation falling on days with precipitation had also been increasing.

In the South of Portugal, Costa and Soares (2009) evaluated temporal patterns in extreme precipitation and uncertainty in rainfall patterns for 1955-1999 period. The research found an evidence of the increasing short-term precipitation intensity over the region during the last three decades of the twentieth century. Mishra and Singh (2010) fitted generalized extreme value (GEV) distribution to precipitation extremes in Texas. The research identified distinguished patterns in 1, 7 and 30 day annual maximum events for the preclimatic change period (1925-1964) and the post-climatic change period (1965-2005).

A peaks over threshold (POT) analysis for durations of 1, 2, 6, 12 and 24 hours was reported by Burn et al. (2011) for British Columbia, Canada. The study identified generally increasing trends in the extreme rainfall events, particularly in summer season and in short rainfall events. In an analysis of the annual maximum rainfall data from 51 stations in Canada, Burn and Taleghani (2013) found more positive trends and larger changes in the longer duration rainfall. A recent study by Yilmaz et al. (2014) examined trends in extreme rainfall data in Melbourne (Australia) and detected statistically significant trends for storm durations of $30 \mathrm{~min}, 3 \mathrm{~h}$ and $48 \mathrm{~h}$. In order to find the effect of urbanization on precipitation patterns, Keuser (2014) investigated changes in mean and extreme precipitation in the 
metropolitan area of Wisconsin for 1950-2006. The study identified no trends for extreme precipitation but significant increasing trends for annual precipitation particularly in the northern part of the study area.

Though large scale examination of precipitation trends provide an overall summary of change and variability, more regional analysis is required for the interpretation of local impact and adequate measures (Bawden et al. 2014). For West Central Florida, Nadarajah (2005) fitted generalized extreme value (GEV) distribution to the annual maxima of daily rainfall data for period of 1901-2003. The study found non-stationarity in trends for eight of the fourteen locations; quantified the change in extreme rainfall for each location and provided return levels for the years 2010, 2020, 2050 and 2100.

Knight and Davis (2009) found significant contribution of tropical cyclones to the total annual precipitation especially in the region of the Southeast Atlantic coast. Obeysekera et al. (2011) investigated the average and extreme precipitation for South Florida and performed a linear trend detection for annual values as well as for dry and wet season values. However, they found no statistical evidence of linear trend either in the magnitude or extremes for the 1950-2007 period.

Martinez et al. (2012) examined the monthly, seasonal and annual precipitation trends over Florida and found significant decreasing trends in the months of October and May for the 1895-2009 and 1970-2009 periods, respectively. They concluded that the significant reduction in May precipitation in the 1970-2009 period is an indication of the delayed onset of the wet season (typically from June to September) in much of the state. A similar finding was also obtained by Irizarry-Ortiz et al. (2013), who noticed a general decline in wet season precipitation across the state of Florida and this decrease was found most evident 
for the month of May. Teegavarapu et al. (2013) determined the influence of Atlantic Multidecadal Oscillation (AMO) phases on precipitation extremes in Florida. Their work emphasized on the spatial and temporal variability of long-term extreme precipitation events during the two phases of AMO. However, the trend analysis studies for Florida were performed mainly for the annual, seasonal and monthly precipitation data sets, therefore trends and variability in the hourly and daily rainfall events remain largely unknown. This study will present a quantitative understanding of the historical trends in extreme precipitation events based on hourly rainfall data for different storm durations across the state of Florida. 


\section{CHAPTER 3}

\section{MATERIALS AND METHODS}

\subsection{Study Area}

The state of Florida is home to over 19 million people with an area of 58,560 square miles (State of Florida Website, 2015). It is located on a peninsula between the Atlantic Ocean, the Gulf of Mexico and the Stairs of Florida. Florida is considered as a hot and humid state where temperatures can exceed $32{ }^{\circ} \mathrm{C}$ for about half of the year and relative humidity typically exceeds 50\% (Black 1993). The majority of the state has a subtropical climate while the southernmost areas can be classified as tropical. There are two main seasons known as wet and dry and each season has a duration of 6 months. The wet season lasts from May to October, whereas the dry season lasts from November to April (Teegavarapu et al. 2013). The average annual rainfall is about $1360 \mathrm{~mm} /$ year (USGS, 2006) and more than half the rain falls in the wet season, which is associated with thundershowers, squalls and tropical cyclones (McPherson and Halley 1996).

The low topographic relief and large spatio-temporal variability in rainfall has made the state of Florida vulnerable to climate change. The highest precipitation occurs in the Panhandle while the lowest occurs in the Keys (Obeysekera et al. 2006). The sea breeze circulation of the coastal areas has effect on enhancing convection which characterize the wet season precipitation, while the dry season precipitation is largely influenced by the frontal systems (Obeysekera et al. 2011). In south Florida, the developed areas in the east coast have received more precipitation than both interior areas and the west coast. Whereas, the northern portion of the state has experienced a second peak in precipitation during winter months associated with frontal low-pressure systems (Irizarry-Ortiz et al. 2013). 
The interactions between the Atlantic Multidecadal Oscillation (AMO), El Niño Southern Oscillation (ENSO) and Pacific Decadal Oscillation (PDO) indices have potential influences on the short-term and multi-decadal trends in central and south Florida precipitation (Trimble et al. 2006).

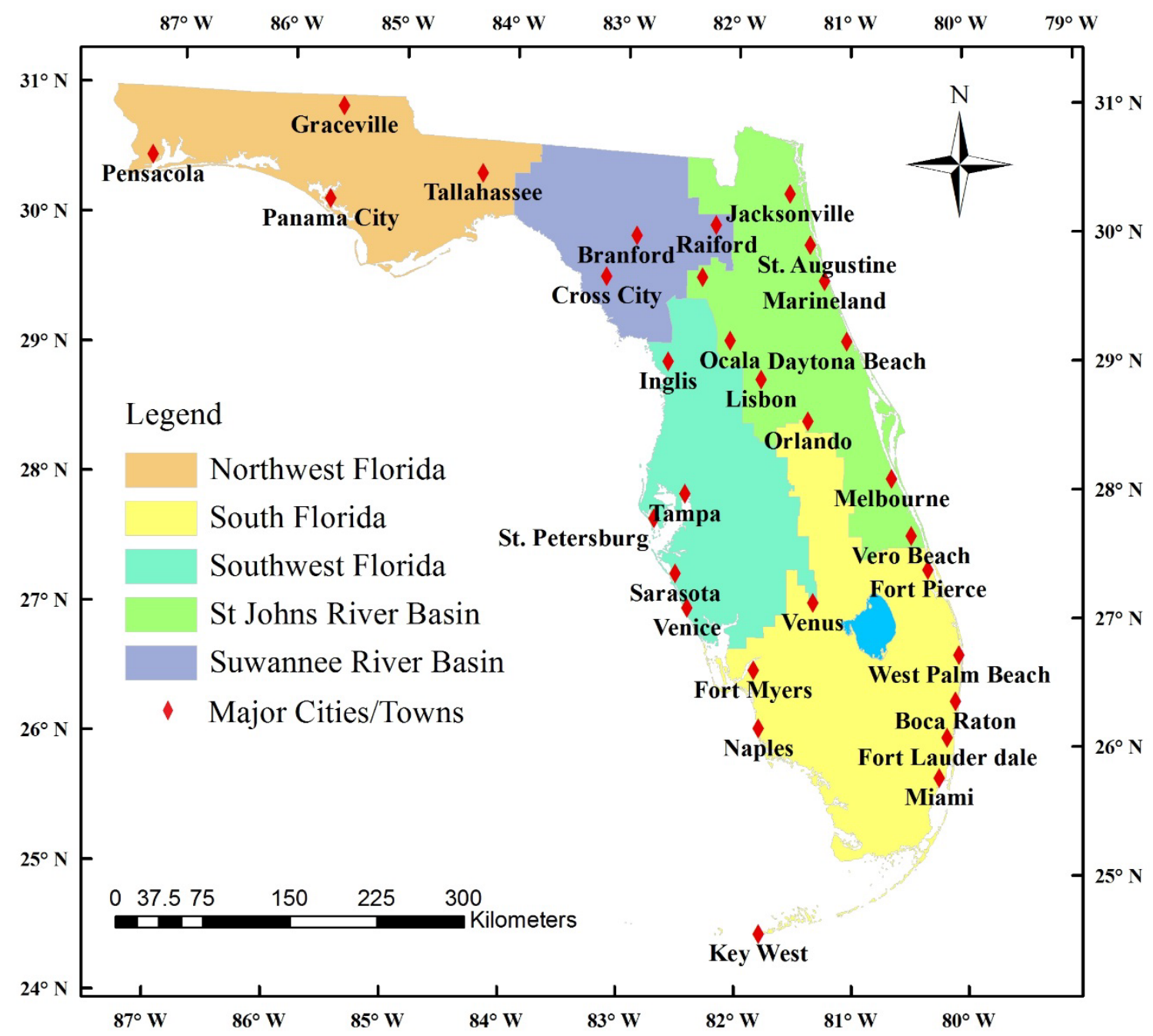

Figure 1: Study area map indicating major cities/towns and five water management districts of Florida. 
In this research, trend analysis was conducted for the whole state of Florida. The study domain is illustrated in Fig. 1. In order to interpret the spatial patterns of trends, we divided the whole study area into five distinct regions which were consistent with the state's five water management districts. These water management districts are named as Northwest Florida, Suwannee River Basin, St Johns River Basin, Southwest Florida and South Florida (Florida Department of Environmental Protection Website, 2015); which are mainly responsible for regulating water resources facilities in Florida. The locations of the major cities and towns are also provided in the map (Fig. 1).

\subsection{Data Preparation}

This study examined long-term precipitation records throughout the state of Florida. The hourly precipitation data were collected from 24 rain gauge stations from the National Climatic Data Center (NCDC) (National Climatic Data Center Website, 2015) for the time period of 1950-2010. The hourly data were then used to derive the rainfall events for durations of 2, 3, 6 and 12 hour and 1, 2, 3, 4, 5, 6 and 7 day, respectively. This database was then used to derive, on an annual basis, the magnitude of the maximum rainfall events, the number of above threshold events and the average magnitude of the above threshold events for twelve particular durations (1 hour to 7 day). The threshold was defined by sorting the data for a given duration; the $99^{\text {th }}$ percentile rainfall magnitude was used as the threshold value. A unique threshold value was identified for each station and duration. Trend analysis was performed for these three defined variables for each storm duration and for specific four analysis periods of 61 (1950-2010), 51 (1960-2010), 41 (1970-2010) and 31 (1980-2010) year. 


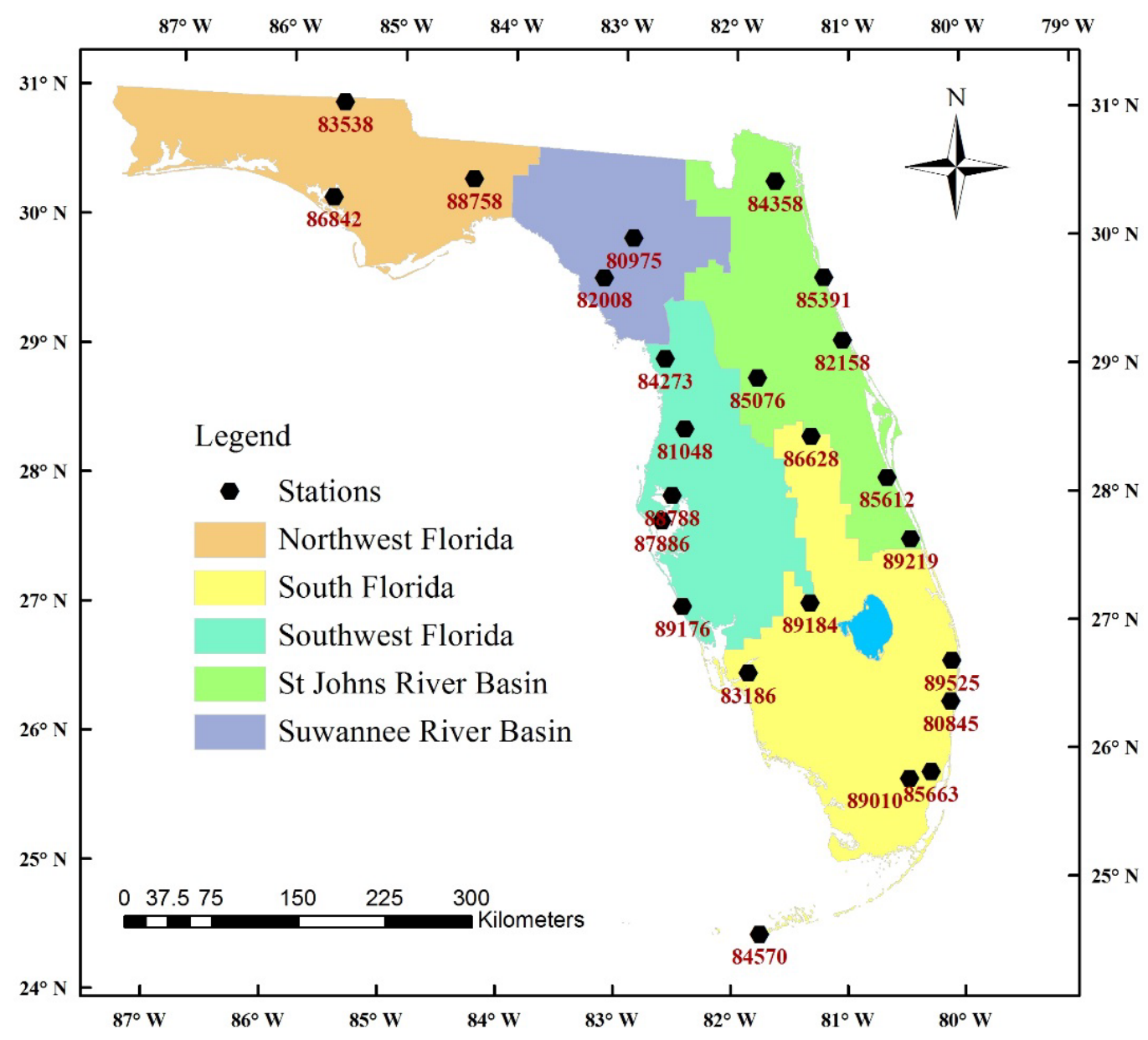

Figure 2: Map indicating the stations used for long-term precipitation trend analysis. Number below the station indicates the COOP ID.

For this research, the stations were selected mainly based on their record length and record completeness. Any year having more than 30\% missing values was eliminated from the dataset. Besides, stations having more than four missing years in each time period were also excluded from the analyses (Abdul-Aziz and Burn 2006; Burn et al. 2011). The study also computed trends by allowing five missing years and eight missing years for each time period. However, in order to be consistent with the current literatures, we finally reported our results which were obtained from permitting four missing years per analysis period. For the time period of 61 and 51 year, respectively 13 and 18 stations were available for 
the analysis. Whether 24 stations were available for each of the last two periods (41 and 31 year). The spatial distributions of the stations are shown in Fig. 2. A brief summary of the stations is also presented in Table 1, which includes the range of the available years, location and elevation of each station. For 61 year of recorded data sets, statistical summary of the annual maximum rainfall values are also illustrated in Appendix 1. The overall range of the derived maximum rainfall was found between 0.5 inch and 27 inch for different durations (Appendix 1).

Table 1: Summary of the 24 stations used for trend analysis

\begin{tabular}{|c|c|c|c|c|c|c|}
\hline \multirow{2}{*}{ Station ID } & \multirow{2}{*}{ Station Name } & \multirow{2}{*}{$\begin{array}{r}\text { Lat } \\
\left({ }^{\circ} \mathrm{C}\right)\end{array}$} & \multirow{2}{*}{$\begin{array}{c}\text { Long } \\
\left({ }^{\circ} \mathrm{C}\right)\end{array}$} & \multirow{2}{*}{$\begin{array}{c}\text { Elevation } \\
\text { (m) }\end{array}$} & \multicolumn{2}{|c|}{ Period of Record } \\
\hline & & & & & Start & End \\
\hline COOP:080845 & BOCA RATON & 26.37 & -80.11 & 4.3 & $1 / 1 / 1950$ & $12 / 1 / 2010$ \\
\hline COOP:089525 & WEST PALM BEACH INTERNATIONAL AIRPORT & 26.68 & -80.10 & 5.8 & $1 / 1 / 1950$ & $12 / 26 / 2010$ \\
\hline COOP:089184 & VENUS & 27.14 & -81.33 & 49.1 & $1 / 1 / 1950$ & $12 / 26 / 2010$ \\
\hline COOP:089176 & VENICE & 27.10 & -82.44 & 2.4 & $2 / 1 / 1950$ & $12 / 26 / 2010$ \\
\hline COOP:082158 & DAYTONA BEACH INTERNATIONAL AIRPORT & 29.18 & -81.05 & 9.4 & $1 / 1 / 1950$ & $12 / 26 / 2010$ \\
\hline COOP:084273 & INGLIS $3 \mathrm{E}$ & 29.03 & -82.62 & 9.1 & $1 / 1 / 1950$ & $12 / 26 / 2010$ \\
\hline COOP:085391 & MARINELAND & 29.67 & -81.22 & 1.5 & $1 / 1 / 1950$ & $12 / 25 / 2010$ \\
\hline COOP:083538 & GRACEVILLE 1 SW & 30.96 & -85.53 & 48.8 & $1 / 1 / 1950$ & $12 / 25 / 2010$ \\
\hline COOP:080975 & BRANFORD & 29.96 & -82.91 & 9.1 & $1 / 1 / 1950$ & $12 / 25 / 2010$ \\
\hline COOP:087886 & ST PETERSBURG ALBERT WHITTED AIRPORT & 27.76 & -82.63 & 2.4 & $1 / 1 / 1950$ & $11 / 1 / 2010$ \\
\hline COOP:088788 & TAMPA INTERNATIONAL AIRPORT & 27.96 & -82.54 & 5.8 & $1 / 1 / 1950$ & $12 / 26 / 2010$ \\
\hline COOP:088758 & TALLAHASSEE REGIONAL AIRPORT & 30.39 & -84.35 & 16.8 & 6/1/1958 & $12 / 26 / 2010$ \\
\hline COOP:085612 & MELBOURNE WEATHER FORECAST OFFICE & 28.11 & -80.65 & 10.7 & $1 / 1 / 1950$ & $12 / 22 / 2010$ \\
\hline COOP:081048 & BROOKSVILLE 7 SSW & 28.48 & -82.44 & 20.4 & $1 / 1 / 1972$ & $12 / 18 / 2010$ \\
\hline COOP:086628 & ORLANDO INTERNATIONAL AIRPORT & 28.43 & -81.33 & 27.4 & $5 / 1 / 1974$ & $12 / 26 / 2010$ \\
\hline COOP:083186 & FORT MYERS PAGE FIELD AIRPORT & 26.59 & -81.86 & 4.6 & $1 / 1 / 1960$ & $12 / 27 / 2010$ \\
\hline COOP:084570 & KEY WEST INTERNATIONAL AIRPORT & 24.55 & -81.75 & 1.2 & 3/1/1958 & $12 / 31 / 2010$ \\
\hline COOP:089010 & TRAIL GLADE RANGES & 25.77 & -80.47 & 3.0 & $1 / 1 / 1973$ & $12 / 1 / 2010$ \\
\hline COOP:085663 & MIAMI INTERNATIONAL AIRPORT & 25.82 & -80.28 & 7.0 & $1 / 1 / 1951$ & $12 / 31 / 2010$ \\
\hline COOP:085076 & LISBON & 28.88 & -81.80 & 21.0 & $1 / 1 / 1959$ & $12 / 25 / 2010$ \\
\hline COOP:084358 & JACKSONVILLE INTERNATIONAL AIRPORT & 30.42 & -81.65 & 11.9 & $1 / 1 / 1950$ & $12 / 26 / 2010$ \\
\hline COOP:082008 & CROSS CITY 2 WNW & 29.65 & -83.17 & 12.8 & 7/1/1966 & $12 / 25 / 2010$ \\
\hline COOP:086842 & PANAMA CITY & 30.22 & -85.60 & 9.8 & $1 / 1 / 1972$ & $12 / 25 / 2010$ \\
\hline COOP:089219 & VERO BEACH 4 SE & 27.63 & -80.45 & 6.1 & $5 / 1 / 1965$ & $12 / 21 / 2010$ \\
\hline
\end{tabular}


While preparing the database, we found some stations containing accumulated values with duration from several hours to months. These accumulated values were equally distributed between their intervals. To find out whether it influenced the result, we picked eleven stations which had negligible accumulated values and performed the analysis. The trend results exhibited by these selected stations were quite similar with the overall results computed from the total 24 stations.

\subsection{Methods}

\subsubsection{Mann-Kendall Non-Parametric Test}

The Mann-Kendall statistical test, established by Mann (1945) and Kendall $(1938,1976)$, was used to estimate the significance of trends in precipitation time-series data. This method computes the significance of trends from standard normal variate Zs (Mann, 1945), which indicates the strength of trend results. A statistical significance level of 0.1 was considered for this research for all the tests. The Mann-Kendall nonparametric method was selected for the study because of its ability to detect monotonic trends in non-normally distributed data. Many studies have effectively used this rank-based method to determine the significance of trends in hydro-meteorological data (Kunkel et al. 1999; Yue et al. 2002; Abdul-Aziz and Burn 2006; Andreadis and Lettenmaier 2006; Novotny and Stefan 2007; Burn 2008; Pryor et al. 2009; Douglas and Fairbank 2010; Martinez et al. 2012; IrizarryOrtiz et al. 2013; Sayemuzzaman and Jha 2014). The Mann-Kendall test statistic, S is calculated by the following Eq. (1).

$$
S=\sum_{i=1}^{n-1} \sum_{j=i+1}^{n} \operatorname{sgn}\left(X_{j}-X_{i}\right)
$$


where $\mathrm{n}$ is the number of data available in the time series, $\mathrm{X}_{\mathrm{i}}$ and $\mathrm{X}_{\mathrm{j}}$ are sequential data values for times $t_{i}$ and $t_{j}(j>i)$, and sgn is the sign function shown in Eq. (2).

$$
\operatorname{sgn}\left(X_{j}-X_{i}\right)=\left\{\begin{array}{c}
+1, \text { if }\left(X_{j}-X_{i}\right)>0 \\
0, \text { if }\left(X_{j}-X_{i}\right)=0 \\
-1, \text { if }\left(X_{j}-X_{i}\right)<0
\end{array}\right.
$$

The null hypothesis $\mathrm{H}_{0}$ states that the data $\left(\mathrm{X}_{1} \ldots \mathrm{X}_{\mathrm{n}}\right)$ are independent and identically distributed random variables (i.e. there is no trend in the data set, $S=0$ ). The alternative hypothesis $\mathrm{H}_{1}$ is that the distribution of $\mathrm{X}_{\mathrm{i}}$ and $\mathrm{X}_{\mathrm{j}}$ are not identical for all $\mathrm{i}, \mathrm{j} \leq \mathrm{n}$ and $\mathrm{i} \neq \mathrm{j}$ (i.e. there exists a trend in the data set, $S \neq 0$ ). The null hypothesis is rejected when $S$ is significantly different from zero and when a monotonic trend is present over time.

In cases where the sample size $\mathrm{n}>10$ and ties are present, a standard normal variate $\mathrm{Z}_{\mathrm{s}}$ (Eq.

3 ) is used following the normal distribution $\sim \mathrm{N}(0,1)$. The null hypothesis is rejected if $\left|\mathrm{Z}_{\mathrm{s}}\right|$ exceeds the critical value $\mathrm{Z}_{\alpha / 2}$ where $\mathrm{F}_{\mathrm{N}}\left(\mathrm{Z}_{\alpha / 2}\right)=\alpha / 2, \mathrm{~F}_{\mathrm{N}}$ denotes the standard normal distribution and $\alpha$ denotes the selected significance level. An upward or downward trend can be identified from a positive or negative $Z_{s}$ value, respectively.

$$
Z_{S}=\left\{\begin{array}{l}
\frac{S-1}{\sigma_{S}} i f S>0 \\
0 i f S=0 \\
\frac{S+1}{\sigma_{S}} i f S<0
\end{array}\right.
$$

The standard deviation of S can be computed by following Kendall (1976).

$$
\sigma_{S}=\sqrt{\frac{n(n-1)(2 n+5)-\sum_{p=1}^{q} t_{p}\left(t_{p}-1\right)\left(2 t_{p}+5\right)}{18}}
$$


where $\mathrm{n}$ is the number of data points, $\mathrm{q}$ is the number of tied groups and $t_{\mathrm{p}}$ represents the size of the $\mathrm{p}^{\text {th }}$ tied group. In our analysis we followed $10 \%$ statistical significance level, which indicated that there was a $90 \%$ certainty in the hypothesis that a trend exists in the data set. Additional information on Mann-Kendall test can be obtained from Yue et al. (2002a, b).

\subsubsection{Theil-Sen Approach (TSA) for Trend Slope}

The Theil-Sen Approach (TSA) (Theil 1950; Sen 1968), a nonparametric alternative to linear regression, was used to estimate the magnitude of the trend slope $(\beta)$ for each rainfall measure and each rainfall station. For all $\mathrm{j}>\mathrm{i}$, a total $n(n-1) / 2$ pairs of slopes can be computed for $n$ number of data points. The TSA method then calculates the trend slope as the median of all pairwise slopes.

The slope of the trend line, $\beta$ can be determined as follows:

$\beta=\operatorname{Median}\left\{\frac{X_{j}-X_{i}}{j-i}\right\}$

where $X_{i}$ and $X_{j}$ are the data values for the corresponding time $i$ and $j(i<j)$, respectively.

The Theil-Sen Approach can be successfully used in conjunction with the Mann-Kendall statistical test. The method assumes that all the data are statistically independent and there is a linear relationship between the variables. It is also capable of handling the missing values present in data set. The TSA is also designated as Sen slope estimator. Sen’s slope estimator has been extensively used as a robust predictor of trend slope in several previous studies (Hirsch et al. 1982; Zhang et al. 2000; Burn and Hag Elnur 2002; Burn et al. 2004; Partal and Kahya 2006; Novotny and Stefan 2007; Tabari et al. 2011; Irizarry-Ortiz et al. 2013; Gocic and Trajkovic 2013; Sayemuzzaman et al. 2014). 


\subsubsection{Trend Free Pre-Whitening (TFPW) Approach}

The correlation structure of the data is an important aspect to be considered. Von Storch and Navarra (1995) reported that the data series should be pre-whitened before applying the Mann-Kendall test in order to remove any serial correlation present in the time series data. Because Mann-Kendall and Theil-Sen Approach require the data to be identically distributed and serially independent. Therefore positive serial correlation can increase the number of false positive outcomes which may create an erroneous interpretation of the test results. Yue et al. (2003) developed a trend free pre-whitening (TFPW) approach to remove the serial correlation from the data series without affecting the actual trend. Following Yue et al. 2002a, b; Burn and Hag Elnur 2002; Burn et al. 2004; Abdul-Aziz and Burn 2006; Novotny and Stefan 2006; Petrow and Merz 2009; Bawden et al. 2014; the necessary steps for TFPW approach are:

(i) For the original data series, the Mann-Kendall statistic, $S$ and the local significance level of the trend, $\alpha$ is estimated. The non-parametric slope, $\beta$ is calculated following Equation (5).

(ii) After that, the monotonic trend, $\beta$ is eliminated from the data by using Eq. (6).

$Y_{t}=X_{t}-\beta t$

Here, $X_{t}$ is the data value at time $t$ and $Y_{t}$ is the de-trended data series.

(iii) For the de-trended series computed in previous step, the lag one serial correlation coefficient $r_{1}$ is evaluated. If $r_{1}$ does not exhibit statistical significance at $5 \%$ level, prewhitening the data series will not be required and trend results from step (i) will be accepted 
as complete. If the correlation coefficient $r_{1}$ becomes significant at $5 \%$ level, the de-trended series is pre-whitened as follows:

$Y_{t}^{\prime}=Y_{t}-r_{1} Y_{t-1}$

where $Y_{t}^{\prime}$ is both de-trended and pre-whitened data series, denoted as the residual series.

(iv) In this step, the monotonic trend $\beta$ is added to the residual series to get the prewhitened series through:

$Y_{t}^{\prime \prime}=Y_{t}^{\prime}+\beta t$

Here, $Y_{t}^{\prime \prime}$ can be stated as the trend free pre-whitened data series.

(v) Finally, for the pre-whitened $Y_{t}^{\prime \prime}$ series, Mann-Kendall statistics, $S$ is estimated along with the associated local significance level.

\subsubsection{Bootstrap Resampling Approach}

Spatial or regional cross correlation between the stations is usually neglected in case of evaluating the collective significance of trends (Douglas et al. 2000). Spatial correlation reduces the number of effective degrees of freedom of the dataset because it assumes that each station is not an independent observation (Livezey and Chen 1983). Therefore, the number of stations which are locally significant does not represent the collective, or field significant trends of a dataset (Wilks 2006). The field significant test addresses the question as whether the number of trends for a particular variable exceeds the number expected to occur by chance. To determine the global or field significance of trends a Bootstrap Resampling Approach (Douglas et al. 2000; Burn and Hag Elnur 2002; Burn et al. 2004; Coulibaly and Shi 2005; Abdul-Aziz and Burn 2006; Novotny and Stefan 2007; Burn et al. 
2011; Martinez et al. 2012; Burn and Taleghani 2013) was applied. The bootstrap technique requires the following steps:

(i) A year is randomly selected from a specified period of record for which the analysis needs to be conducted (e.g. 1950-2010).

(ii) The data value for each station that has a data value for that particular year is added to the resampled data set.

(iii) Steps (i) and (ii) are repeated until the resampled data set has the required number of station-years of data. The target number of station-years of data is set equal to the number of station-years in the initial data set.

(iv) The Mann-Kendall test is applied to the data from each station in the resampled data set and the percentage of results that are significant at the $\alpha_{l} \%$ level is determined, where $\alpha_{l}$ is the local significance level.

(v) Steps (i) to (iv) are repeated a total of NS times (NS was set to 1000) resulting in a distribution for the percentage of results that are significant at the $\alpha_{l} \%$ level. From this distribution, the value that is exceeded $\alpha_{f} \%$ of the time is selected as the critical value, $P_{\text {crit }} ; \alpha_{f}$ is referred to as the field or global significance level. Results obtained with a percentage of stations showing a significant trend larger than $P_{\text {crit }}$ will be considered significant at the $\alpha_{f} \%$ level. In this work, the value of $\alpha_{f}$ is chosen as $10 \%$. 


\section{CHAPTER 4}

\section{RESULTS}

\subsection{Trend Summary}

The summary of the detected trends in the magnitude of the annual maximum rainfall events, the number of above threshold events and the average magnitude of the above threshold events are exhibited in Table 2, Table 3 and Table 4, respectively. These Tables reveal the trend results for the analysis period of $61,51,41$, and 31-year and for the twelve variables (1, 2, 3, 6 and 12 hour, and 1, 2, 3, 4, 5, 6 and 7 day durations). Considering a $10 \%$ level of significance, the percentage of stations with significant positive trends and the percentage of stations with significant negative trends are presented separately for each variable. The number of stations that were available for each time period is also indicated. The global or field significant results are shown in bold and the field significance level was considered the same as that of the local significance level (i.e. 10\%).

\subsubsection{Annual Maximum Rainfall Events}

The data set for the magnitude of the annual maximum rainfall events exhibited strongly increasing trends over all periods of analysis. For the longest analysis period (1950-2010), strong positive trends were identified for 1, 2, 3, 6, 12 hour and 1 day events, among which 2, 3, 6 and 12 hour events were found to be field significant. No significant decreasing trend was obtained for this entire period. The next time period (1960-2010) estimated a small percentage of significant increasing trends for most of the variables, though none of them were field significant. For the 41-year (1970-2010) study period, almost all of the events (6 hour to 7 day) indicated positive trends, however only 5 day event revealed negative trends; field significant results occurred only for the 6 and 7 day events. The last 
analysis period (1980-2010) detected a significant percentage of both positive and negative trends. For 2 hour and 3 hour events, the results identified more decreasing than increasing trends. However the large rainfall events (6 hour to 7 day) had more positive trends than negative trends. In this period, 4, 5, 6, and 7 day durations exhibited both local and field significant trends.

Table 2: Percent of stations with significant trends (at 10\% significance level) for the annual maximum rainfall events.

\begin{tabular}{lcccccccc}
\hline & \multicolumn{7}{c}{ Time Period } \\
\cline { 2 - 9 } Variables & $\mathbf{1 9 5 0 - 2 0 1 0}$ & $\mathbf{1 9 6 0 - 2 0 1 0}$ & $\mathbf{1 9 7 0 - 2 0 1 0}$ & $\mathbf{1 9 8 0 - 2 0 1 0}$ \\
& \multicolumn{1}{c}{ (13 stations) } & (18 stations) & (24 stations) & \multicolumn{2}{c}{ (24 stations) } \\
& + +ve & -ve & +ve & -ve & +ve & -ve & +ve & -ve \\
\hline $\mathbf{1}$ hour (\%) & 15 & 0 & 6 & 0 & 0 & 0 & 8 & 8 \\
$\mathbf{2}$ hour (\%) & $\mathbf{3 8}$ & 0 & 6 & 0 & 0 & 0 & 4 & 8 \\
$\mathbf{3}$ hour (\%) & $\mathbf{3 1}$ & 0 & 0 & 0 & 0 & 0 & 4 & 8 \\
$\mathbf{6}$ hour (\%) & $\mathbf{2 3}$ & 0 & 6 & 0 & 4 & 0 & 8 & 4 \\
$\mathbf{1 2}$ hour (\%) & $\mathbf{2 3}$ & 0 & 6 & 0 & 8 & 0 & 13 & 4 \\
$\mathbf{1}$ day (\%) & 8 & 0 & 0 & 0 & 8 & 0 & 13 & 0 \\
$\mathbf{2}$ day (\%) & 0 & 0 & 0 & 0 & 17 & 0 & 13 & 4 \\
$\mathbf{3}$ day (\%) & 0 & 0 & 0 & 0 & 17 & 0 & 13 & 4 \\
$\mathbf{4}$ day (\%) & 0 & 0 & 6 & 0 & 13 & 0 & $\mathbf{1 3}$ & $\mathbf{8}$ \\
$\mathbf{5}$ day (\%) & 0 & 0 & 6 & 0 & 8 & 4 & $\mathbf{1 3}$ & $\mathbf{8}$ \\
$\mathbf{6}$ day (\%) & 0 & 0 & 6 & 0 & $\mathbf{2 1}$ & 0 & $\mathbf{1 7}$ & $\mathbf{8}$ \\
$\mathbf{7}$ day (\%) & 0 & 0 & 6 & 0 & $\mathbf{2 5}$ & 0 & $\mathbf{1 3}$ & $\mathbf{8}$ \\
\hline
\end{tabular}

*Entries in bold indicate variables that are field significant at the 10\% level.

With the decrease in the analysis period (from 61 to 51 year), the number of field significant trends also decreased (four to zero) at the $10 \%$ level of significance. Further decrease in time periods (i.e. 51 to 41 year and 41 to 31 year) established an increase in the number of field significant trends (which was zero to two and two to four, respectively). In general, 
the percentage of significant positive trends decreased for short duration events and increased for long duration events along with the longer to recent time periods. On the other hand, the percentage of significant negative trends increased for all the rainfall durations as the length of the study period decreased.

\subsubsection{Number of Above Threshold Events}

The data set for the number of above threshold events indicated mostly decreasing trends for all the time periods. The longest time period (1950-2010) estimated strong negative trends for 1, 2, 3 and 6 hour events, whereas positive trends were identified only for 1 hour and 2 day events. The field significant trends occurred for 1, 2 and 3 hour events. The 19602010 analysis period also exhibited significant percentage of decreasing trends for 1, 2, 3 and 6 hour, and 7 day events. These events (except for 6 hour duration) also showed a small percentage of increasing trends and all the above mentioned events (except for 7 day duration) were found as field significant. More decreasing than increasing local and field significant trends were observed for 1 to 6 hour events for the 1970-2010 period, while an increase in duration lead to more positive than negative trends. During the most recent time period, both positive and negative significant trends were identified. However, more decreasing than increasing trends were detected for the 1 hour to 5 day durations and more increasing than decreasing trends were estimated for the last two durations. The field significant trends were found for 2, 3 and 6 hour durations and for 3, 6, and 7 day durations. Comparing the results for the different analysis periods leads to several observations. Such as, the hourly rainfall events exhibited more decreasing than increasing trends over all period of analysis. However, the percentage of stations showing negative trends for these events generally decreased as the length of the study period decreased. The daily rainfall 
events showed more positive trends during the longer time periods. However, in the shortest period, 1 day to 5 day durations indicated more decreasing than increasing trends and, 6 and 7 day durations showed the opposite pattern (i.e., more increasing than decreasing). The field significant results occurred for most of the hourly events over all the time period, while for some of the daily events in the recent time periods.

Table 3: Percent of stations with significant trends (at 10\% significance level) for the number of above threshold events.

\begin{tabular}{lcccccccc}
\hline & \multicolumn{7}{c}{ Time Period } \\
\cline { 2 - 8 } Variables & $\mathbf{1 9 5 0 - 2 0 1 0}$ & $\mathbf{1 9 6 0 - 2 0 1 0}$ & $\mathbf{1 9 7 0 - 2 0 1 0}$ & $\mathbf{1 9 8 0 - 2 0 1 0}$ \\
& (13 stations) & \multicolumn{2}{c}{$(18$ stations) } & (24 stations) & (24 stations) \\
& + ve & - ve & +ve & - ve & +ve & -ve & +ve & -ve \\
\hline $\mathbf{1}$ hour (\%) & $\mathbf{8}$ & $\mathbf{5 4}$ & $\mathbf{6}$ & $\mathbf{4 4}$ & $\mathbf{4}$ & $\mathbf{1 7}$ & 4 & 8 \\
$\mathbf{2}$ hour (\%) & 0 & $\mathbf{3 1}$ & $\mathbf{6}$ & $\mathbf{2 8}$ & $\mathbf{8}$ & $\mathbf{1 7}$ & $\mathbf{4}$ & $\mathbf{1 7}$ \\
$\mathbf{3}$ hour (\%) & 0 & $\mathbf{2 3}$ & $\mathbf{6}$ & $\mathbf{2 8}$ & $\mathbf{8}$ & $\mathbf{1 7}$ & 0 & $\mathbf{2 1}$ \\
$\mathbf{6}$ hour (\%) & 0 & 15 & 0 & $\mathbf{2 2}$ & $\mathbf{8}$ & $\mathbf{1 7}$ & 0 & $\mathbf{2 1}$ \\
$\mathbf{1 2}$ hour (\%) & 0 & 0 & 0 & 0 & 8 & 8 & 0 & 17 \\
$\mathbf{1}$ day (\%) & 0 & 0 & 0 & 0 & 8 & 0 & 4 & 8 \\
$\mathbf{2}$ day (\%) & 15 & 0 & 0 & 0 & 0 & 0 & 0 & 8 \\
$\mathbf{3}$ day (\%) & 0 & 0 & 0 & 0 & 4 & 0 & $\mathbf{8}$ & $\mathbf{1 3}$ \\
$\mathbf{4}$ day (\%) & 0 & 0 & 0 & 0 & 8 & 0 & 4 & 13 \\
$\mathbf{5}$ day (\%) & 0 & 0 & 0 & 0 & 13 & 0 & 4 & 8 \\
$\mathbf{6}$ day (\%) & 0 & 0 & 0 & 0 & 17 & 0 & $\mathbf{1 7}$ & $\mathbf{1 3}$ \\
$\mathbf{7}$ day (\%) & 0 & 0 & 6 & 6 & 13 & 0 & $\mathbf{1 7}$ & $\mathbf{8}$ \\
\hline
\end{tabular}

*Entries in bold indicate variables that are field significant at the $10 \%$ level.

\subsubsection{Average Magnitude of the Above Threshold Events}

For all study periods and all durations (except for 1 and 2 hour duration in the 31-year period), the data set for average magnitude of the above threshold events revealed more increasing trends than decreasing trends. The 1950-2010 time period indicated significant 
percentage of increasing trends for 1 hour to 2 day durations and decreasing trends for only 2 hour duration. Except for 2 day event, the above mentioned events were also found as field significant. The 51-year period detected strong positive trends for all the durations (except for 2 day), and negative trends only for 4 day duration. Field significant trends occurred for the first three events. Significant positive trends were observed for all the events in 1970-2010 analysis period, while significant negative trends were obtained for only 1 and 2 hour events.

Table 4: Percent of stations with significant trends (at 10\% significance level) for the average magnitude of the above threshold events.

\begin{tabular}{|c|c|c|c|c|c|c|c|c|}
\hline \multirow{3}{*}{ Variables } & \multicolumn{8}{|c|}{ Time Period } \\
\hline & \multicolumn{2}{|c|}{$\begin{array}{c}\mathbf{1 9 5 0 - 2 0 1 0} \\
\text { (13 stations) }\end{array}$} & \multicolumn{2}{|c|}{$\begin{array}{c}\mathbf{1 9 6 0 - 2 0 1 0} \\
\text { (18 stations) }\end{array}$} & \multicolumn{2}{|c|}{$\begin{array}{c}\mathbf{1 9 7 0 - 2 0 1 0} \\
\text { (24 stations) }\end{array}$} & \multicolumn{2}{|c|}{$\begin{array}{c}\mathbf{1 9 8 0}-\mathbf{2 0 1 0} \\
\text { (24 stations) }\end{array}$} \\
\hline & +ve & -ve & +ve & -ve & +ve & -ve & +ve & -ve \\
\hline 1 hour (\%) & 54 & 0 & 56 & 0 & 13 & 8 & 8 & 13 \\
\hline 2 hour (\%) & 54 & 8 & 39 & 0 & 8 & 4 & 8 & 13 \\
\hline 3 hour (\%) & 38 & 0 & 33 & 0 & 13 & 0 & 13 & 8 \\
\hline 6 hour (\%) & 46 & 0 & 17 & 0 & 8 & 0 & 13 & 0 \\
\hline 12 hour (\%) & 31 & 0 & 6 & 0 & 4 & 0 & 13 & 0 \\
\hline 1 day (\%) & 23 & 0 & 6 & 0 & 4 & 0 & 13 & 0 \\
\hline 2 day (\%) & 8 & 0 & 0 & 0 & 8 & 0 & 17 & 0 \\
\hline 3 day (\%) & 0 & 0 & 6 & 0 & 17 & 0 & 13 & 0 \\
\hline 4 day (\%) & 0 & 0 & 11 & 6 & 17 & 0 & 13 & 4 \\
\hline 5 day (\%) & 0 & 0 & 11 & 0 & 21 & 0 & 13 & 4 \\
\hline 6 day (\%) & 0 & 0 & 6 & 0 & 17 & 0 & 13 & 4 \\
\hline 7 day (\%) & 0 & 0 & 6 & 0 & 17 & 0 & 17 & 4 \\
\hline
\end{tabular}

*Entries in bold indicate variables that are field significant at the $10 \%$ level.

From 41-year to 31-year study period, significant negative trends increased for 1 to 3 hour and 4 to 7 day events, while significant positive trends increased for 6 hour, 12 hour, 1 day 
and 2 day events, decreased for 1 hour, 3 day, 4 day, 5 day and 6 day events and remained same for the other events. For the last two time periods, globally significant trends were observed for the 1 hour and 5 day durations and for the 1 hour, 2 hour, 3 hour and 7 day durations, respectively.

\subsection{Trend Slopes}

The slope values for each station are illustrated in Box-and-whisker plots for 61(19502010), 51(1960-2010), 41(1970-2010) and 31(1980-2010) year study periods and for all the twelve rainfall durations (Fig. 3, Fig. 4 and Fig. 5). The magnitude of the trend slope provides a measure of the effect of trend for a particular variable (i.e., the magnitude of the annual maximum rainfall events, the number of above threshold events and the average magnitude of the above threshold events). The line inside the box denotes the median value and width of the box shows the interquartile range; whiskers extend to the minimum and maximum values of the data. The hollow circle indicates an outlier, which is the value that lies more than one and a half times the length of the box from either end of the box. The slope results are also presented in tabular format (Appendix 2 - Appendix 13) for the stations that had a locally significant trend for a particular variable.

\subsubsection{Trend Slopes for the Annual Maximum Rainfall Events}

The slope values for the magnitude of the annual maximum events are illustrated in Fig. 3 and Appendix 2 to 5. The 1 hour event exhibited a slope ranging from -0.09 to 0.18 $\mathrm{mm} /$ year for the longest time period and -0.64 to $0.52 \mathrm{~mm} /$ year for the shortest time period. Which indicated that with the decrease in analysis period, negative slope increased more than the positive slope for this particular event. The maximum significant positive slope (0.021 $\mathrm{mm} /$ year) and the maximum significant negative slope $(-0.025 \mathrm{~mm} /$ year) for 1 hour 
event were also observed during the 1980-2010 period. The 2 and 3 hour events also revealed the similar results with that of the 1 hour event. This outcome is consistent with the trend results in Table 2. The median slopes were found as greater than or equal to zero for all the durations in 61, 51 and 41-year period, while negative median slopes were obtained for 3 and 6 hour duration in 31-year period. For 6 hour to 7 day durations, both positive and negative slope increased along with the longer to shorter periods. Particularly a large increase in negative slopes for long duration events were observed from 41-year to 31-year study period, which showed consistency with the results presented in Table 2.
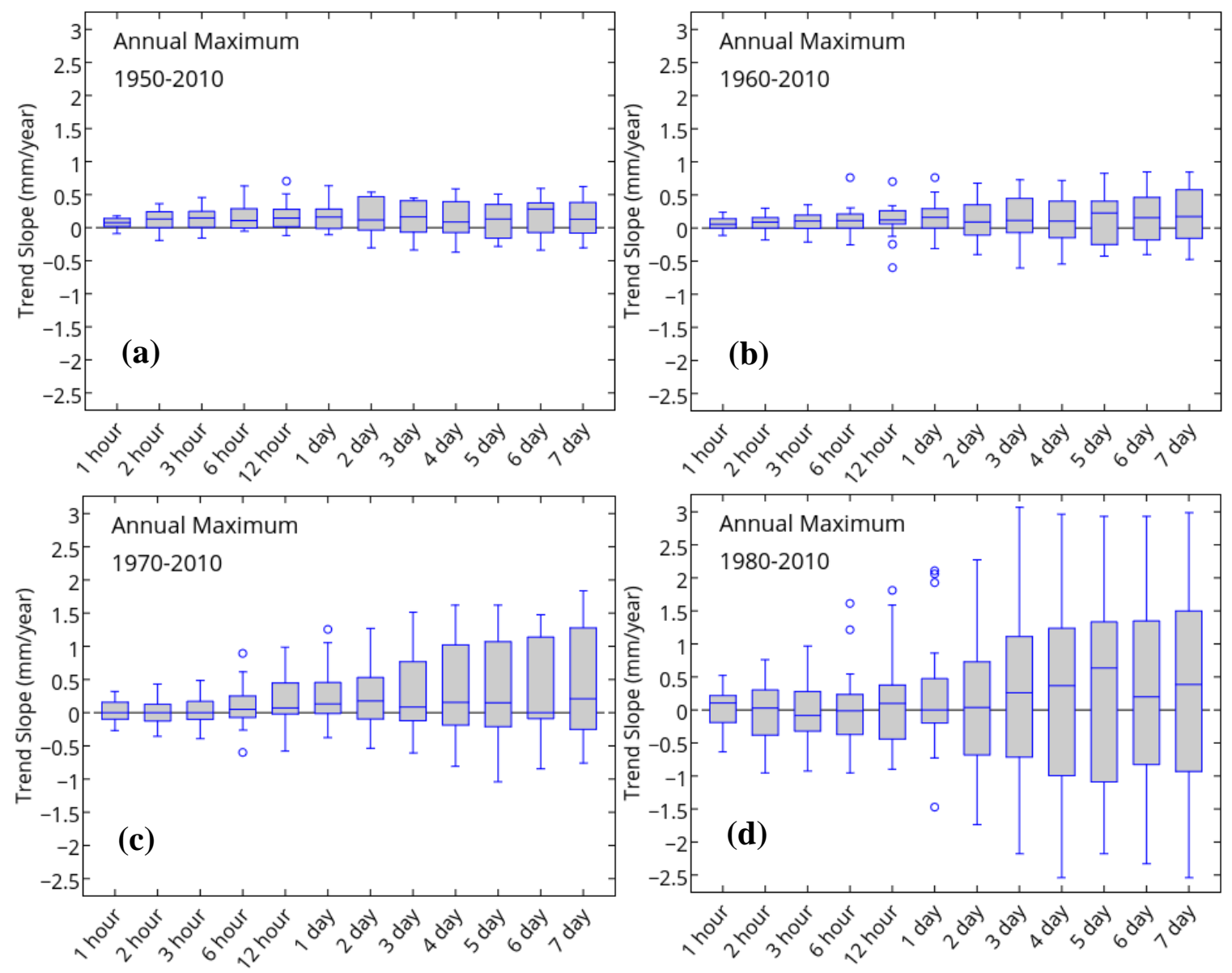

Figure 3: Box-and-whisker plots of trend slopes ( $\mathrm{mm} /$ year) for the magnitude of the annual maximum rainfall events for (a) 1950-2010, (b) 1960-2010, (c) 1970-2010 and (d) 19802010 analysis periods. 


\subsubsection{Trend Slopes for the Number of Above Threshold Events}

The slope values for the number of above threshold events are illustrated in Fig. 4 and Appendix 6 to 9. For all the events, highest significant slopes, both positive and negative, occurred for the 1980-2010 analysis period. With the decrease of length of the study period, both positive and negative slopes increased for all the events, specifically for the long duration events. The negative median slopes were found for most of the hourly events, while positive median slopes were found for most of the daily rainfall events. However, a large number of stations estimated zero slope values for the long duration events.
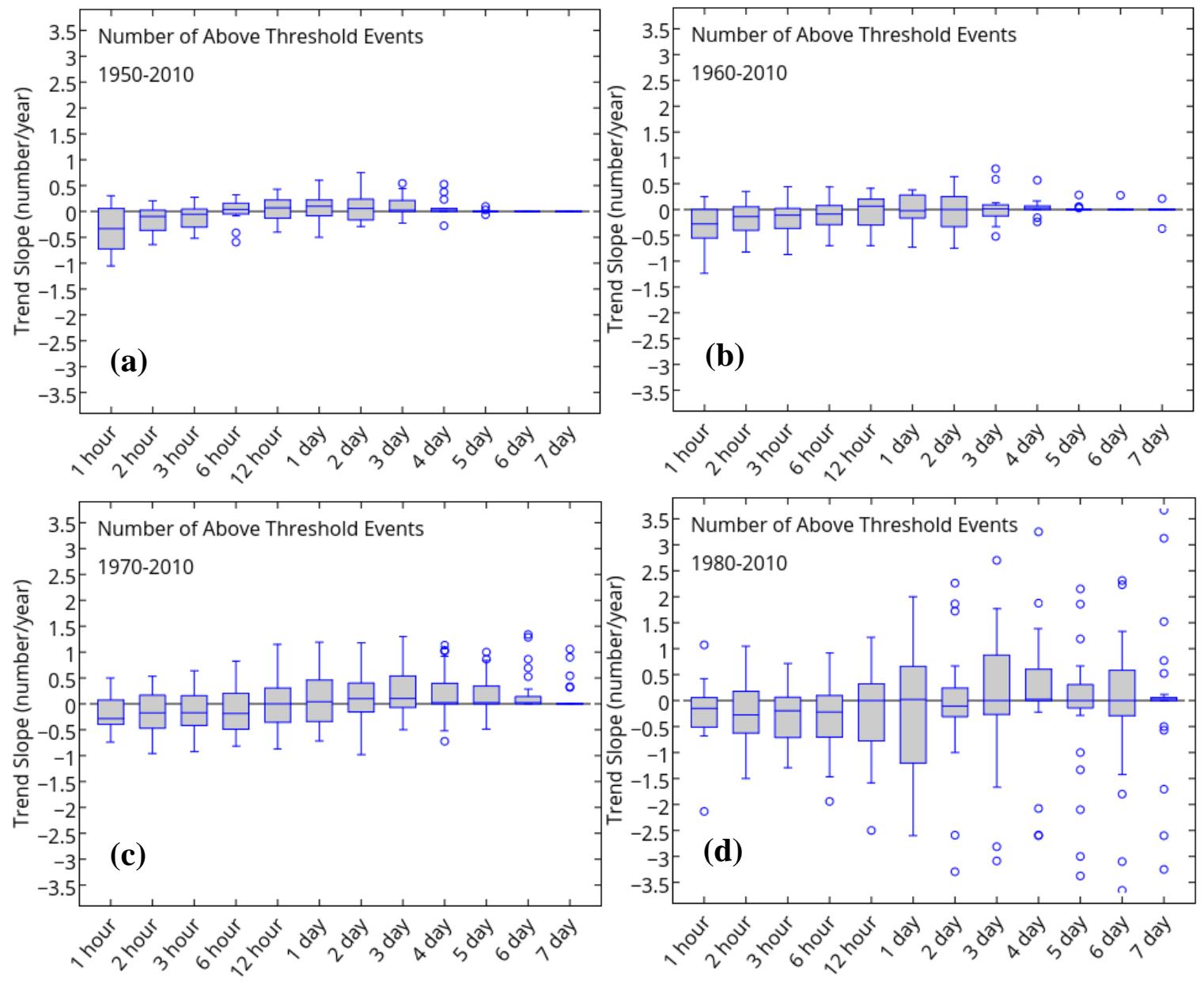

Figure 4: Box-and-whisker plots of trend slopes (number/year) for the number of above threshold events for (a) 1950-2010, (b) 1960-2010, (c) 1970-2010 and (d) 1980-2010 analysis periods. 


\subsubsection{Trend Slopes for the Average Magnitude of the Above Threshold Events}

The slope values for the average magnitude of the above threshold events are illustrated in

Fig. 5 and Appendix 10 to 13. Large changes in slope values were found for daily events from 61-year to 31-year period. For example, the 5 day event exhibited a slope ranging from -0.1 to $0.25 \mathrm{~mm} /$ year for the longest time period and -1.51 to $2.54 \mathrm{~mm} /$ year for the shortest time period. However, a large number of stations calculated zero slope values for the long duration events during 61, 51 and 41-year study period. Highest positive and negative significant slopes were obtained during the recent years.
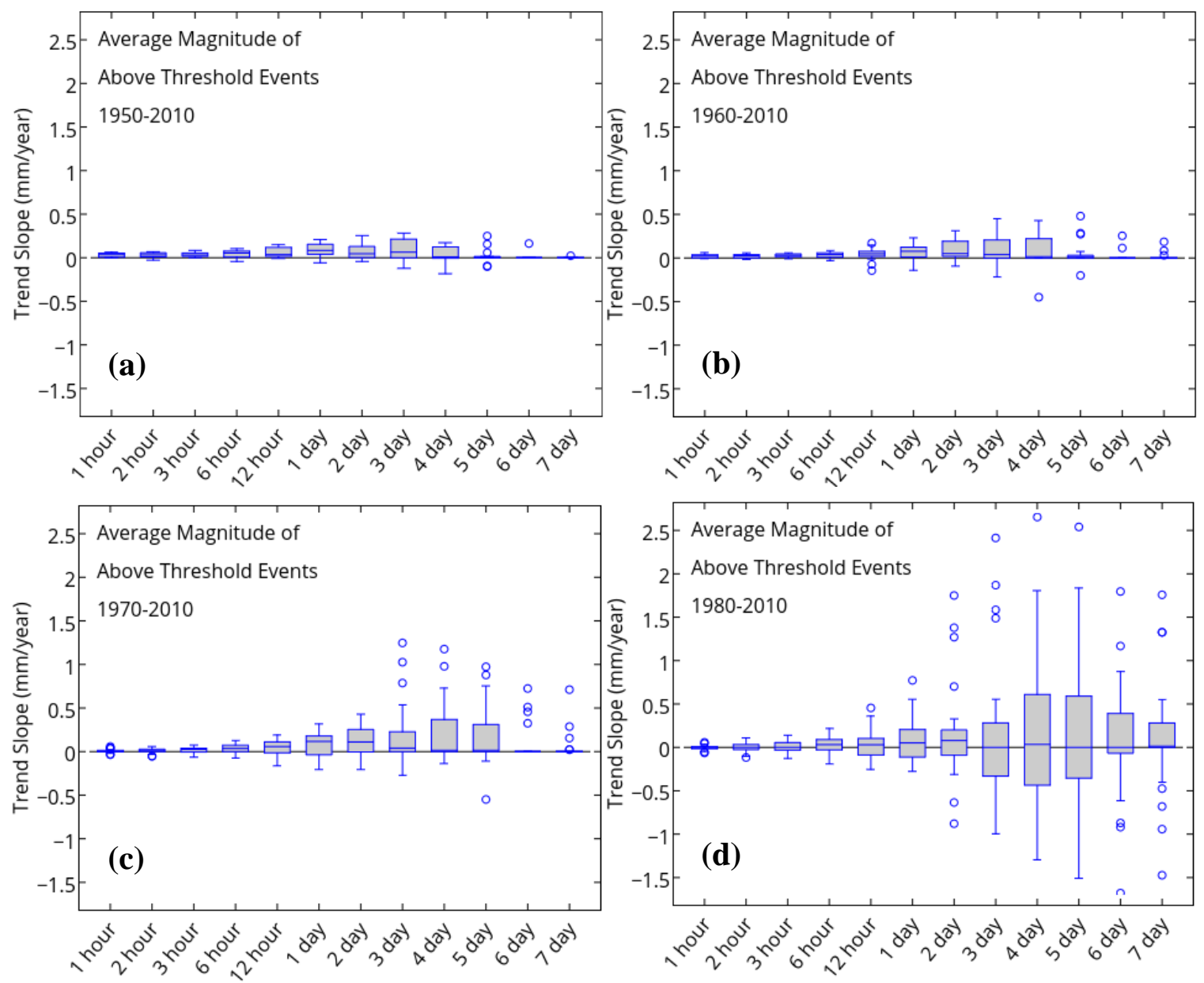

Figure 5: Box-and-whisker plots of trend slopes (mm/year) for the average magnitude of the above threshold events for (a) 1950-2010, (b) 1960-2010, (c) 1970-2010 and (d) 19802010 analysis periods. 


\subsection{Spatial Patterns of Trends for Annual Maximum Events}

The spatial patterns of the trend results for the magnitude of annual maximum events are presented in Figures 6-17 for different stations and for the longest period (1950-2010) and most recent period (1980-2010). In the next sections of this thesis, a regional analyses of trends for annual maximum rainfall are described in detail for each variable separately.

\subsubsection{One Hour Event}

For 61-year time period, one hour event (Fig. 6) exhibited upward trends in almost all over the Florida except for some stations in northeast region. Among them only two stations from upper southwest Florida and Suwannee river basin showed significant positive trends. In the recent period, significant upward trends were observed in Jacksonville and Tallahassee, whereas significant downward trends were found for stations located in Lisbon and Boca Raton.
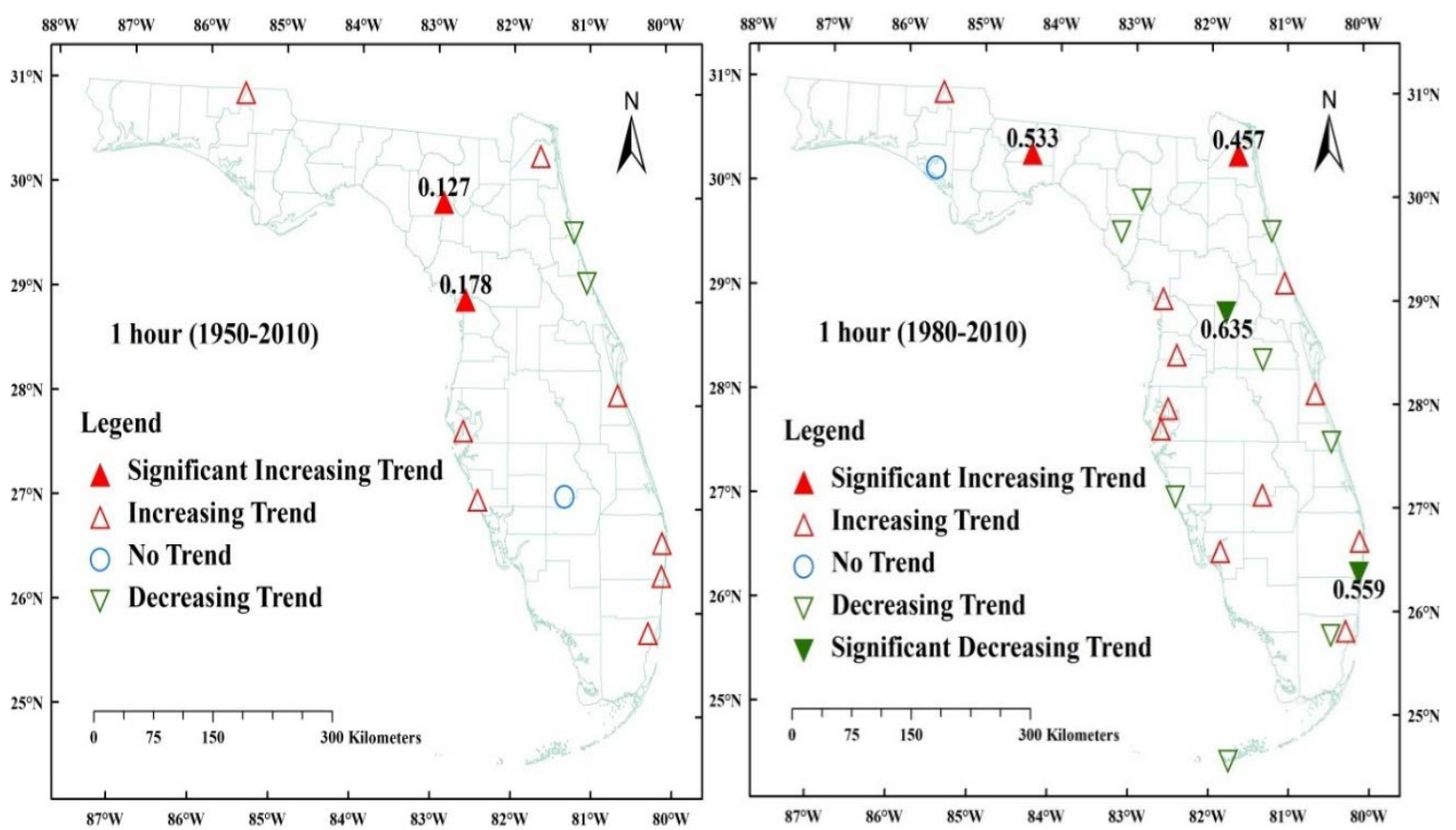

Figure 6: Spatial pattern of the trend results for the annual maximum rainfall event for one hour duration for the 1950-2010 (left) and 1980-2010 (right) analysis periods. The slope value (mm/year) for significant trend is also indicated. 


\subsubsection{Two Hour Event}

The two hour event (Fig. 7) identified significant positive trends in five stations during the 1950-2010 period, which are mainly located in Graceville, Branford, St. Petersburg, Melbourne and West Palm Beach cities. The magnitude of slopes for these stations varied from 0.178 to $0.356 \mathrm{~mm}$ per year. In recent period, only one station in Tallahassee was found to be positively significant. For one and two hour event, similar spatial distributions were observed for 1980-2010 period. For example, Lisbon indicated significant decreasing trend for both one and two hour events. However, significant negative change was observed in city of Vero Beach for two hour duration only. In the recent years, both south Florida and southwest Florida exhibited more upward trends than downward. Both the stations in Suwannee river basin showed downward trends whereas the rest of the regions (i.e. Northwest Florida and St Johns river basin) showed a mixture of positive and negative trends in recent time period.

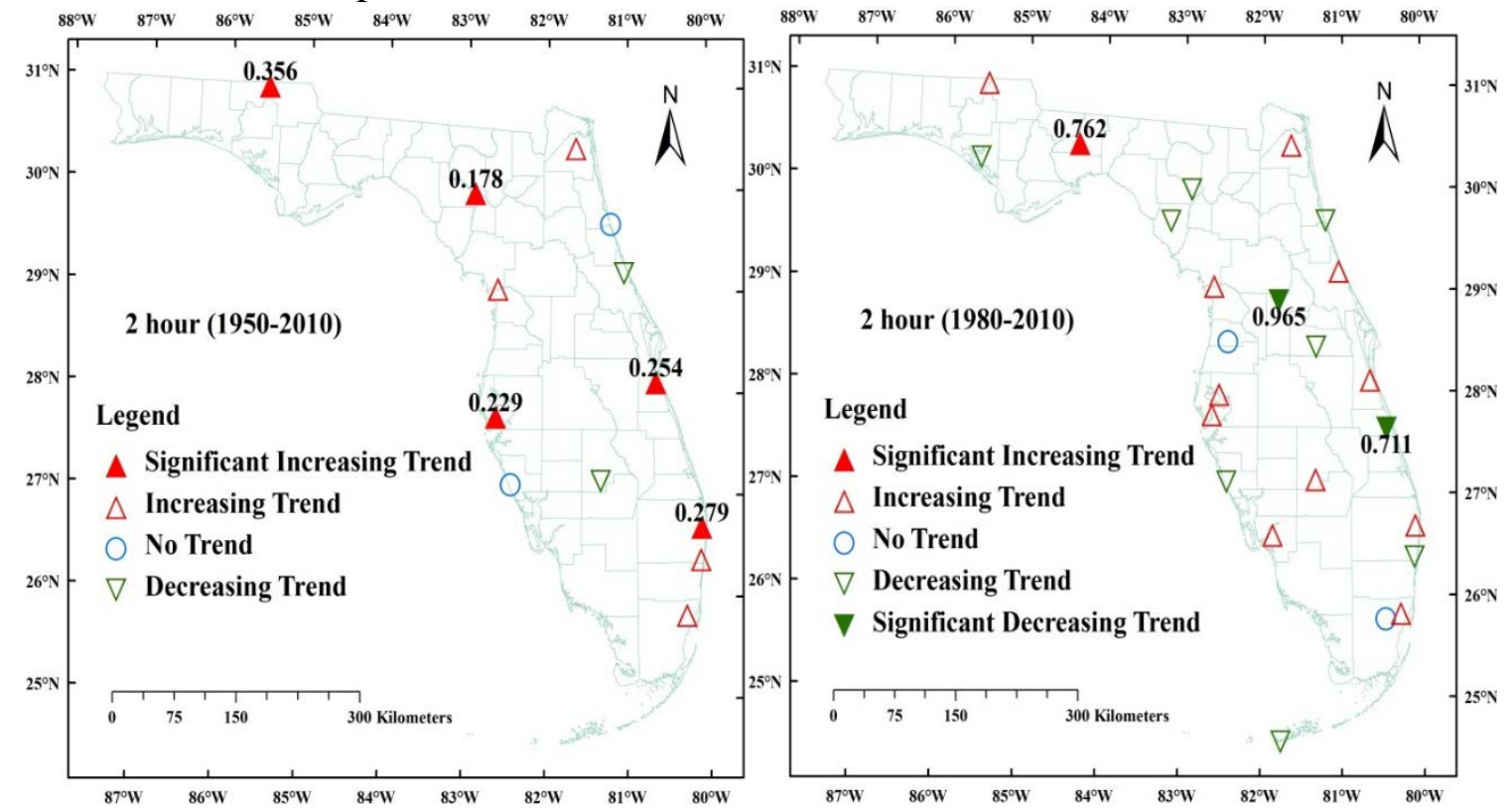

Figure 7: Spatial pattern of the trend results for the annual maximum rainfall event for two hour duration for the 1950-2010 (left) and 1980-2010 (right) analysis periods. The slope value (mm/year) for significant trend is also indicated. 


\subsubsection{Three Hour Event}

For the longest period, three hour event (Fig. 8) exhibited similar spatial pattern with the two hour event except for St. Petersburg region, which previously showed significant increasing trend but later exhibited non-significant increasing trend. With the decrease in analysis period (61 to 31 year) for three hour event, city of West Palm Beach was changed from significant positive to non-significant positive and city of Boca Raton was changed from non-significant positive to non-significant negative trend. For both time periods, city of Melbourne exhibited significant upward trends. In recent years (1980-2010), significant decreasing trends were observed in Cross City and Lisbon areas, with equal slope values of $0.914 \mathrm{~mm}$ per year.

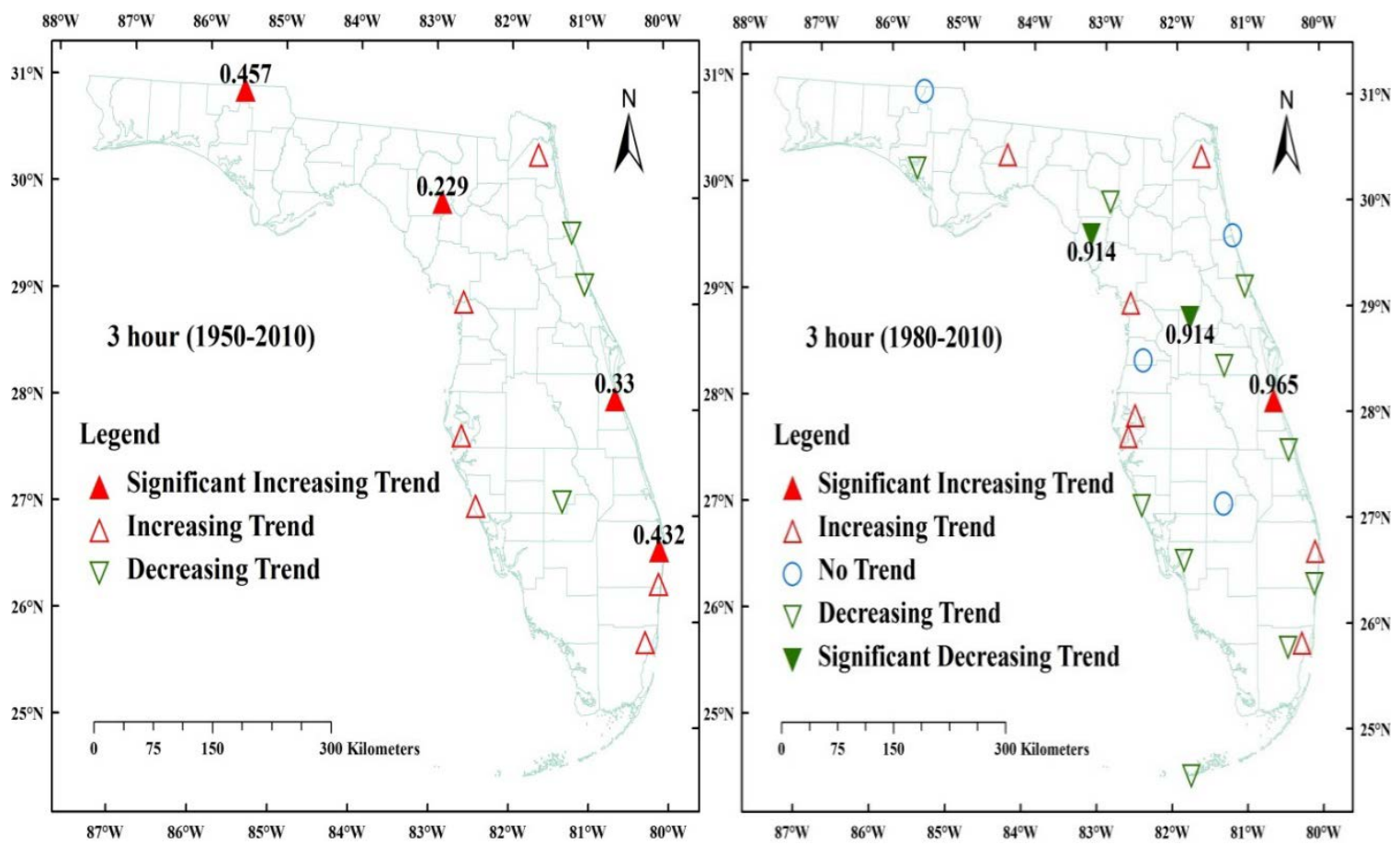

Figure 8: Spatial pattern of the trend results for the annual maximum rainfall event for three hour duration for the 1950-2010 (left) and 1980-2010 (right) analysis periods. The slope value (mm/year) for significant trend is also indicated. 


\subsubsection{Six Hour Event}

For 1950-2010 analysis period, six hour event (Fig. 9) estimated significant increasing trends in Graceville, Melbourne and West Palm Beach regions with trend slope values of 0.381, 0.432 and $0.635 \mathrm{~mm} /$ year, respectively. Significant positive trends were also found for the city of Melbourne and West Palm Beach for 1980-2010 time period, with trend slope values of 1.219 and $1.626 \mathrm{~mm}$ /year, respectively. Only one station in Cross City indicated significant decreasing trend in recent period (1980-2010) with a slope value of $0.965 \mathrm{~mm} /$ year. In general, southwest Florida showed mostly increasing trend for both the analysis periods; whereas south Florida indicated mostly upward trends for the largest period and showed mixed trends (increasing/decreasing) for short analysis period.

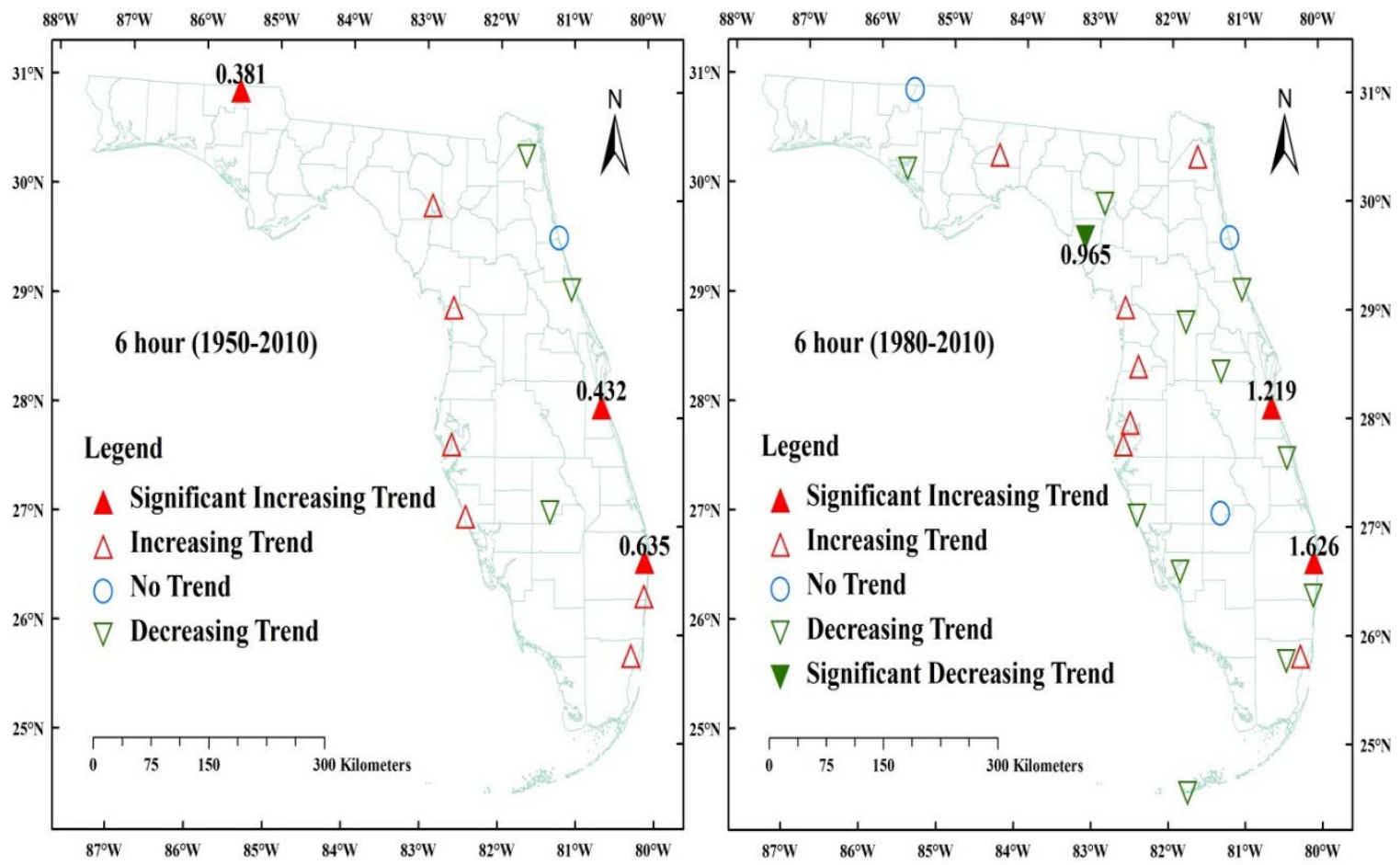

Figure 9: Spatial pattern of the trend results for the annual maximum rainfall event for six hour duration for the 1950-2010 (left) and 1980-2010 (right) analysis periods. The slope value (mm/year) for significant trend is also indicated. 


\subsubsection{Twelve Hour Event}

For twelve hour duration (Fig. 10), almost all of the stations (11 among 13) showed upward trends during 1950-2010 period. Among them Graceville, Melbourne and West Palm Beach showed significant upward trends with slope values of $0.381,0.508$ and 0.711 mm/year, respectively. The recent time period (1980-2010) indicated mostly increasing trends for St Johns River basin, southwest and northwest Florida; among which Jacksonville and Melbourne showed statistically significant positive trends with slope values of 1.092 and $1.6 \mathrm{~mm} /$ year, respectively. South Florida and Suwannee river basin identified mostly decreasing trends; among which Cross City exhibited statistically significant decreasing trend with slope value of $0.889 \mathrm{~mm} / \mathrm{year}$. Overall, the city of Melbourne and West Palm Beach showed significant upward trends for two, three, six and twelve hour events during longest period; as well as for six and twelve hour events in recent time period.

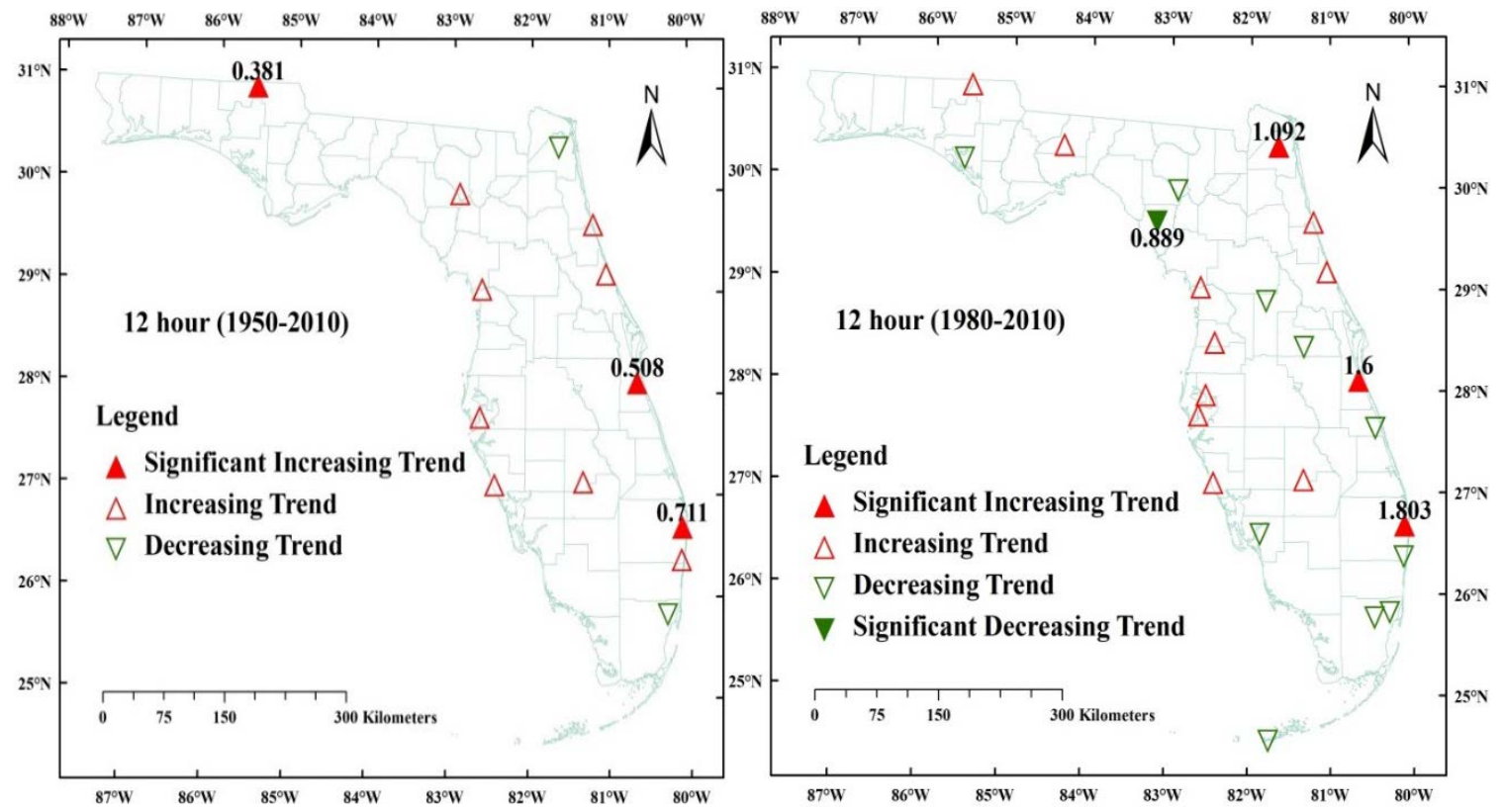

Figure 10: Spatial pattern of the trend results for the annual maximum rainfall event for twelve hour duration for the 1950-2010 (left) and 1980-2010 (right) analysis periods. The slope value (mm/year) for significant trend is also indicated. 


\subsubsection{One Day Event}

During the recent time period (1980-2010), one day event (Fig. 11) revealed significant increasing trends for the Jacksonville, Melbourne and West Palm Beach with trend slope values of 1.93, 2.057 and $2.108 \mathrm{~mm} /$ year, respectively. With an increase in analysis periods (31 to 61 years), only city of Melbourne was found be significantly positive with trend slope value of $0.635 \mathrm{~mm}$ per year, while Jacksonville and West Palm Beach changed to non-significant negative and non-significant positive, respectively. For one day duration, statistically significant negative trend was not observed in either of the two time periods.

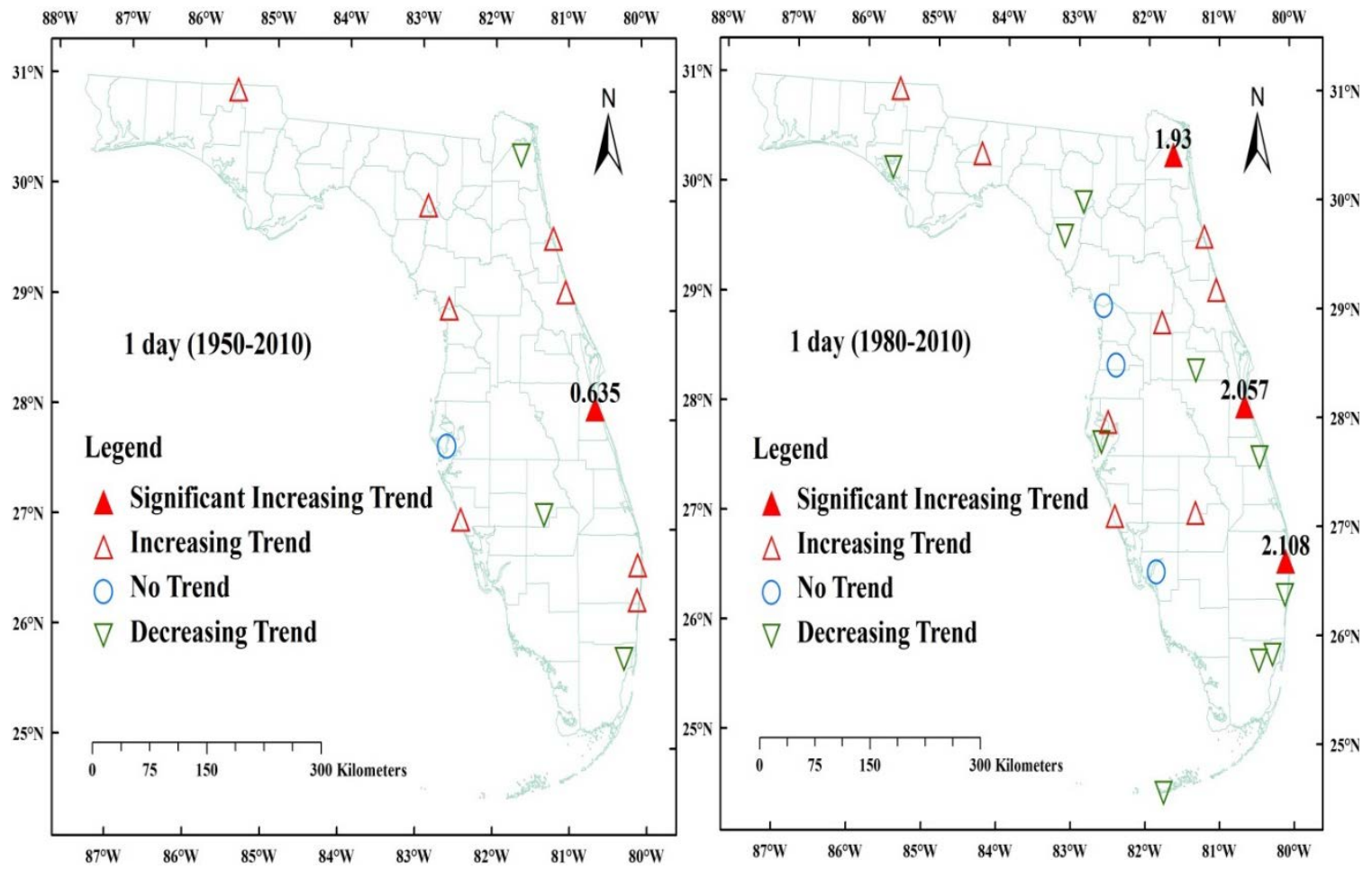

Figure 11: Spatial pattern of the trend results for the annual maximum rainfall event for one day duration for the 1950-2010 (left) and 1980-2010 (right) analysis periods. The slope value (mm/year) for significant trend is also indicated. 


\subsubsection{Two Day Event}

For two day event (Fig. 12), there were no statistically significant trends, either positive or negative, during the 1950-2010 study period. Among 13 stations, 10 stations (located mostly along the coastal areas) indicated upward trends, while the remaining 3 stations indicated non-significant downward trends. During the 1980-2010 analysis period, three stations from Tampa, Melbourne and West Palm Beach exhibited statistically significant upward trends. The slopes values for these stations were 1.676, 2.261 and $2.286 \mathrm{~mm} /$ year, respectively. One station from Suwannee river basin showed significant downward change with a trend slope of $0.068 \mathrm{~mm} /$ year for the recent time period.

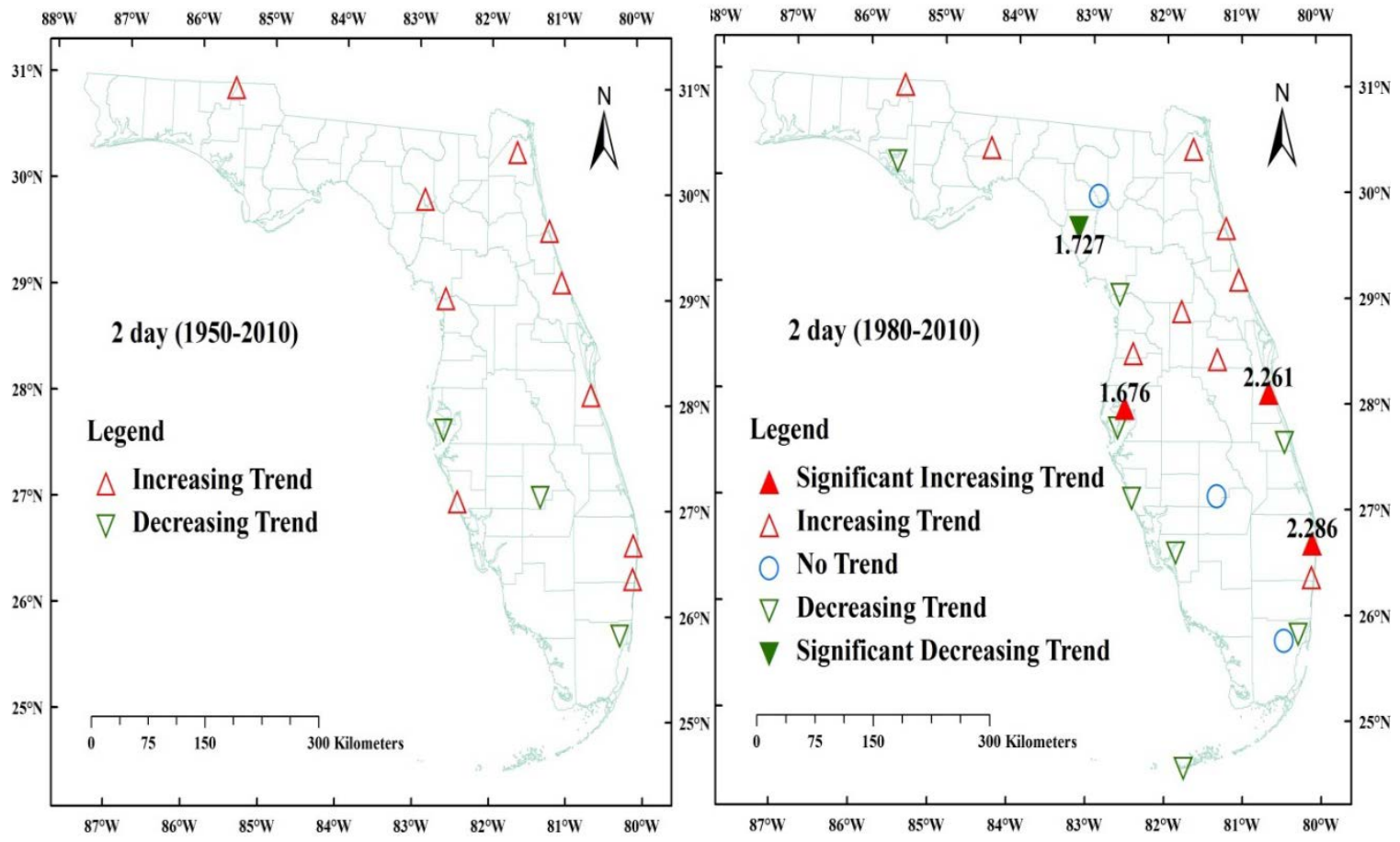

Figure 12: Spatial pattern of the trend results for the annual maximum rainfall event for two day duration for the 1950-2010 (left) and 1980-2010 (right) analysis periods. The slope value $(\mathrm{mm} / \mathrm{year})$ for significant trend is also indicated. 


\subsubsection{Three Day Event}

No significant positive or negative trends were observed for three day event (Fig. 13) during the 1950-2010 time period. For 1980-2010 study period, two day and three day events showed quite similar spatial pattern. For both events, all the stations located in St. Johns River basin indicated non-significant increasing trends; while one station from Suwannee river basin detected statistically significant decreasing trends. The other regions (south Florida, southwest Florida and Northwest Florida) showed a mixture of positive and negative trends for the same analysis period.
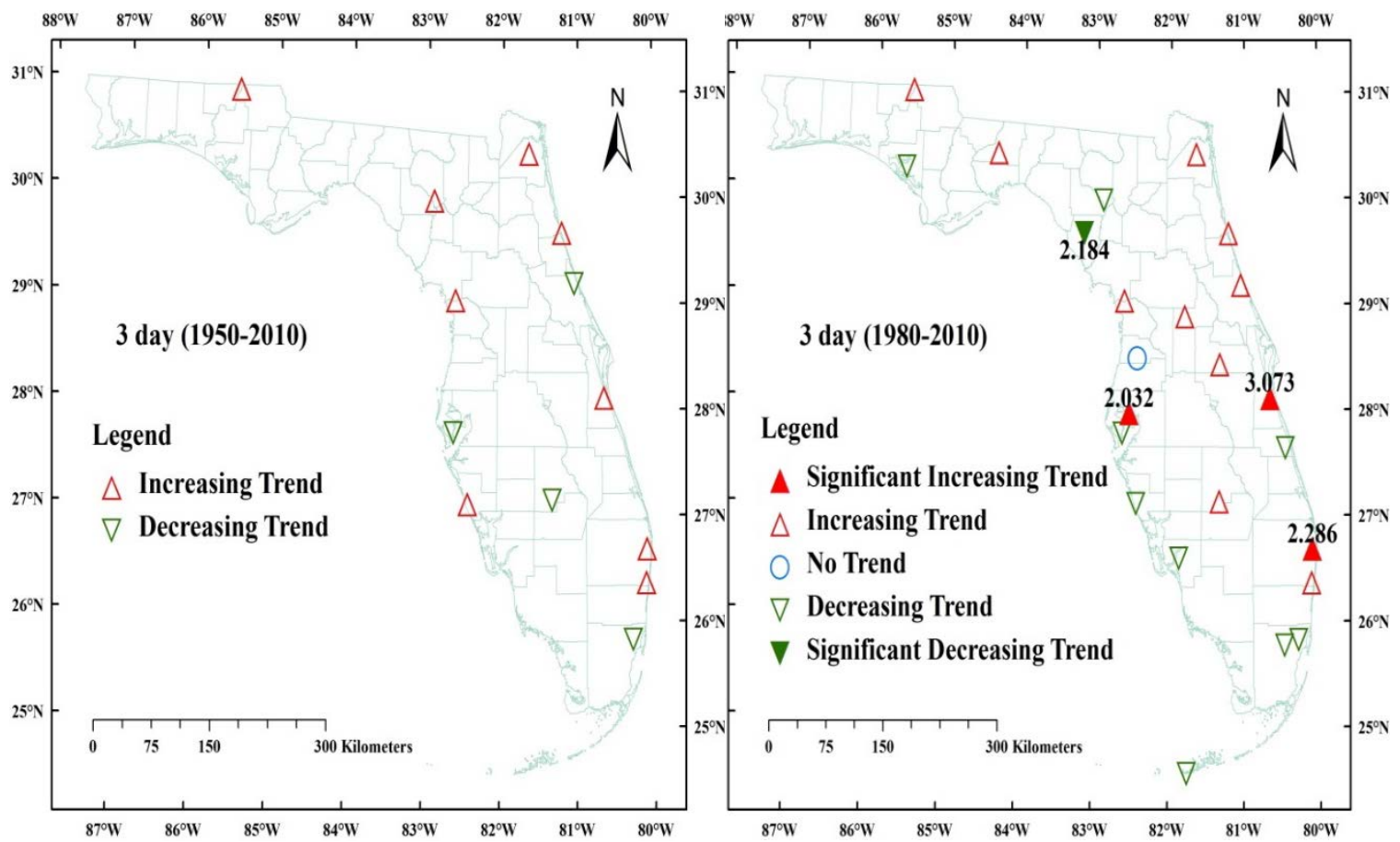

Figure 13: Spatial pattern of the trend results for the annual maximum rainfall event for three day duration for the 1950-2010 (left) and 1980-2010 (right) analysis periods. The slope value (mm/year) for significant trend is also indicated. 


\subsubsection{Four Day Event}

Four day event (Fig. 14) identified significant positive changes in Tampa, Melbourne and West Palm Beach; and significant negative changes in Cross City and Vero Beach during 1980-2010 analysis period. The magnitude of trend slopes for these locations were found as $2.311,2.972,2.464,2.54$ and $2.032 \mathrm{~mm} /$ year, respectively. For recent years, the spatial trend scenario exhibited more increasing than decreasing trends along the cost of the Atlantic Ocean; while more downward than upward trends were identified along the coast of the Gulf of Mexico. For this event, the largest analysis period did not show any kinds of significant (positive/negative) trends.

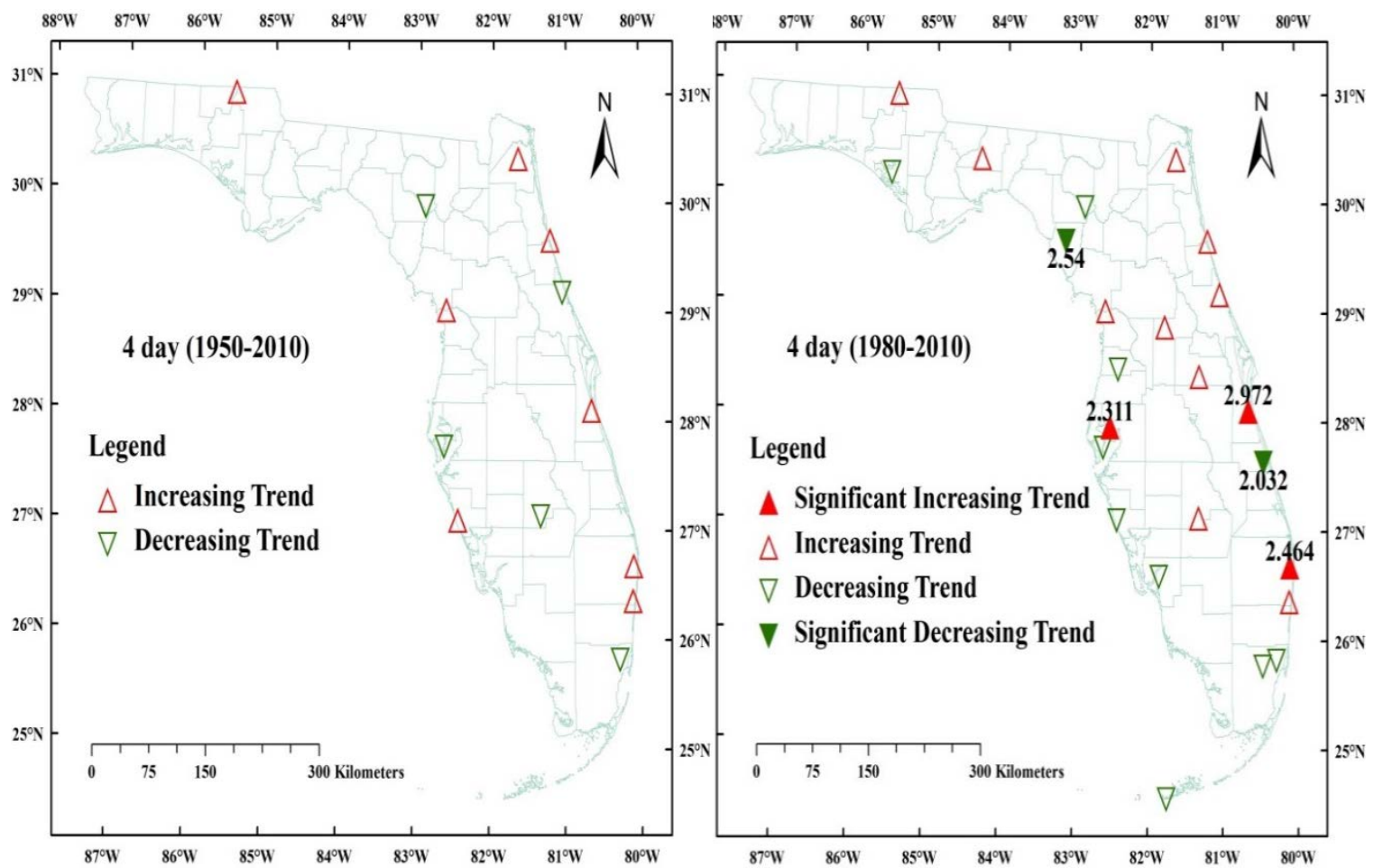

Figure 14: Spatial pattern of the trend results for the annual maximum rainfall event for four day duration for the 1950-2010 (left) and 1980-2010 (right) analysis periods. The slope value (mm/year) for significant trend is also indicated. 


\subsubsection{Five Day Event}

For both the longest (1950-2010) and the shortest (1980-2010) records, five day event (Fig. 15) exhibited quite similar spatial patterns to the previously discussed two, three and four day events. No significant trends (increasing/decreasing) were found during 1950-2010 analysis period. Three significant upward and two significant downward trends were found for 1980-2010 study period. The St. Johns River basin and northwest Florida showed mostly increasing trends and Suwannee river basin exhibited mostly decreasing trends, while the remaining regions depicted mixed trends.

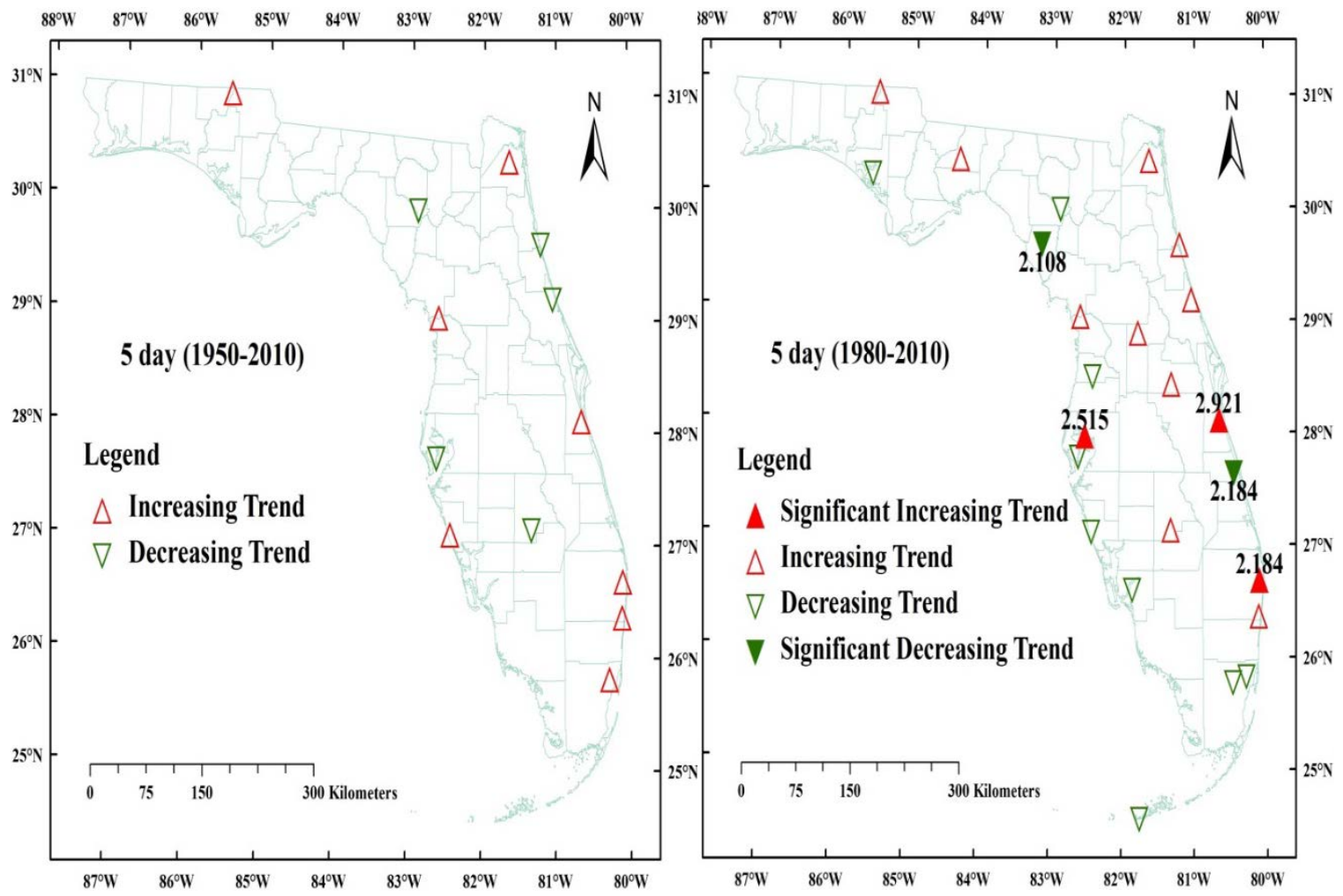

Figure 15: Spatial pattern of the trend results for the annual maximum rainfall event for five day duration for the 1950-2010 (left) and 1980-2010 (right) analysis periods. The slope value (mm/year) for significant trend is also indicated. 


\subsubsection{Six Day Event}

A large number of stations (14 among 24) indicated upward trends for six day duration (Fig. 16) for 1980-2010 analysis period. Among these stations, statistically significant trends were obtained for Venus, Tampa, Melbourne and Jacksonville with slope values of 1.016, 2.515, 2.921 and $2.438 \mathrm{~mm} /$ year, respectively. Statistically significant downward trends were found for Vero Beach and Cross City with slope magnitudes of 1.829 and 2.337 $\mathrm{mm} /$ year for the same analysis period. Non-significant decreasing trends were found for Daytona Beach, Marineland, Branford and Venus for longest analysis period; which changed into rising trends for recent period. Also increasing trends in Venice and Inglis were noted for 1950-2010, which changed into decreasing and no trend, respectively for 1980-2010.

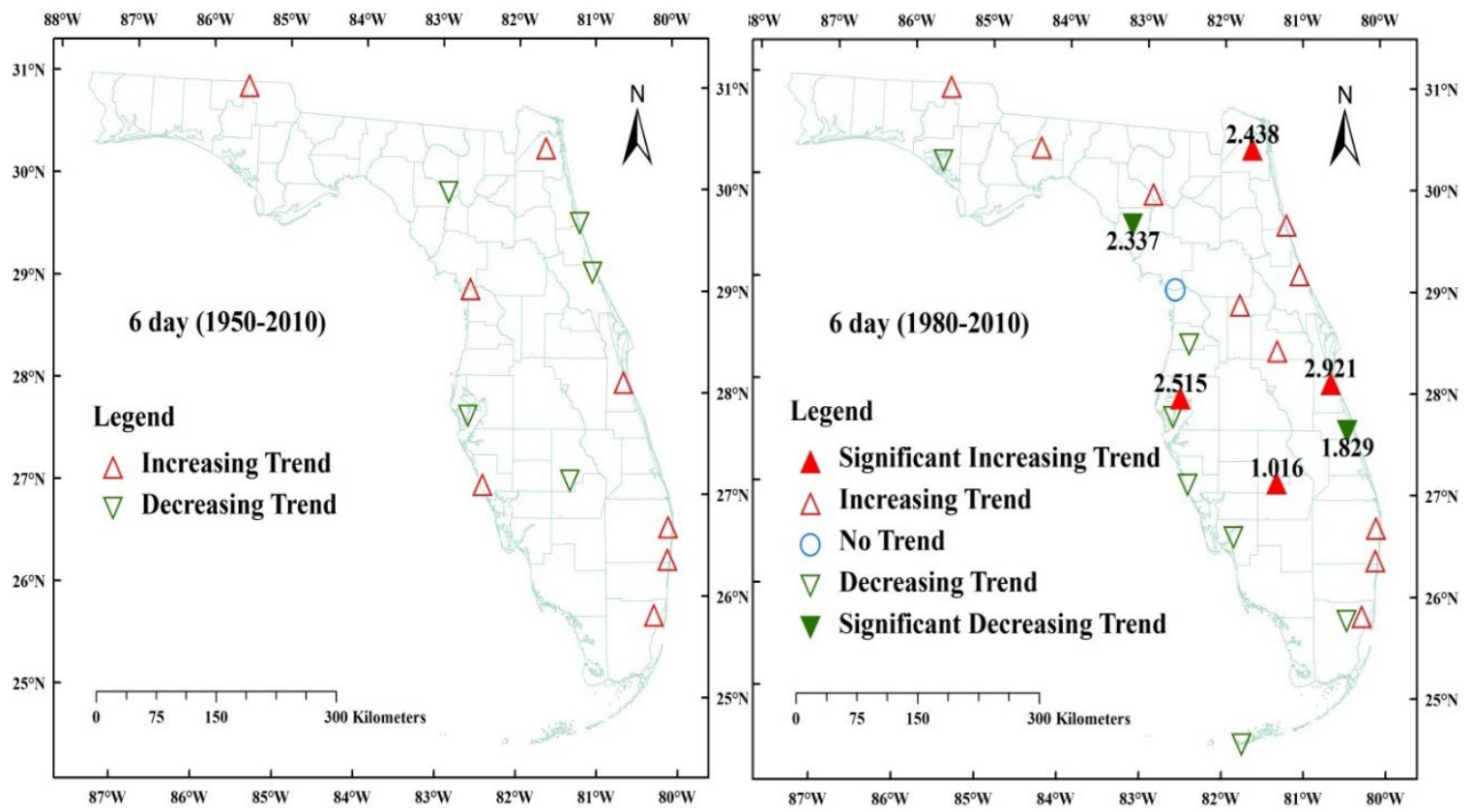

Figure 16: Spatial pattern of the trend results for the annual maximum rainfall event for six day duration for the 1950-2010 (left) and 1980-2010 (right) analysis periods. The slope value (mm/year) for significant trend is also indicated. 


\subsubsection{Seven Day Event}

The seven day event (Fig. 17) revealed positive trends for nine stations and negative trends for four stations during 1950-2010 period, although none of them were statistically significant. In general, two, three, four, five, six and seven day events provided almost similar spatial patterns for longest time period with no statistically significant trends. In contrast, more statistically significant trends, both positive and negative, were found in 1980-2010 analysis period. For example, Jacksonville, Melbourne and Tampa exhibited significant increasing trends and Vero Beach and Cross City indicated significant decreasing trends for seven day duration. Similar trend results were also detected in the above mentioned locations for two, three, four, five and six day events during the same time period.
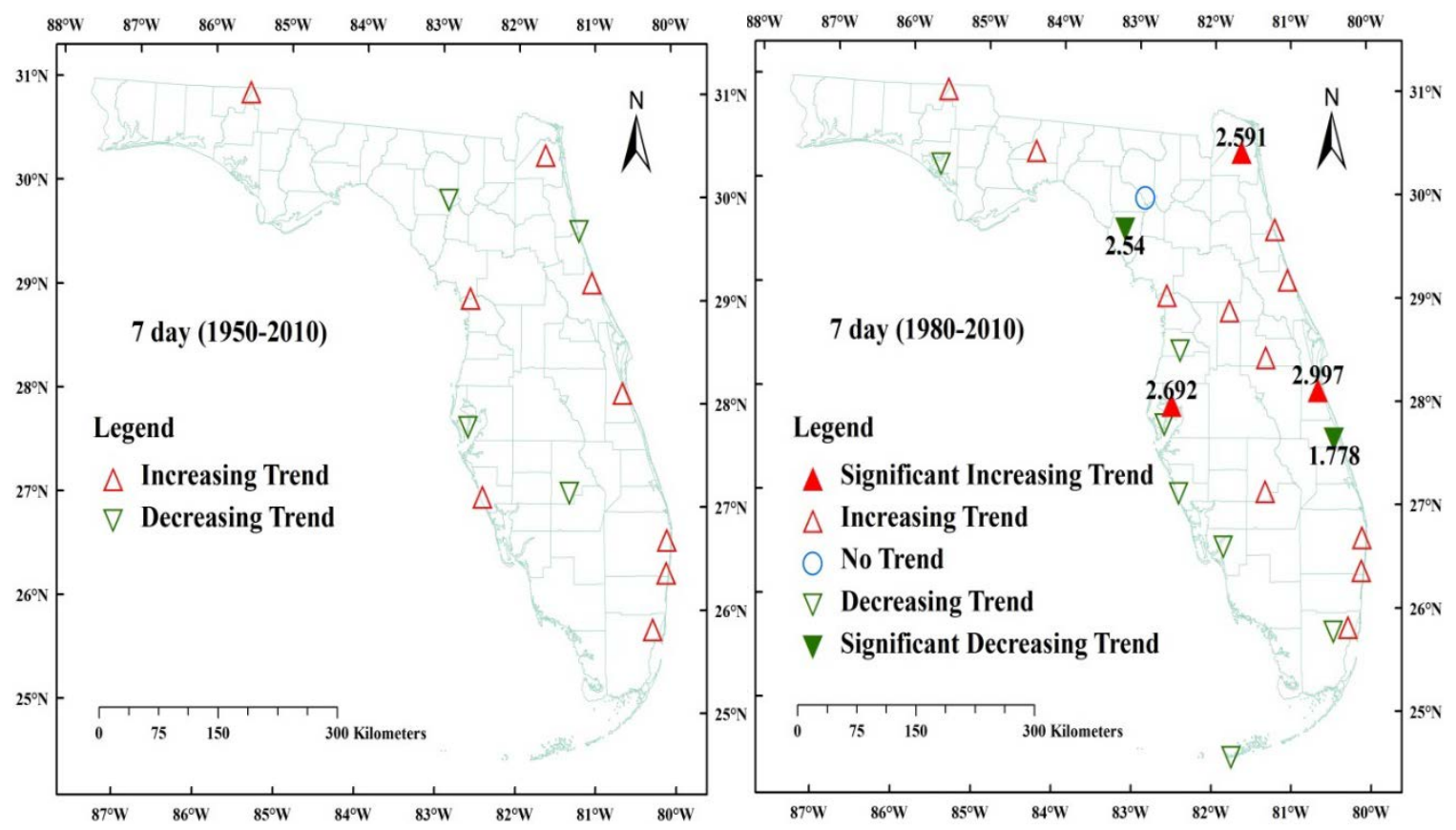

Figure 17: Spatial pattern of the trend results for the annual maximum rainfall event for seven day duration for the 1950-2010 (left) and 1980-2010 (right) analysis periods. The slope value (mm/year) for significant trend is also indicated. 


\subsection{Spatial Patterns of Trends for Number of Above Threshold Events}

The spatial patterns of trend results for the number of above threshold events are presented in Figures 18-29 for different stations and for the longest period (1950-2010) and most recent period (1980-2010). In the next sections, regional analysis of trends for number of above threshold events are described in detail for hourly events as well as for daily events.

\subsubsection{Hourly Events}

During the longest analysis period, one hour event (Fig. 18) showed significant decreasing trends for seven stations located in Graceville, Inglis, St. Petersburg, Venice, Venus, Melbourne and Marineland with slope values ranging from 0.333 to 1.053 no. of events per year. Only one station in Boca Raton exhibited significant upward trend for this time period. In the recent period (1980-2010), significant downward trends were observed in Panama City and Cross City, while significant upward trend was found for Fort Myers.

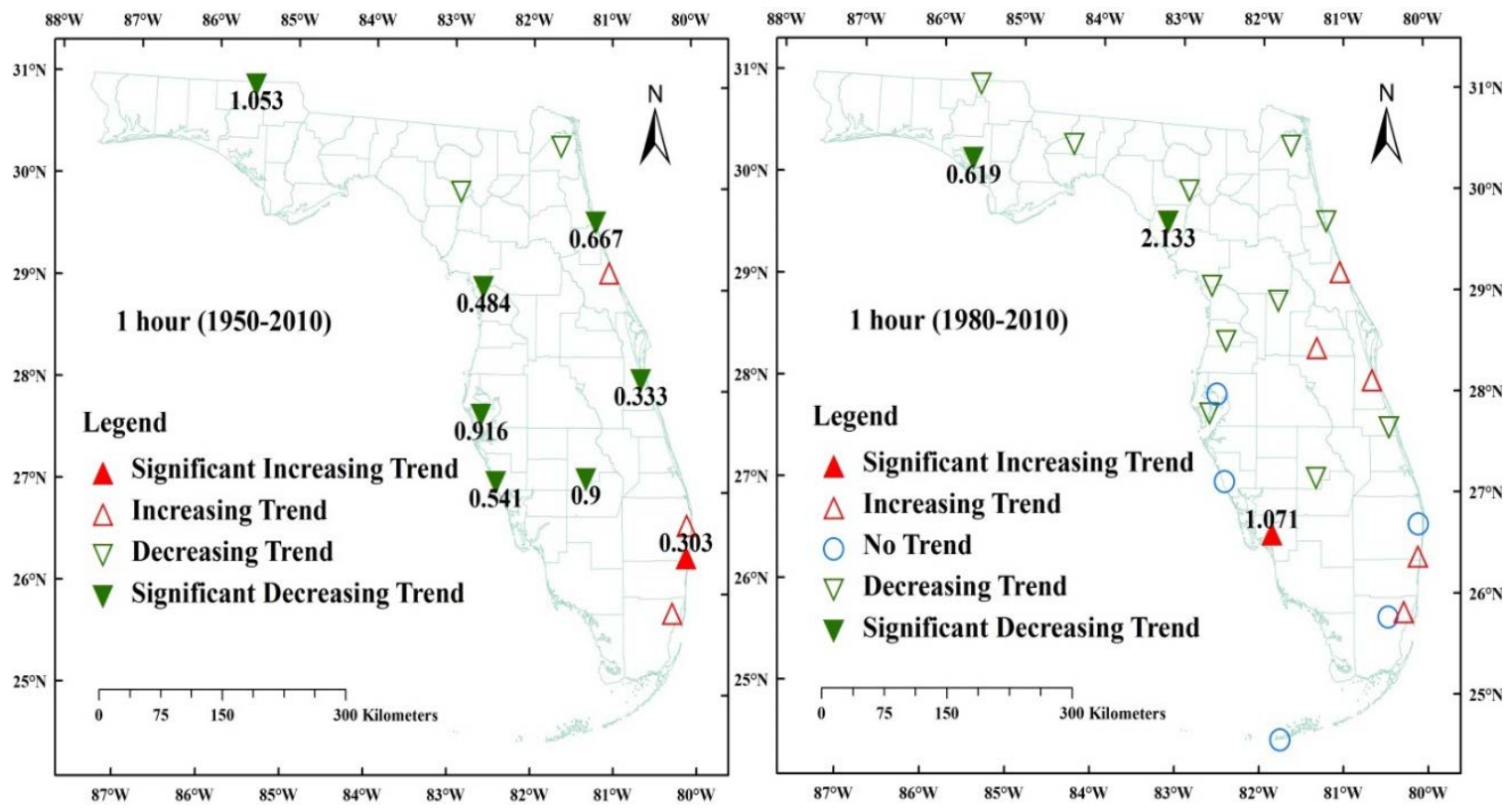

Figure 18: Spatial pattern of the trend results for the number of above threshold events for one hour duration for the 1950-2010 (left) and 1980-2010 (right) analysis periods. The slope value (no. of events/year) for significant trend is also indicated. 


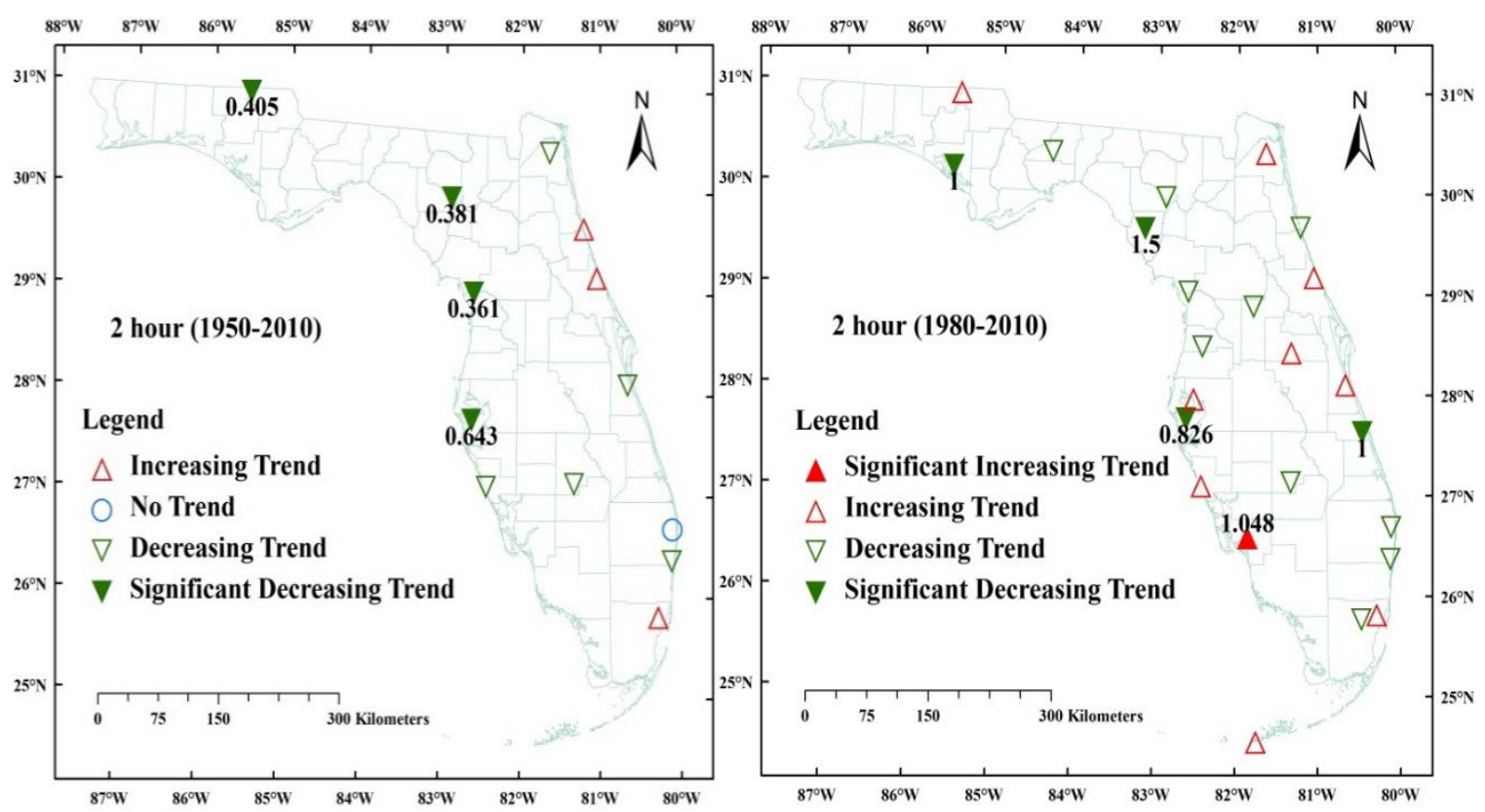

Figure 19: Spatial pattern of the trend results for the number of above threshold events for two hour duration for the 1950-2010 (left) and 1980-2010 (right) analysis periods. The slope value (no. of events/year) for significant trend is also indicated.

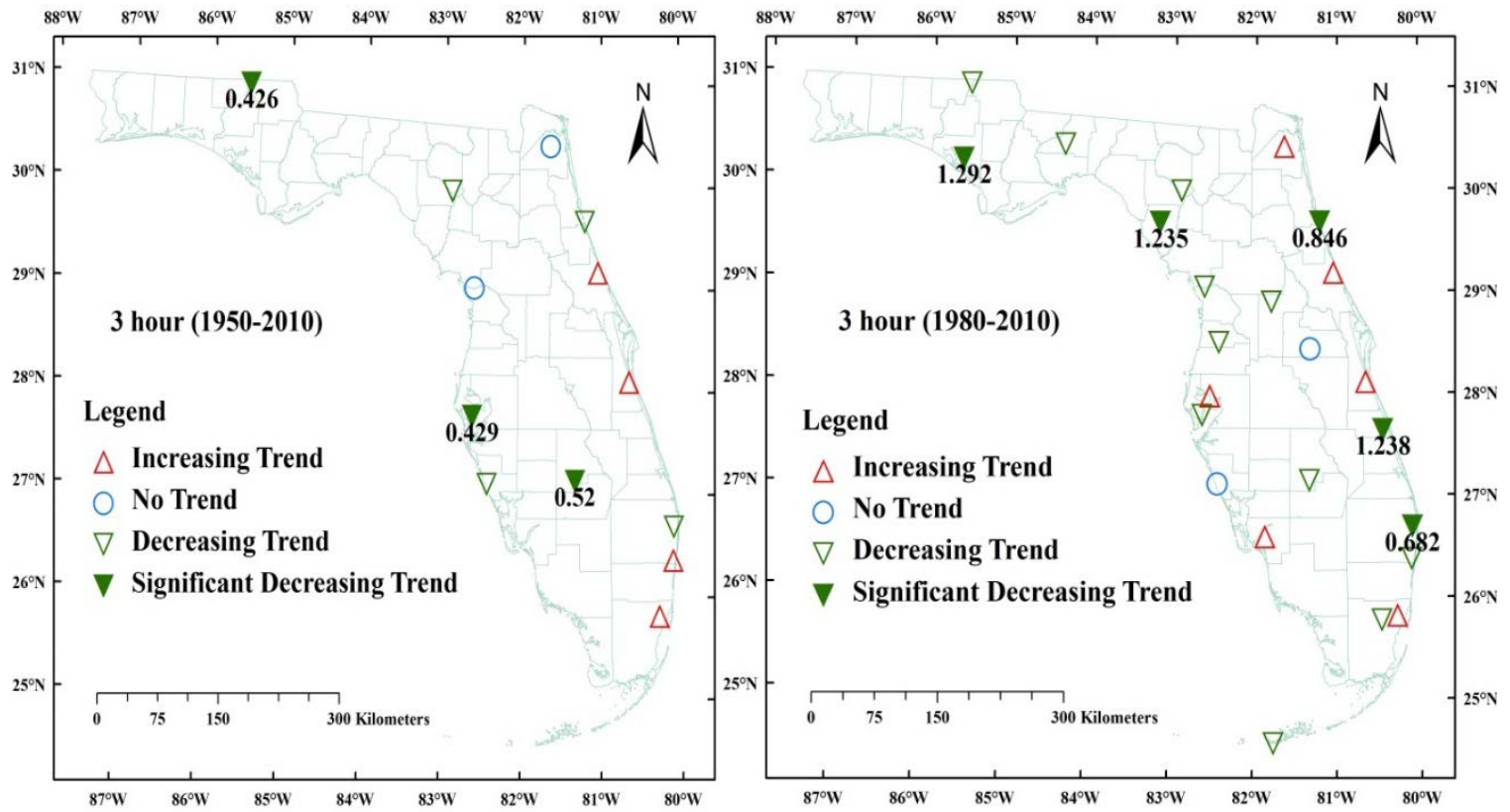

Figure 20: Spatial pattern of the trend results for the number of above threshold events for three hour duration for the 1950-2010 (left) and 1980-2010 (right) analysis periods. The slope value (no. of events/year) for significant trend is also indicated. 

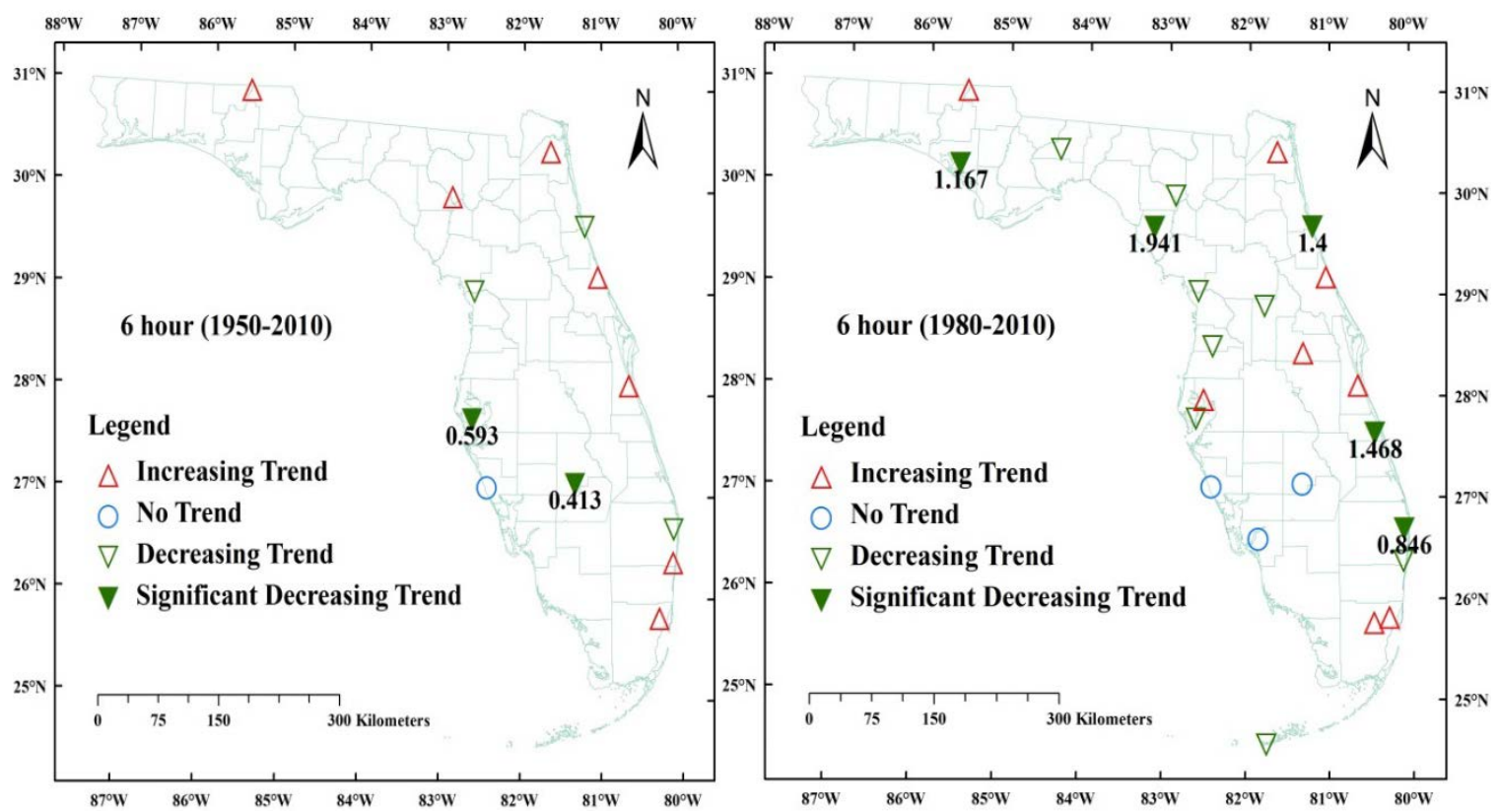

Figure 21: Spatial pattern of the trend results for the number of above threshold events for six hour duration for the 1950-2010 (left) and 1980-2010 (right) analysis periods. The slope value (no. of events/year) for significant trend is also indicated.

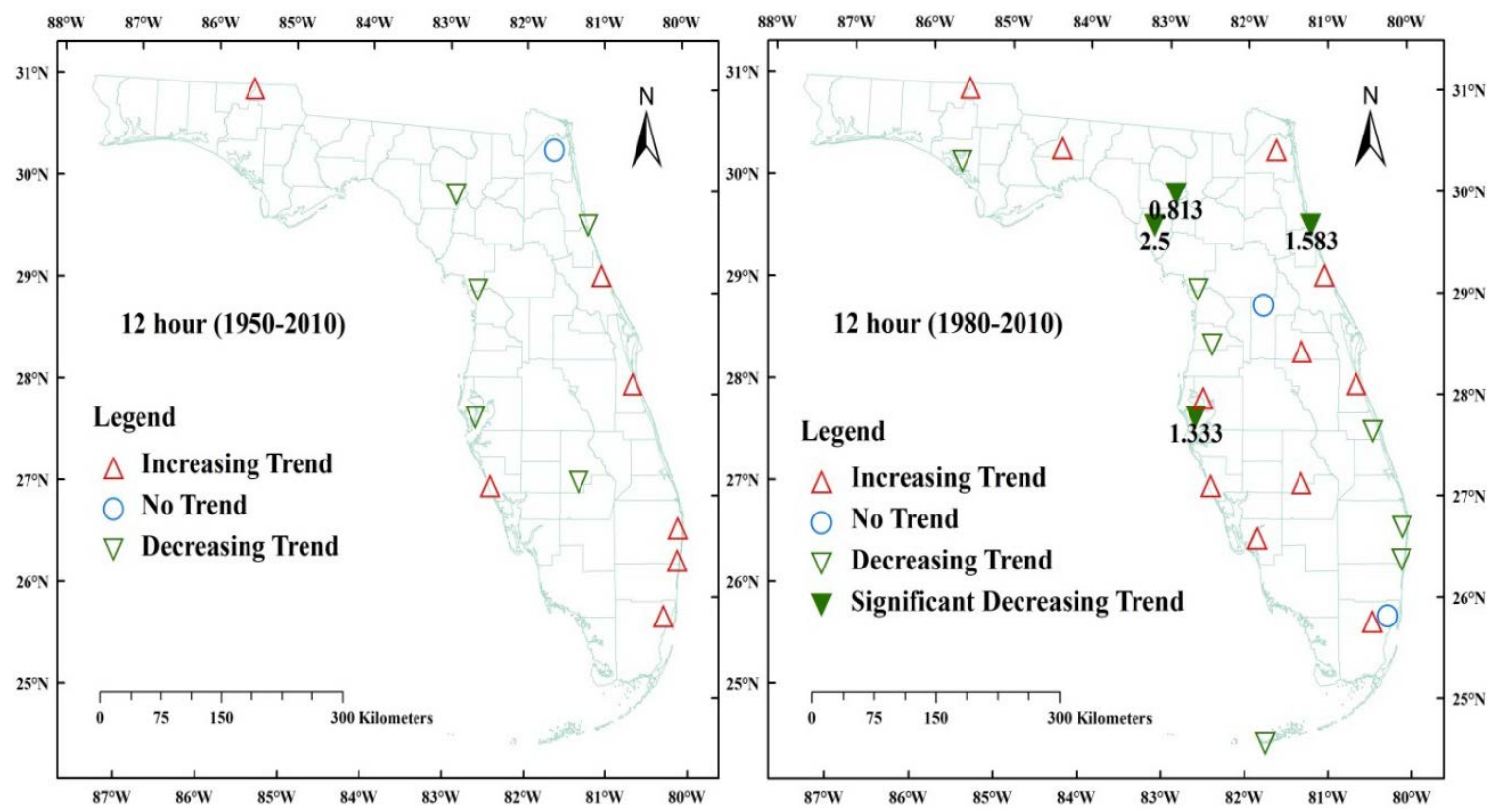

Figure 22: Spatial pattern of the trend results for the number of above threshold events for twelve hour duration for the 1950-2010 (left) and 1980-2010 (right) analysis periods. The slope value (no. of events/year) for significant trend is also indicated. 
The two hour event (Fig. 19) revealed almost similar spatial pattern of trends for 19502010 with significant decreasing trends in Graceville, Branford, Inglis and St. Petersburg cities. With the decrease in analysis period for two hour event (61 years to 31 years), station in Graceville changed to non-significant upward trend, whereas stations in Branford and Inglis transformed to non-significant downward trends. Panama City, Cross City, St. Petersburg and Vero Beach exhibited significant decreasing trends for the analysis period. Fort Myers showed significant increasing trend like it showed for one hour event for 19802010. For three hour (Fig. 20) and six hour (Fig. 21) events in 1950-2010, both Venus and St. Petersburg showed significant downward trends with different slope values whereas Graceville exhibited significant downward trend for three hour event only. No significant increasing trend was observed for this analysis period. On the other hand, for 1980-2010, Panama City, Cross City, Marineland, Vero Beach and West Palm Beach showed significant decreasing trends for both the events. Twelve hour events (Fig. 22) exhibited no significant trend (increasing/decreasing) for the longest analysis period. For 31 years analysis period, stations in Cross city, St. Petersburg, Marineland and Branford showed significant decreasing trends.

\subsubsection{Daily Events}

One day event for the analysis period 1950-2010 (Fig. 23) did not exhibit any significant trend (increasing/decreasing) all over the Florida. Seven stations among thirteen stations showed non-significant increasing trends, mostly located in South Florida, Southwest Florida and Northwest Florida. All the stations in St. Johns river basin along with one station in South Florida and one station in Southwest Florida showed non-significant negative trend. With the decrease in analysis period (61 years to 31 years) for one day 
event, two stations exhibited significant trends; one in Cross City which showed significant decreasing trend and another in Melbourne which showed significant positive trend. For two day event (Fig. 24) in 1950-2010, two stations located in Graceville and West Palm Beach exhibited significant positive trends with slope values of 0.75 and 0.612 number of events per year, respectively. For short analysis period for the same event, Cross City and Vero Beach showed significant negative trends. Graceville and West Palm Beach which showed significant positive trend for 1950-2010 analysis period, changed to nonsignificant positive trends for the short analysis period. For three day (Fig. 25), four day (Fig. 26) and five day (Fig. 27) events, none of the stations showed any significant trend (positive/negative) for 1950-2010 analysis period. Six day (Fig. 28) and Seven day (Fig. 29) events exhibited no trend for all the stations for the same analysis period. In recent period (1980-2010), for three and four day events, Panama City, Cross City and Vero Beach showed significant decreasing trends. Melbourne exhibited significant positive trend for both the events while Jacksonville showed significant positive trend for three day event only. Five day event for 1980-2010 exhibited quite similar spatial pattern with four day event while station in Panama City changed to non-significant decreasing trend from significant decreasing trend. Cross city and Vero Beach showed significant decreasing trends for six and seven day event while St. Petersburg showed significant decreasing trend for six day only. Stations in Tampa, Boca Raton, West Palm Beach and Melbourne exhibited significant increasing trends for both the events. 

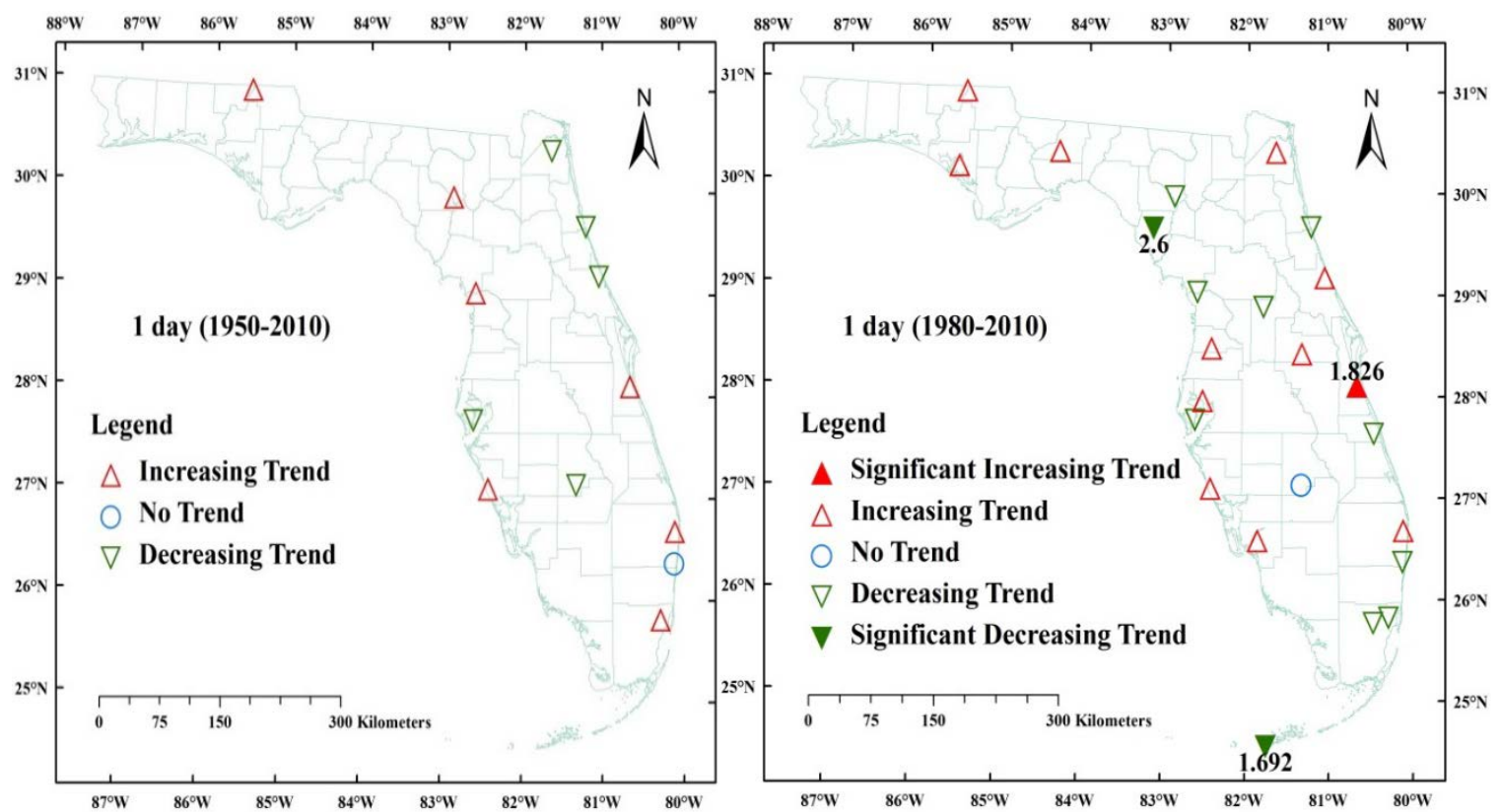

Figure 23: Spatial pattern of the trend results for the number of above threshold events for one day duration for the 1950-2010 (left) and 1980-2010 (right) analysis periods. The slope value (no. of events/year) for significant trend is also indicated.
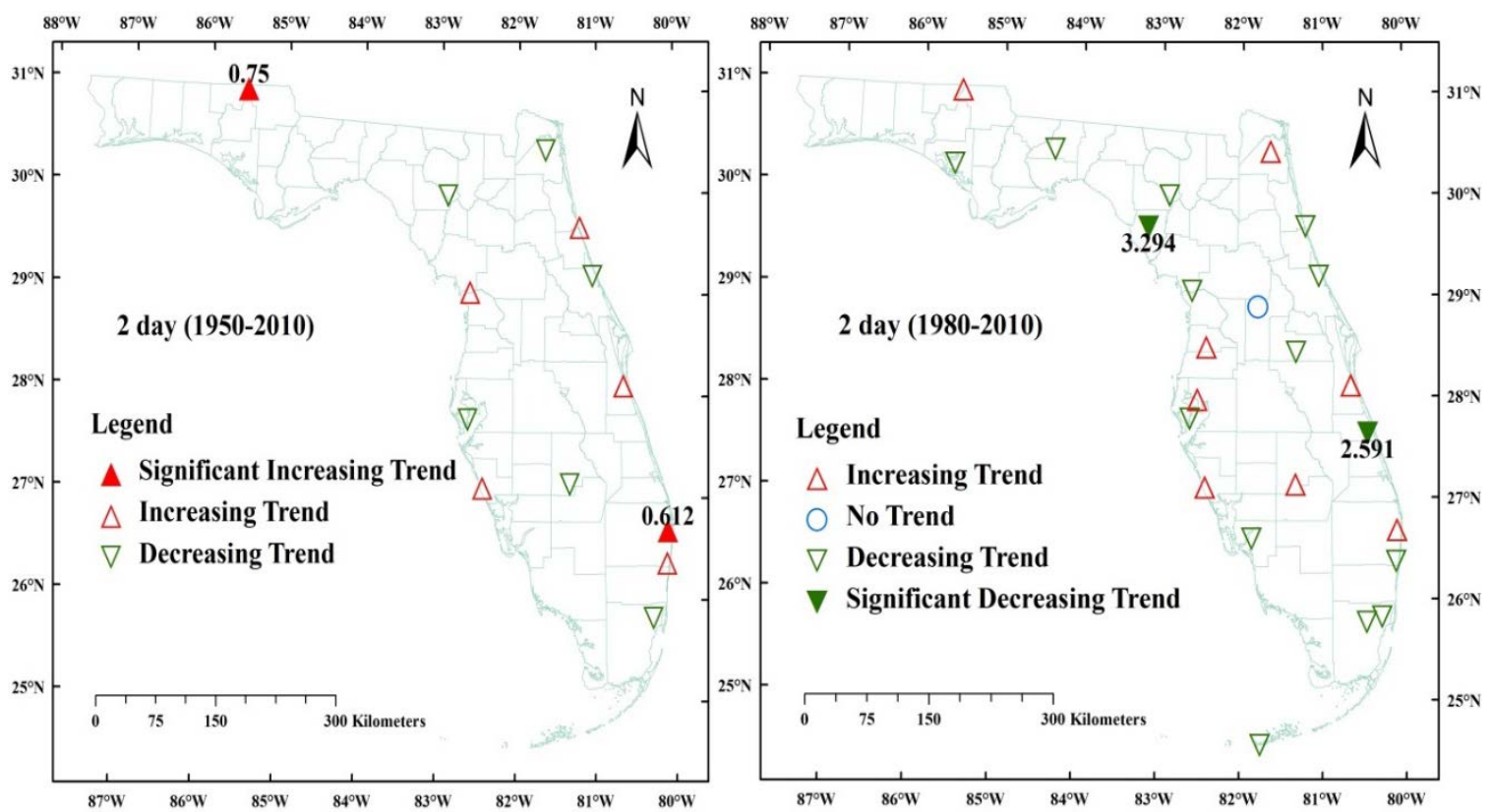

Figure 24: Spatial pattern of the trend results for the number of above threshold events for two day duration for the 1950-2010 (left) and 1980-2010 (right) analysis periods. The slope value (no. of events/year) for significant trend is also indicated. 

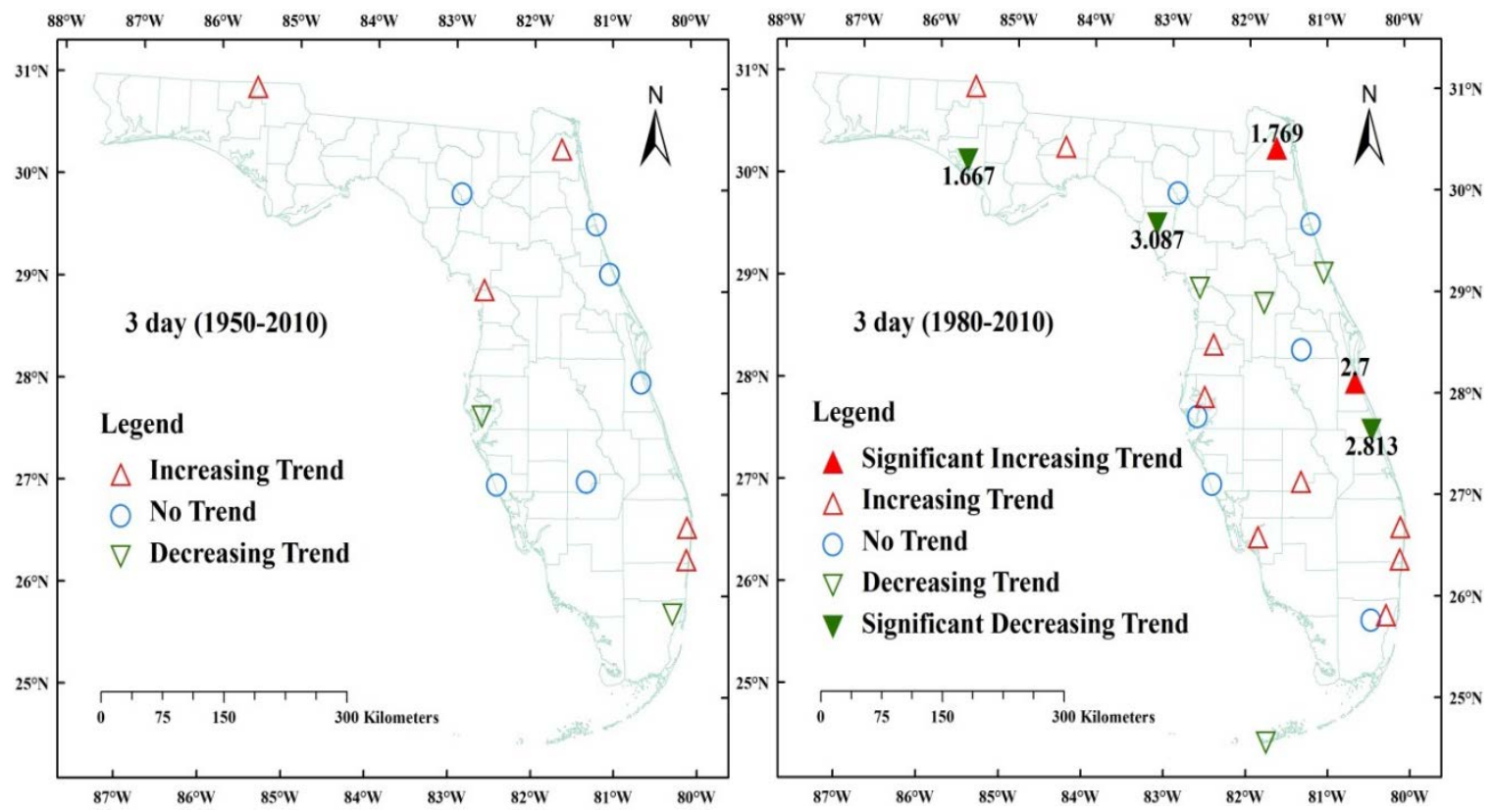

Figure 25: Spatial pattern of the trend results for the number of above threshold events for three day duration for the 1950-2010 (left) and 1980-2010 (right) analysis periods. The slope value (no. of events/year) for significant trend is also indicated.
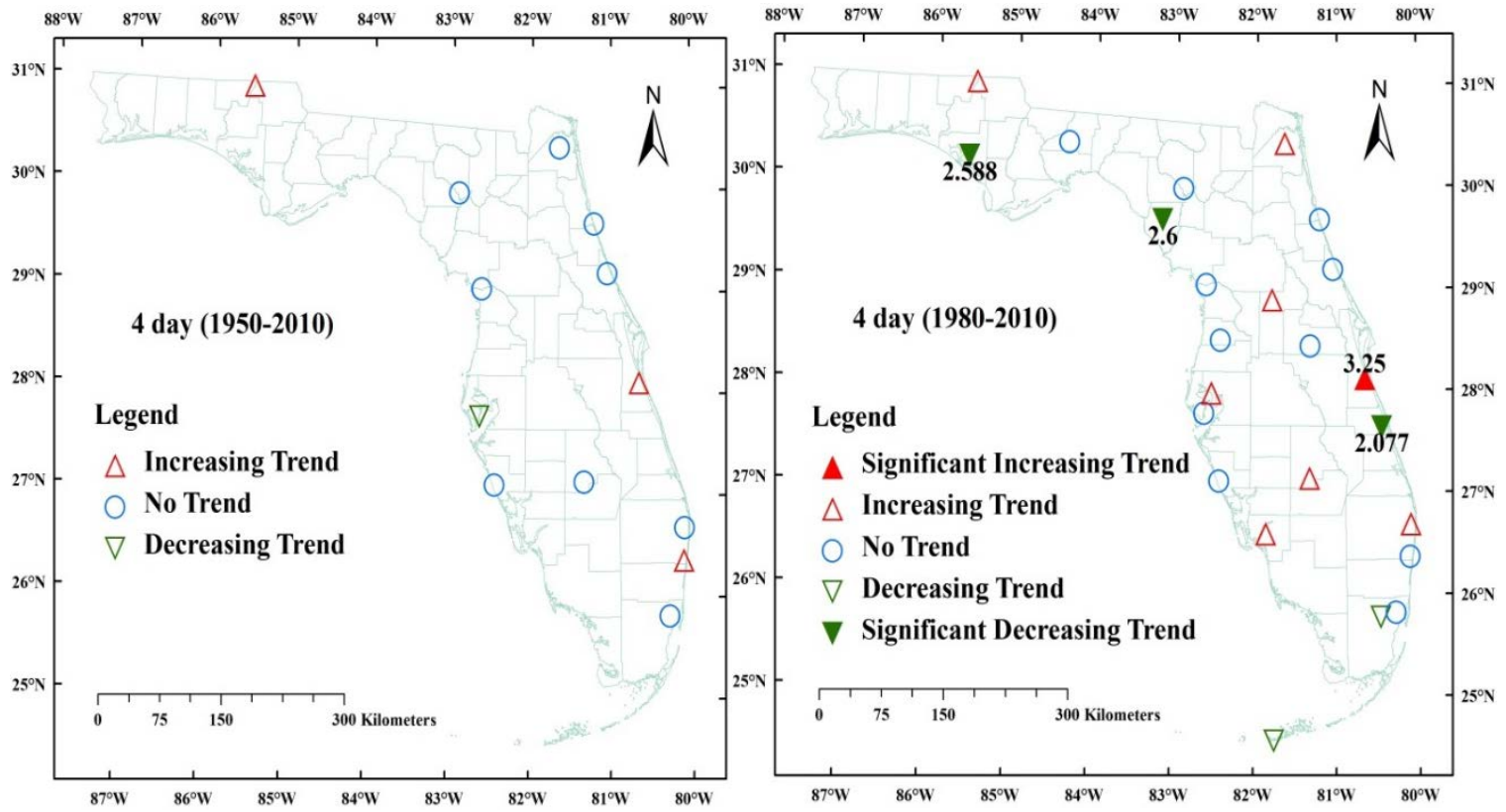

Figure 26: Spatial pattern of the trend results for the number of above threshold events for four day duration for the 1950-2010 (left) and 1980-2010 (right) analysis periods. The slope value (no. of events/year) for significant trend is also indicated. 

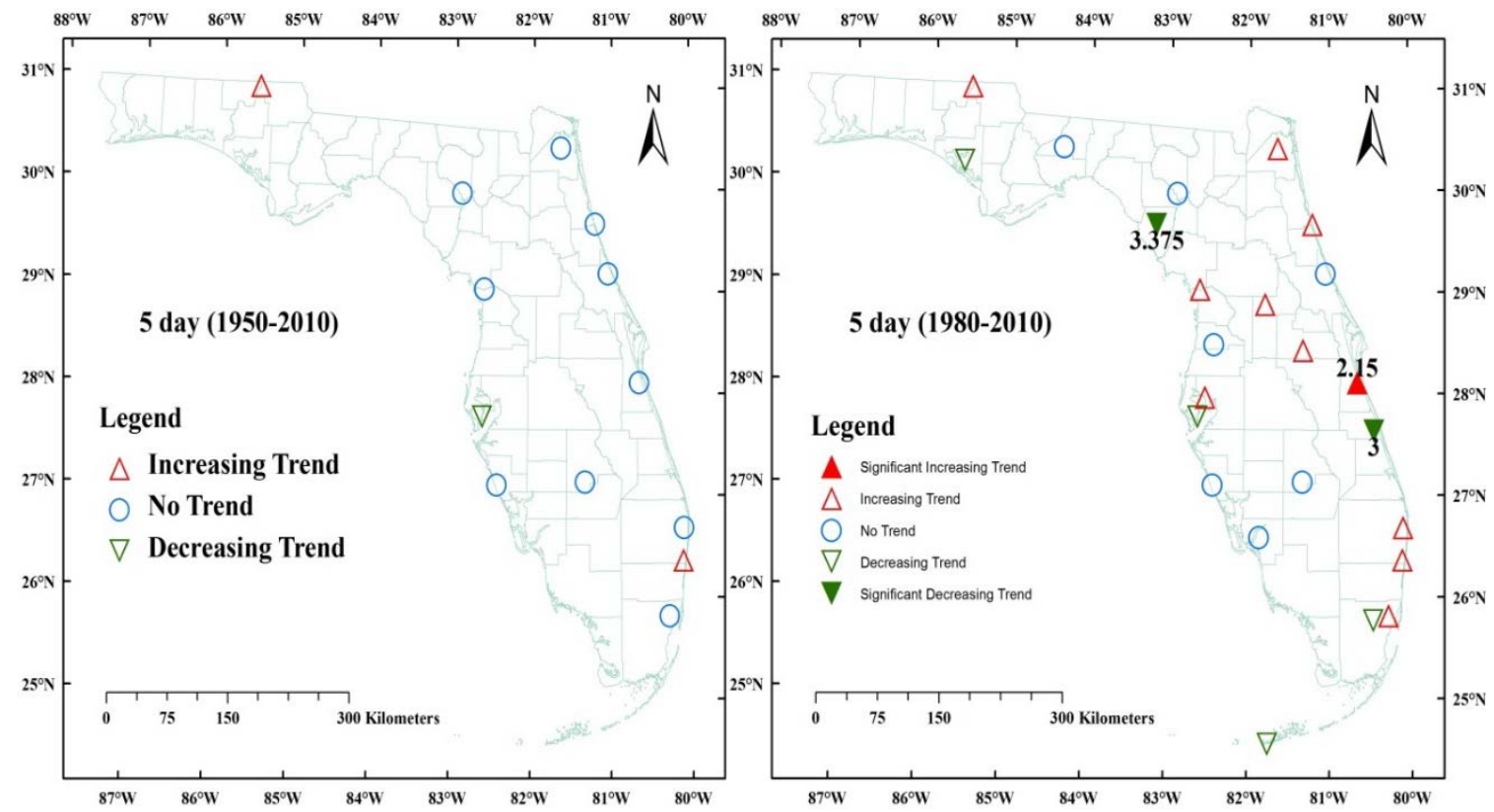

Figure 27: Spatial pattern of the trend results for the number of above threshold events for five day duration for the 1950-2010 (left) and 1980-2010 (right) analysis periods. The slope value (no. of events/year) for significant trend is also indicated.

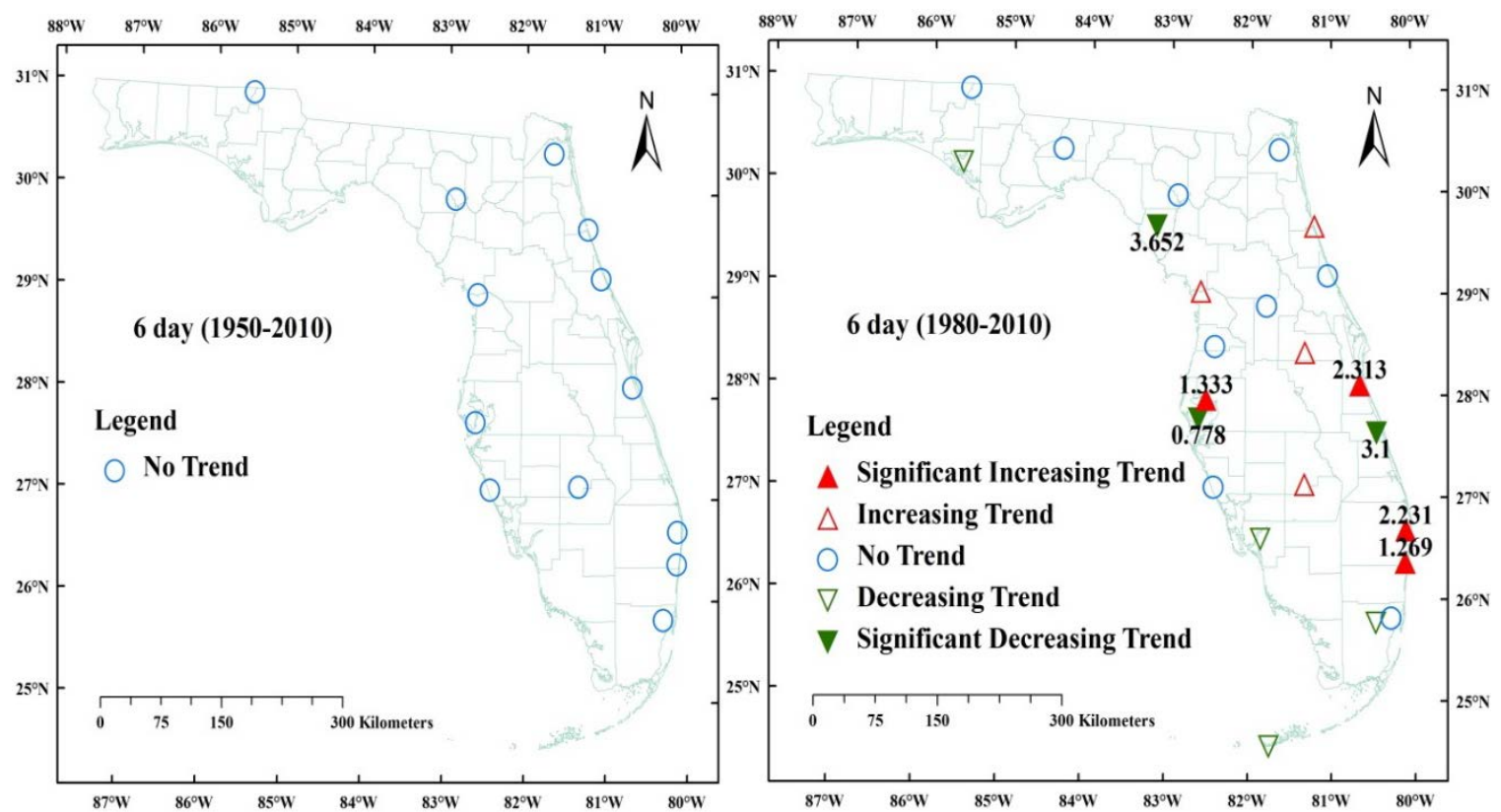

Figure 28: Spatial pattern of the trend results for the number of above threshold events for six day duration for the 1950-2010 (left) and 1980-2010 (right) analysis periods. The slope value (no. of events/year) for significant trend is also indicated. 

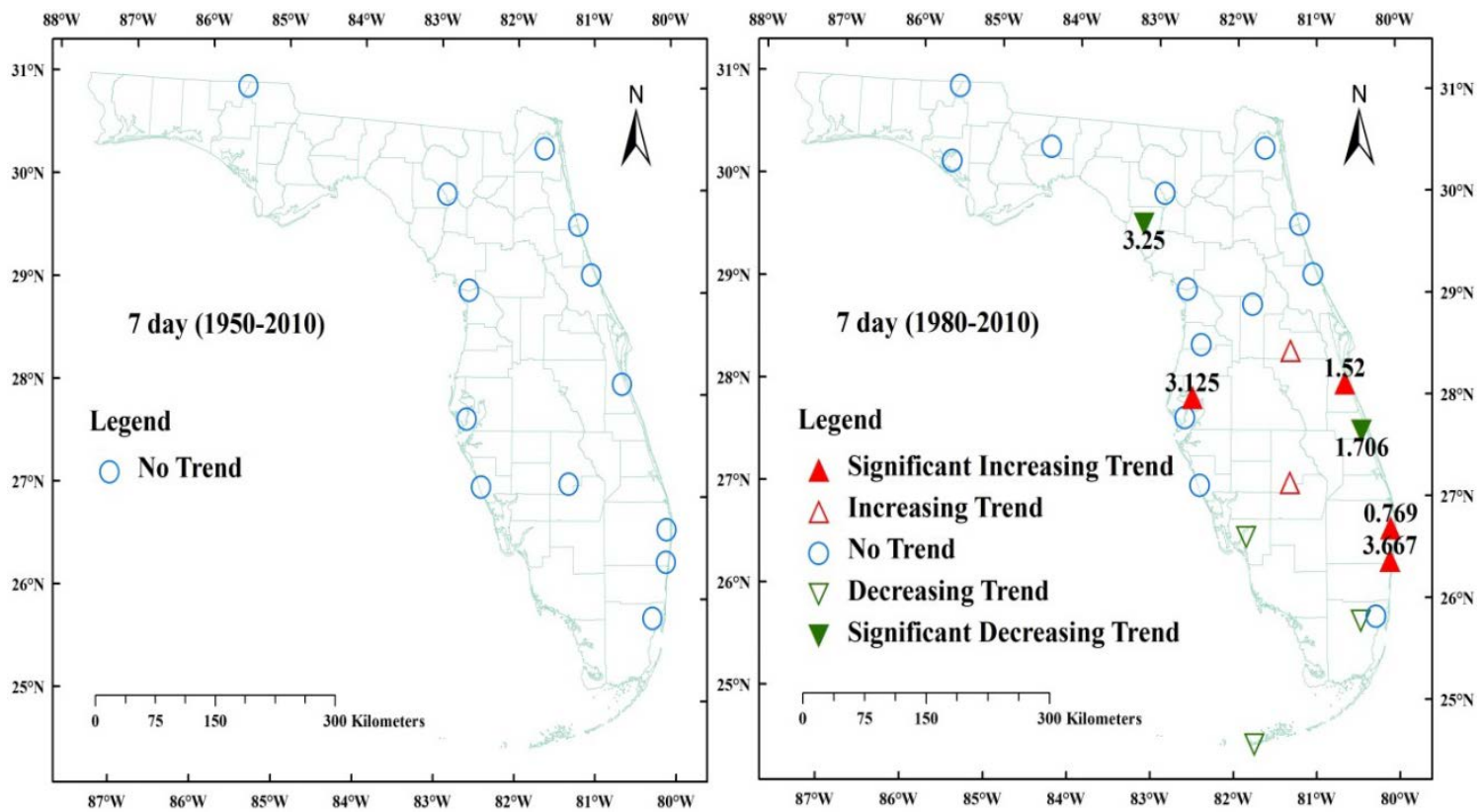

Figure 29: Spatial pattern of the trend results for the number of above threshold events for seven day duration for the 1950-2010 (left) and 1980-2010 (right) analysis periods. The slope value (no. of events/year) for significant trend is also indicated. 


\section{CHAPTER 5 \\ DISCUSSION AND CONCLUSIONS}

\subsection{Discussion}

The comparisons between the trend results from this research and other prior studies are mainly described in this section. It is a very challenging task because different studies consider different measures of precipitation for their analyses. Most of the studies mainly focused on daily and monthly precipitation data, while in this study hourly data was used. Moreover, a regional analysis was conducted in this research based on the most recent precipitation dataset. The results from this research suggested that extreme rainfall events are becoming more intense (higher in magnitudes), but less frequent for the Florida Peninsula. The research findings can aid in updating stormwater management infrastructure and practices in complex urban-natural environments of Florida and similar regions around the world. However, further research is recommended in order to explain the nature versus anthropogenic impacts on precipitation trends in different regions of Florida.

For the recent analysis period (1980-2010), this study estimated more upward trends than downward for durations above 1 day. Similar trend results were also observed for daily precipitation extremes by Curtis (2008). Teegavarapu et al. (2013) also detected a large number of significant increasing trends in the extreme precipitation depths of 1-5 day events during the most recent AMO phases (1970-1994 and 1995-2010) in Florida. The current research identified mostly increasing trends distributed in Northwest, Southwest, Southeast and Central regions of Florida whereas negative trends were found in Suwanee river basin and in the Southern corner of the state (i.e. Key West). The spatial distribution 
of these trend results conforms to the findings of Teegavarapu et al. (2013), except for the northwest region.

For Florida, Irizarry-Ortiz et al. (2013) found more negative than positive significant trend in 2 day and 3 day maximum rainfall events, no significant trend in 5 day event and more positive than negative trend in 7 day event for the 1950-2008 period. Their results are not consistent with the findings of the current work as no significant trends were found in 2, 3 and 7 day events for the same time period. However, the current study found significant increasing trends in 4 to 7 day events during the 1960-2010 period. This dissimilarity may occur due to the consideration of different stations for the trend analysis. Also IrizarryOrtiz et al. (2013) fitted Generalized Extreme Value (GEV) distribution to detect trends in daily extreme events, while in this research non-parametric Mann-Kendall test was applied for both hourly and daily extreme events.

Peterson et al. (2008) examined the daily precipitation gridded data to estimate the changes in extreme precipitation for North America. Considering the 1950 to 2004 analysis period, they found generally increasing trends in heavy precipitation particularly in the highest 1 day and 5 day precipitation events. The results showed no significant trends for Florida, although the general tendency indicated increasing trends in heavy precipitation. These results are consistent with the results from the current work as no significant trend was found for 2 day to 7 day events. Also the current research estimated more non-significant positive than negative trends for the analysis period.

Knight and Davis (2009) indicated increasing contribution of tropical cyclone precipitation to the overall extreme precipitation over the past few decades in the southeastern Atlantic coastal states. Our research also revealed similar findings as more significant increasing 
trends for annual maximum rainfall were observed in 1-7 day durations along the Atlantic coast of Florida during the recent years. An increase in the frequency of tropical storms and hurricanes has also been observed since 1995 in the Atlantic basin (Science \& Public Policy Institute Website, 2015). Similar outcomes were also evident in our study as the number of above threshold events exhibited strong increasing trends for daily durations in the $1980-2010$ period along the Atlantic coast.

\subsection{Conclusions}

The extreme climatic events may create significant challenges for water resources management of Florida. Heavy rainfall can produce short duration flash flood and long duration river floods which have an enormous impacts on human life and property. Therefore, the findings from this study will be helpful in making important decisions related to Florida's water management systems. The overall summary of trends in extreme precipitation can be highlighted as follows:

(i) The magnitude of the annual maximum rainfall events indicated strong increasing local and field significant trends for hourly events during the longest analysis period. For the most recent period, the long duration events exhibited more increasing trends than the short duration events.

(ii) For the number of above threshold events, strong decreasing trends were observed for hourly durations for all the time period, though the percentage of stations with negative trends decreased as the length of the study period decreased.

(iii) The average magnitude of the number of above threshold events exhibited similar trend results with the maximum rainfall events, specifically for the longest and shortest analysis periods. 
(iv) For annual maximum events, number of above threshold events and average magnitude of above threshold events, maximum change per year occurred during the most recent period. However, average magnitude of above threshold events estimated comparatively smaller changes per year than the annual maximum rainfall events.

(v) The hourly annual maximum events identified mostly upward trends in Southwest Florida and downward trends in Suwannee river basin for shorter record lengths; the other regions experienced mixed trends. For longest analysis period, the hourly events exhibited increasing trends for most of the regions in Florida.

(vi) All the daily annual maximum precipitation events showed highly increasing trends along the coast of Atlantic Ocean during the recent time period, while these events indicated mostly decreasing trends along the coast of Gulf of Mexico for the same time period. For the longest time period, the daily events showed mixed trends for Florida.

(vii) For hourly durations in 1950-2010 period, the number of above threshold events revealed upwards trends in southeast region, whereas it depicted mostly downwards trends along the coast of Gulf of Mexico. For 1980-2010, the number of above threshold events showed mixed trends.

(viii) For the number of above threshold events, 3 to 7 day events showed mostly no trends for the longest record length. However, southeast coast experienced highly increasing trends for the same events in the shortest record length. 


\section{REFERENCES}

Abdul-Aziz OI, Burn DH. 2006. Trends and variability in the hydrological regime of the Mackenzie River Basin. Journal of hydrology. 319(1), 282-294.

Andreadis KM, Lettenmaier DP. 2006. Trends in 20th century drought over the continental United States. Geophysical Research Letters. 33(10).

Bates BC, Kundzewicz ZW, Wu S, Palutikof JP (eds). 2008. Climate change and water. Technical Paper of the Intergovernmental Panel on Climate Change, IPCC Secretariat, Geneva, 210.

Bawden AJ, Linton HC, Burn DH, Prowse TD. 2014. A spatiotemporal analysis of hydrological trends and variability in the Athabasca River region, Canada. Journal of Hydrology. 509, 333-342.

Black RJ. 1993. Florida climate data. EES5, Environmental Horticulture Department, Florida Cooperative Extension Service, IFAS, U. of Florida [Available online at http://edis.ifas.ufl.edu/eh105].

Burn DH, Hag Elnur MA. 2002. Detection of hydrologic trends and variability. Journal of Hydrology 255: 107-122.

Burn DH, Cunderlik JM, Pietroniro A. 2004. Hydrological trends and variability in the Liard river basin. Hydrological Sciences Journal 49(1): 53-67.

Burn DH. 2008. Climatic influences on streamflow timing in the headwaters of the Mackenzie River Basin. Journal of Hydrology 352: 225-238.

Burn DH, Mansour R, Zhang K, Whitfield PH. 2011. Trends and variability in extreme rainfall events in British Columbia. Canadian Water Resources Journal. 36(1), 6782.

Burn DH, Taleghani A. 2013. Estimates of changes in design rainfall values for Canada. Hydrological Processes. 27(11), 1590-1599.

Costa AC, Soares A. 2009. Trends in extreme precipitation indices derived from a daily rainfall database for the South of Portugal. International Journal of Climatology. 29(13), 1956-1975.

Coulibaly P, Shi X. 2005. Identification of the effect of climate change on future design standards of drainage infrastructure in Ontario - highway infrastructure innovation funding (HIIFP) program - HIIFP-022. Report to Ministry of Transportation of Ontario, Hamilton, ON. 
Curtis S. 2008. The Atlantic multidecadal oscillation and extreme daily precipitation over the US and Mexico during the hurricane season. Clim. Dyn. 30, 343-351.

Douglas EM, Vogel RM, Kroll CN. 2000. Trends in floods and low flows in the United States: impact of spatial correlation. J. Hydrol. 240, 90-105.

Douglas EM, Fairbank CA. 2010. Is precipitation in northern New England becoming more extreme? Statistical analysis of extreme rainfall in Massachusetts, New Hampshire, and Maine and updated estimates of the 100-year storm. Journal of Hydrologic Engineering. 16(3), 203-217.

Florida Department of Environmental Protection Website, 2015, http://www.dep.state.fl.us/secretary/watman/

Frich P, Alexander LV, Della-Marta P, Gleason B, Haylock M, Klein Tank AMG, Peterson T. 2002. Observed coherent changes in climatic extremes during the second half of the twentieth century. Climate Research 19: 193-212.

Gocic M, Trajkovic S. 2013. Analysis of changes in meteorological variables using MannKendall and Sen's slope estimator statistical tests in Serbia. Glob Planet Chang 100:172-182.

Hirsch RM, Slack JR, Smith RA. 1982. Techniques of trend analysis for monthly water quality data. Water Resour. Res. 18, 107-121.

Irizarry-Ortiz MM, Obeysekera J, Park J, Trimble P, Barnes J, Park-Said W, Gadzinski E. 2013. Historical trends in Florida temperature and precipitation. Hydrological Processes. 27(16), 2225-2246.

Karl TR, Knight RW. 1998. Secular trends of precipitation amount, frequency, and intensity in the United States. Bull. Am. Meteorol. Soc. 79, 231-241.

Kendall MG. 1938. A new measure of rank correlation. Biometrika 30: 81-93.

Kendall MG. 1976. Rank Correlation Methods, 4th edn. Charles Griffin; 210.

Keuser AP. (2014). Precipitation patterns and trends in the metropolitan area of Milwaukee, Wisconsin. International Journal of Geospatial and Environmental Research. 1(1), 6.

Knight DB, Davis RE. 2009. Contribution of tropical cyclones to extreme rainfall events in the southeastern United States. Journal of Geophysical Research: Atmospheres (1984-2012). 114(D23). 
Kunkel KE, Andsager K, Easterling DR. 1999. Long-term trends in extreme precipitation events over the conterminous United States and Canada. Journal of climate. 12(8), 2515-2527.

Kunkel KE, Easterling DR, Redmond K, Hubbard K. 2003. Temporal variations of extreme precipitation events in the United States: 1895-2000.Geophysical research letters. 30(17).

Kunkel KE, Karl TR, Easterling DR. 2007. A Monte Carlo assessment of uncertainties in heavy precipitation frequency variations. Journal of Hydrometeorology. 8(5), $1152-1160$.

Kunkel KE, Stevens LE, Stevens SE, Sun L, Janssen E, Wuebbles D, ... and Dobson JG. 2013. Regional climate trends and scenarios for the U.S. national climate assessment: Part 2. Climate of the Southeast U.S.NOAA technical report NESDIS. 142(4), 91.

Lettenmaier DP, Wood EF, Wallis JR. 1994. Hydro-climatological trends in the Continental United States, 1948-1988. J. Clim. 7, 586-607.

Livezey RE, Chen WY. 1983. Statistical field significance and its determination by Monte Carlo techniques. Mon. Weather Rev. 111, 46-59.

Mailhot A, Kingumbi A, Talbot G, Poulin A. 2010. Future changes in intensity and seasonal pattern of occurrence of daily and multi-day annual maximum precipitation over Canada. Journal of Hydrology 388: 173-185.

Mailhot A, Beauregard I, Talbot G, Caya D, Biner S. 2011. Future changes in intense precipitation over Canada assessed from multi-model NARCCAP ensemble simulations. International Journal of Climatology. Published online doi:10.1002/joc.2343.

Mann HB. 1945. Nonparametric tests against trend. Econometrica 13: 245-259.

Martinez JC, Maleski JJ, Miller FM. 2012. Trends in precipitation and temperature in Florida, USA. J Hydrol 452-453: 259-281.

McPherson BF, Halley RB. 1996. Circular (Vol. 1134). The Survey.

Meehl GA, Stocker TF, Collins WD, Friedlingstein P, Gaye AT, Gregory JM, Kitoh A, Knutti R, Murphy JM, Noda A, Raper SCB, Watterson IG, Weaver AJ, Zhao Z-C. 2007. Global Climate Projections. In Climate Change 2007: The Physical Science Basis. Contribution of Working Group I to the Fourth Assessment Report of the Intergovernmental Panel on Climate Change, Solomon S, Qin D, Manning M, Chen Z, Marquis M, Averyt KB, Tignor M, Miller HL (eds). Cambridge University Press: Cambridge, United Kingdom and New York, NY, USA. 
Mishra AK, Singh VP. 2010. Changes in extreme precipitation in Texas. Journal of Geophysical Research: Atmospheres (1984-2012). 115(D14).

Nadarajah S. 2005. Extremes of daily rainfall in west central Florida. Climatic Change 69: 325-342.

National Climatic Data Center Website, 2015, http://www.ncdc.noaa.gov/

Novotny EV, Stefan HG. 2007. Stream flow in Minnesota: indicator of climate change. Journal of Hydrology. 334(3), 319-333.

Obeysekera J, Trimble P, Neidrauer C, Pathak C, VanArman J, Strowd T, Hall C. 2006. Consideration of Long-Term Climatic Variability in Regional Modeling for SFWMD Planning and Operations - Draft. SFWMD, 51 pp.

Obeysekera J, Park J, Irizarry-Ortiz M, Trimble P, Barnes J, Van Arman J, Said W, Gadzinski E. 2011. Past and projected trends in climate and sea level for South Florida. Interdepartmental Climate Change Group. South Florida Water Management District, West Palm Beach, Florida, Hydrologic and Environmental Systems Modeling Technical Report.

Obeysekera J, Irizarry M, Park J, Barnes J, Dessalegne T. 2011. Climate change and its implications for water resources management in south Florida. Stochastic Environmental Research and Risk Assessment. 25(4), 495-516.

Parry ML, Canziani OF, Palutikof JP, Co-authors. 2007. Technical Summary. In Climate Change 2007: Impacts, Adaptation and Vulnerability. Contribution of Working Group II to the Fourth Assessment Report of the Intergovernmental Panel on Climate Change. Parry ML, Canziani OF, Palutikof JP, van der Linden PJ, Hanson CE (eds). Cambridge University Press: Cambridge, UK; 23-78.

Partal T, Kahya E. 2006. Trend analysis in Turkish precipitation data. Hydrol Process. 20:2011-2026.

Peterson TC, Zhang X, Brunet-India M, Vázquez-Aguirre JL. 2008. Changes in North American extremes derived from daily weather data. Journal of Geophysical Research: Atmospheres (1984-2012). 113(D7).

Petrow T, Merz B. 2009. Trends in flood magnitude, frequency and seasonality in Germany in the period 1951-2002. Journal of Hydrology 371: 129-141.

Pryor SC, Howe JA, Kunkel KE. 2009. How spatially coherent and statistically robust are temporal changes in extreme precipitation in the contiguous USA?. International Journal of Climatology. 29(1), 31-45. 
Sayemuzzaman M, Jha MK. 2014. Seasonal and annual precipitation time series trend analysis in North Carolina, United States. Atmos Res 137:183-194.

Sayemuzzaman M, Jha MK, Mekonnen A. 2014. Spatio-temporal long-term (1950-2009) temperature trend analysis in North Carolina, United States. Theoretical and Applied Climatology. 120(1-2), 159-171.

Science \& Public Policy Institute Website, 2015, http://scienceandpublicpolicy.org/

Sen PK. 1968. Estimates of the regression coefficient based on Kendall's Tau. Journal of the American Statistical Association 63(324): 1379-1389.

Small D, Islam S, Vogel RM. 2006. Trends in precipitation and streamflow in the eastern US.: paradox or perception? Geophys. Res. Lett. 33.

State of Florida Website, 2015, http://www.stateofflorida.com/

Tabari H, Shifteh SB, Rezaeian ZM. 2011. Testing for long-term trends in climatic variables in Iran. Atmos Res 100(1):132-140.

Teegavarapu RS, Goly A, Obeysekera J. 2013. Influences of Atlantic multidecadal oscillation phases on spatial and temporal variability of regional precipitation extremes. Journal of Hydrology. 495, 74-93.

Theil H. 1950. A rank-invariant method of linear and polynomial regression analysis. III. Proc. Koninklijke Nederlandse Akademie van Wetenschappen A 53: 1397-1412.

Trimble PJ, Obeysekera JTB, Cadavid LG, Santee ER. 2006. Applications of climate outlooks for water management in south Florida. In Climate variations, climate change, and water resources engineering, Garbrecht JD, Piechota TC (eds). ASCE/EWRI: Reston, VA.

Von Storch H, Navarra A. (eds). 1995. Analysis of Climate Variability. Springer-Verlag, New York, USA.

Wang HS, Schubert MS, Junye C, Martin H, Arun K, Pegion P. 2009. Attribution of the seasonality and regionality in climate trends over the United States during 19502000. J Climate 22:2571-2590.

Wilks DS. 2006. On 'field Significance' and the false discovery rate. Journal of Applied Meteorology and Climatology 45: 1181-1189.

Willems P, Arnbjerg-Nielsen K, Olsson J, Nguyen VTV. 2009. Climate change impact assessment on urban rainfall extremes and urban drainage: methodologies and 
difficulties, 8th International Workshop on Precipitation in Urban Areas, Rainfall in the Urban Context: Forecasting, Risk and Climate Change, 149-154.

Yilmaz AG, Hossain I, Perera BJC. 2014. Effect of climate change and variability on extreme rainfall intensity-frequency-duration relationships: a case study of Melbourne. Hydrology and Earth System Sciences. 18(10), 4065-4076.

Yue S, Pilon P, Cavadias G. 2002a. Power of the Mann-Kendall and Spearman's rho tests for detecting monotonic trends in hydrological series. Journal of hydrology. 259(1), 254-271.

Yue S, Pilon PJ, Phinney B, Cavadias G. 2002b. The influence of autocorrelation on the ability to detect trend in hydrological series. Hydrological Processes 16(9): 18071829.

Yue S, Pilon P, Phinney BOB. 2003. Canadian streamflow trend detection: impacts of serial and cross-correlation. Hydrological Sciences Journal. 48(1), 51-63.

Zhang X, Vincent LA, Hogg WD, Niitsoo A. 2000. Temperature and precipitation trends in Canada during the 20th century. Atmosphere-ocean. 38(3), 395-429. 


\section{APPENDICES}

Appendix 1. Statistical summary of the annual maximum rainfall values for the 61 years recorded dataset.

\begin{tabular}{ccccc}
\hline Duration & Mean (in) & Median (in) & $\begin{array}{c}\text { Standard } \\
\text { Deviation (in) }\end{array}$ & Range (in) \\
& & & & \\
\hline $\mathbf{1}$ hour & 1.91 & 1.81 & 0.58 & $0.48-6.14$ \\
$\mathbf{2}$ hour & 2.53 & 2.40 & 0.83 & $0.77-8.30$ \\
$\mathbf{3}$ hour & 2.82 & 2.63 & 1.00 & $0.78-11.18$ \\
$\mathbf{6}$ hour & 3.30 & 3.05 & 1.26 & $0.89-14.85$ \\
$\mathbf{1 2}$ hour & 3.82 & 3.50 & 1.59 & $0.99-21.87$ \\
$\mathbf{1}$ day & 4.44 & 4.08 & 1.86 & $1.06-23.28$ \\
$\mathbf{2}$ day & 5.18 & 4.70 & 2.16 & $1.08-24.41$ \\
$\mathbf{3}$ day & 5.62 & 5.05 & 2.34 & $1.25-24.67$ \\
$\mathbf{4}$ day & 6.00 & 5.43 & 2.43 & $1.82-25.05$ \\
$\mathbf{5}$ day & 6.34 & 5.80 & 2.49 & $1.87-26.24$ \\
$\mathbf{6}$ day & 6.68 & 6.15 & 2.55 & $1.89-26.65$ \\
$\mathbf{7}$ day & 6.99 & 6.47 & 2.59 & $1.90-26.86$ \\
\hline
\end{tabular}


Appendix 2. Slope values (mm/year) for the magnitude of the annual maximum rainfall for stations with significant trends during the 1950-2010 time period.

\begin{tabular}{|c|c|c|c|c|c|c|c|c|c|c|c|c|}
\hline Station & 1 hour & 2 hour & 3 hour & 6 hour & 12 hour & 1 day & 2 day & 3 day & 4 day & 5 day & 6 day & 7 day \\
\hline \multicolumn{13}{|l|}{ 2C80845 } \\
\hline 4C89525 & & 0.267 & 0.437 & 0.632 & 0.704 & & & & & & & \\
\hline \multicolumn{13}{|l|}{ 6C89184 } \\
\hline \multicolumn{13}{|l|}{ 7C89176 } \\
\hline \multicolumn{13}{|l|}{ 8C82158 } \\
\hline 10C84273 & 0.178 & & & & & & & & & & & \\
\hline \multicolumn{13}{|l|}{ 11C85391 } \\
\hline 12C83538 & & 0.363 & 0.457 & 0.378 & 0.376 & & & & & & & \\
\hline 16C80975 & 0.137 & 0.185 & 0.224 & & & & & & & & & \\
\hline 18C87886 & & 0.236 & & & & & & & & & & \\
\hline 23C85612 & & 0.254 & 0.318 & 0.424 & 0.511 & 0.635 & & & & & & \\
\hline \multicolumn{13}{|l|}{ 43C85663 } \\
\hline 45C84358 & & & & & & & & & & & & \\
\hline
\end{tabular}

Appendix 3. Slope values ( $\mathrm{mm} / \mathrm{year}$ ) for the magnitude of the annual maximum rainfall for stations with significant trends during the 1960-2010 time period.

\begin{tabular}{|c|c|c|c|c|c|c|c|c|c|c|c|c|}
\hline Station & 1 hour & 2 hour & 3 hour & 6 hour & 12 hour & 1 day & 2 day & 3 day & 4 day & 5 day & 6 day & 7 day \\
\hline \multicolumn{13}{|l|}{2 2C80845 } \\
\hline 4C89525 & & & & 0.762 & 0.701 & & & & & & & \\
\hline \multicolumn{13}{|l|}{ 6C89184 } \\
\hline \multicolumn{13}{|l|}{ 7C89176 } \\
\hline \multicolumn{13}{|l|}{ 8C82158 } \\
\hline \multicolumn{13}{|l|}{ 10C84273 } \\
\hline \multicolumn{13}{|l|}{ 11C85391 } \\
\hline \multicolumn{13}{|l|}{ 12C83538 } \\
\hline \multicolumn{13}{|l|}{$16 C 80975$} \\
\hline \multicolumn{13}{|l|}{$18 \mathrm{C} 87886$} \\
\hline 19C88788 & 0.239 & 0.234 & & & & & & & & & & \\
\hline \multicolumn{13}{|c|}{ 21C88758 } \\
\hline \multicolumn{13}{|l|}{ 23C85612 } \\
\hline \multicolumn{13}{|l|}{ 27C83186 } \\
\hline \multicolumn{13}{|l|}{ 41C84570 } \\
\hline \multicolumn{13}{|l|}{ 43С 85663} \\
\hline $44 C 85076$ & & & & & & & & & 0.719 & 0.826 & 0.790 & 0.846 \\
\hline $45 C 84358$ & & & & & & & & & & & & \\
\hline
\end{tabular}


Appendix 4. Slope values (mm/year) for the magnitude of the annual maximum rainfall for stations with significant trends during the 1970-2010 time period.

\begin{tabular}{|c|c|c|c|c|c|c|c|c|c|c|c|c|}
\hline Station & 1 hour & 2 hour & 3 hour & 6 hour & 12 hour & 1 day & 2 day & 3 day & 4 day & 5 day & 6 day & 7 day \\
\hline $2 \mathrm{C} 80845$ & & & & & & & & & & & & 1.836 \\
\hline 4C89525 & & & & 0.894 & 0.986 & 1.255 & 1.199 & 1.402 & 1.372 & & & \\
\hline \multicolumn{13}{|c|}{ (1) } \\
\hline 7C89176 & & & & & 0.480 & & & & & & & \\
\hline 8C82158 & & & & & & & & & & & 1.321 & 1.511 \\
\hline \multicolumn{13}{|l|}{$10 \mathrm{C} 84273$} \\
\hline 11C85391 & & & & & & & 0.953 & 1.107 & & & 1.156 & 1.270 \\
\hline \multicolumn{13}{|l|}{$12 C 83538$} \\
\hline 16C80975 & & & & & & & & & & -1.041 & & \\
\hline \multicolumn{13}{|l|}{$18 C 87886$} \\
\hline 19C88788 & & & & & & & 1.082 & 1.514 & 1.621 & 1.621 & 1.427 & 1.486 \\
\hline \multicolumn{13}{|l|}{ 21C88758 } \\
\hline 23C85612 & & & & & & 1.054 & 1.270 & 1.156 & 1.270 & 1.275 & 1.123 & 1.321 \\
\hline \multicolumn{13}{|l|}{ 25C81048 } \\
\hline \multicolumn{13}{|l|}{ 26C86628 } \\
\hline \multicolumn{13}{|l|}{ 27C83186 } \\
\hline \multicolumn{13}{|l|}{ 41C84570 } \\
\hline \multicolumn{13}{|l|}{ 42C89010 } \\
\hline \multicolumn{13}{|l|}{ 43C85663 } \\
\hline \multicolumn{13}{|l|}{ 44C85076 } \\
\hline $45 C 84358$ & & & & & & & & & & & 1.476 & 1.519 \\
\hline \multicolumn{13}{|l|}{ 46C82008 } \\
\hline \multicolumn{13}{|l|}{ 48C86842 } \\
\hline 50С89219 & & & & & & & & & & & & \\
\hline
\end{tabular}


Appendix 5. Slope values (mm/year) for the magnitude of the annual maximum rainfall for stations with significant trends during the 1980-2010 time period.

\begin{tabular}{|c|c|c|c|c|c|c|c|c|c|c|c|c|}
\hline Station & 1 hour & 2 hour & 3 hour & 6 hour & 12 hour & 1 day & 2 day & 3 day & 4 day & 5 day & 6 day & 7 day \\
\hline 2C80845 & -0.564 & & & & & & & & & & & \\
\hline 4C89525 & & & & 1.613 & 1.811 & 2.108 & 2.273 & 2.286 & 2.474 & 2.177 & & \\
\hline 6C89184 & & & & & & & & & & & 1.016 & \\
\hline \multicolumn{13}{|l|}{ 7C89176 } \\
\hline \multicolumn{13}{|l|}{ 8C82158 } \\
\hline \multicolumn{13}{|l|}{$10 \mathrm{C} 84273$} \\
\hline \multicolumn{13}{|l|}{ 11C85391 } \\
\hline \multicolumn{13}{|l|}{ 12C83538 } \\
\hline \multicolumn{13}{|l|}{ 16C80975 } \\
\hline \multicolumn{13}{|l|}{ 18C87886 } \\
\hline 19C88788 & & & & & & & 1.666 & 2.032 & 2.309 & 2.520 & 2.520 & 2.697 \\
\hline 21C88758 & 0.523 & 0.762 & & & & & & & & & & \\
\hline 23C85612 & & & 0.968 & 1.214 & 1.588 & 2.060 & 2.258 & 3.068 & 2.964 & 2.931 & 2.931 & 2.987 \\
\hline \multicolumn{13}{|l|}{$25 C 81048$} \\
\hline \multicolumn{13}{|l|}{ 26C86628 } \\
\hline \multicolumn{13}{|l|}{ 27C83186 } \\
\hline \multicolumn{13}{|l|}{ 41C84570 } \\
\hline \multicolumn{13}{|l|}{ 42C89010 } \\
\hline \multicolumn{13}{|l|}{ 43С 85663} \\
\hline 44C85076 & -0.635 & -0.953 & -0.925 & & & & & & & & & \\
\hline $45 C 84358$ & 0.447 & & & & 1.095 & 1.928 & & & & & 2.426 & 2.591 \\
\hline 46C82008 & & & -0.925 & -0.953 & -0.897 & & -1.737 & -2.177 & -2.540 & -2.116 & -2.329 & -2.540 \\
\hline \multicolumn{13}{|l|}{$48 C 86842$} \\
\hline 50С89219 & & -0.706 & & & & & & & -2.032 & -2.177 & -1.834 & -1.778 \\
\hline
\end{tabular}


Appendix 6. Slope values (number/year) for the number of above threshold events for stations with significant trends during the 1950-2010 time period.

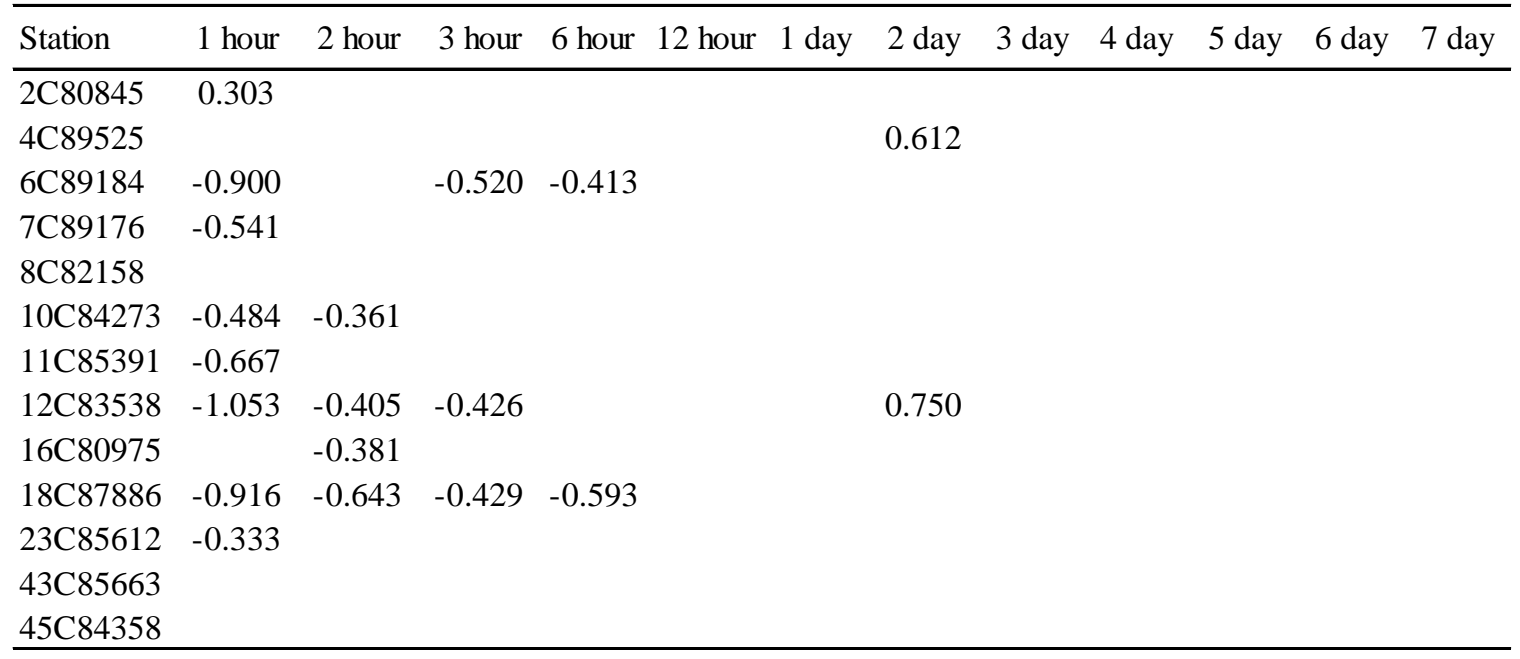

Appendix 7. Slope values (number/year) for the number of above threshold events for stations with significant trends during the 1960-2010 time period.

\begin{tabular}{|c|c|c|c|c|c|c|c|c|c|c|c|c|}
\hline Station & 1 hour & 2 hour & 3 hour & 6 hour & 12 hour & 1 day & 2 day & 3 day & 4 day & 5 day & 6 day & 7 day \\
\hline \multicolumn{13}{|l|}{ 2C80845 } \\
\hline \multicolumn{13}{|l|}{ 4C89525 } \\
\hline 6C89184 & -0.929 & & -0.524 & -0.444 & & & & & & & & \\
\hline 7C89176 & -0.353 & & & & & & & & & & & \\
\hline \multicolumn{13}{|l|}{ 8C82158 } \\
\hline $10 \mathrm{C} 84273$ & -0.474 & & & & & & & & & & & \\
\hline 11C85391 & -0.553 & & & & & & & & & & & \\
\hline $12 C 83538$ & -1.235 & -0.823 & -0.871 & -0.633 & & & & & & & & \\
\hline 16C80975 & & -0.593 & -0.367 & & & & & & & & & \\
\hline 18C87886 & -0.600 & -0.500 & & -0.462 & & & & & & & & -0.370 \\
\hline \multicolumn{13}{|l|}{ 19C88788 } \\
\hline 21C88758 & -0.559 & -0.565 & -0.643 & -0.700 & & & & & & & & \\
\hline \multicolumn{13}{|c|}{ 23C85612 } \\
\hline \multicolumn{13}{|l|}{ 27C83186 } \\
\hline \multicolumn{13}{|l|}{ 41C84570 } \\
\hline 43C85663 & 0.249 & 0.350 & 0.441 & & & & & & & & & \\
\hline 44C85076 & -0.500 & -0.405 & -0.371 & & & & & & & & & 0.210 \\
\hline 45C84358 & & & & & & & & & & & & \\
\hline
\end{tabular}


Appendix 8. Slope values (number/year) for the number of above threshold events for stations with significant trends during the 1970-2010 time period.

\begin{tabular}{|c|c|c|c|c|c|c|c|c|c|c|c|c|}
\hline Station & 1 hour & 2 hour & 3 hour & 6 hour & 12 hour & 1 day & 2 day & 3 day & 4 day & 5 day & 6 day & 7 day \\
\hline 2 2C80845 & & & & & & & & & & & 0.525 & 1.059 \\
\hline 4C89525 & & & & & & & & & & 0.838 & 1.286 & 0.542 \\
\hline 6C89184 & -0.691 & & & & & & & & & & & \\
\hline \multicolumn{13}{|l|}{ 7C89176 } \\
\hline \multicolumn{13}{|l|}{ 8C82158 } \\
\hline \multicolumn{13}{|l|}{ 10C84273 } \\
\hline $11 C 85391$ & & & & & & & & & & 1.000 & 1.340 & \\
\hline \multicolumn{13}{|l|}{$12 C 83538$} \\
\hline $16 C 80975$ & -0.413 & -0.690 & -0.420 & -0.659 & -0.659 & & & & & & & \\
\hline \multicolumn{13}{|c|}{$18 \mathrm{C} 87886$} \\
\hline 19C88788 & & & & & & & & & 1.036 & 0.863 & 0.863 & 0.900 \\
\hline 21C88758 & -0.739 & -0.714 & -0.814 & -0.784 & & & & & & & & \\
\hline 23C85612 & & 0.500 & 0.620 & 0.826 & 1.148 & 1.164 & & 1.300 & 1.134 & & & \\
\hline \multicolumn{13}{|l|}{ 25C81048 } \\
\hline \multicolumn{13}{|l|}{$26 C 86628$} \\
\hline \multicolumn{13}{|l|}{ 27C83186 } \\
\hline \multicolumn{13}{|l|}{$41 C 84570$} \\
\hline \multicolumn{13}{|l|}{ 42C89010 } \\
\hline $43 C 85663$ & 0.477 & 0.533 & 0.640 & 0.820 & 0.863 & 1.191 & & & & & & \\
\hline \multicolumn{13}{|l|}{ 44C85076 } \\
\hline \multicolumn{13}{|l|}{ 45C84358 } \\
\hline \multicolumn{13}{|l|}{ 46C82008 } \\
\hline 48C86842 & -0.464 & -0.958 & -0.923 & -0.769 & & & & & & & & \\
\hline 50C89219 & & -0.500 & -0.761 & -0.817 & -0.870 & & & & & & & \\
\hline
\end{tabular}


Appendix 9. Slope values (number/year) for the number of above threshold events for stations with significant trends during the 1980-2010 time period.

\begin{tabular}{|c|c|c|c|c|c|c|c|c|c|c|c|c|}
\hline Station & 1 hour & 2 hour & 3 hour & 6 hour & 12 hour & 1 day & 2 day & 3 day & 4 day & 5 day & 6 day & 7 day \\
\hline 2C80845 & & & & & & & & & & & 1.269 & 3.667 \\
\hline 4C89525 & & & -0.682 & -0.846 & & & & & & & 2.231 & 0.769 \\
\hline \multicolumn{13}{|l|}{ 6C89184 } \\
\hline \multicolumn{13}{|l|}{ 7C89176 } \\
\hline \multicolumn{13}{|l|}{ 8C82158 } \\
\hline \multicolumn{13}{|l|}{$10 \mathrm{C} 84273$} \\
\hline 11C85391 & & & -0.846 & -1.400 & -1.583 & & & & & & & \\
\hline \multicolumn{13}{|l|}{ 12C83538 } \\
\hline 16C80975 & & & & & -0.813 & & & & & & & \\
\hline $18 C 87886$ & & -0.826 & & & -1.333 & & & & & & -0.778 & \\
\hline 19C88788 & & & & & & & & & & & 1.333 & 3.125 \\
\hline \multicolumn{13}{|l|}{$21 C 88758$} \\
\hline 23C85612 & & & & & & 1.826 & & 2.700 & 3.250 & 2.150 & 2.313 & 1.520 \\
\hline \multicolumn{13}{|l|}{ 25C81048 } \\
\hline \multicolumn{13}{|l|}{ 26C86628 } \\
\hline 27C83186 & 1.0714 & 1.0476 & & & & & & & & & & \\
\hline $41 \mathrm{C} 84570$ & & & & & & -1.692 & & & & & & \\
\hline \multicolumn{13}{|l|}{ 42C89010 } \\
\hline \multicolumn{13}{|l|}{$43 C 85663$} \\
\hline \multicolumn{13}{|l|}{ 44C85076 } \\
\hline 45C84358 & & & & & & & & 1.769 & & & & \\
\hline 46C82008 & -2.133 & -1.500 & -1.235 & -1.941 & -2.500 & -2.600 & -3.294 & -3.087 & -2.600 & -3.375 & -3.652 & -3.250 \\
\hline 48C86842 & -0.619 & -1.000 & -1.292 & -1.167 & & & & -1.667 & -2.588 & & & \\
\hline 50C89219 & & -1.000 & -1.238 & -1.467 & & & -2.591 & -2.813 & -2.077 & -3.000 & -3.100 & -1.706 \\
\hline
\end{tabular}


Appendix 10. Slope values (mm/year) for the average magnitude of the above threshold events for stations with significant trends during the 1950-2010 time period.

\begin{tabular}{|c|c|c|c|c|c|c|c|c|c|c|c|c|}
\hline Station & 1 hour & 2 hour & 3 hour & 6 hour & 12 hour & 1 day & 2 day & 3 day & 4 day & 5 day & 6 day & 7 day \\
\hline $2 \mathrm{C} 80845$ & & 0.043 & & & & & & & & & & \\
\hline 4C89525 & & & & 0.074 & 0.145 & 0.208 & & & & & & \\
\hline 6C89184 & 0.051 & & 0.030 & & & & & & & & & \\
\hline 7C89176 & 0.061 & 0.033 & 0.064 & 0.056 & & & & & & & & \\
\hline \multicolumn{13}{|l|}{ 8C82158 } \\
\hline $10 \mathrm{C} 84273$ & 0.038 & 0.053 & & 0.081 & & & & & & & & \\
\hline 11C85391 & 0.036 & -0.028 & & & & & & & & & & \\
\hline $12 C 83538$ & 0.064 & 0.069 & 0.084 & 0.104 & 0.150 & 0.201 & & & & & & \\
\hline $16 C 80975$ & & 0.056 & 0.051 & & 0.137 & & & & & & & \\
\hline 18C87886 & 0.038 & 0.061 & & 0.061 & & & & & & & & \\
\hline 23C85612 & 0.056 & 0.061 & 0.066 & 0.084 & 0.112 & 0.183 & 0.254 & & & & & \\
\hline \multicolumn{13}{|c|}{ 43C85663 } \\
\hline 45C84358 & & & & & & & & & & & & \\
\hline
\end{tabular}

Appendix 11. Slope values (mm/year) for the average magnitude of the above threshold events for stations with significant trends during the 1960-2010 time period.

\begin{tabular}{|c|c|c|c|c|c|c|c|c|c|c|c|c|}
\hline Station & 1 hour & 2 hour & 3 hour & 6 hour & 12 hour & 1 day & 2 day & 3 day & 4 day & 5 day & 6 day & 7 day \\
\hline \multicolumn{13}{|l|}{2 280845 } \\
\hline 4C89525 & & & & 0.079 & & 0.231 & & 0.450 & & 0.284 & & \\
\hline 6C89184 & 0.061 & & 0.038 & & & & & & & & & \\
\hline 7C89176 & 0.036 & & 0.046 & & & & & & & & & \\
\hline \multicolumn{13}{|l|}{ 8C82158 } \\
\hline $10 \mathrm{C} 84273$ & 0.043 & 0.058 & & 0.084 & & & & & & & & \\
\hline 11C85391 & 0.033 & & & & & & & & 0.282 & & & \\
\hline 12C83538 & 0.046 & 0.043 & 0.058 & & & & & & & & & \\
\hline $16 C 80975$ & & 0.046 & & & 0.170 & & & & & & & \\
\hline $18 \mathrm{C} 87886$ & 0.028 & 0.038 & & & & & & & -0.450 & & & \\
\hline \multicolumn{13}{|l|}{ 19C88788 } \\
\hline 21C88758 & 0.025 & 0.030 & 0.053 & & & & & & & & & \\
\hline $23 C 85612$ & 0.053 & 0.053 & 0.058 & & & & & & & & & \\
\hline \multicolumn{13}{|l|}{ 27C83186 } \\
\hline \multicolumn{13}{|l|}{$41 \mathrm{C} 84570$} \\
\hline \multicolumn{13}{|l|}{ 43С 85663} \\
\hline $44 C 85076$ & 0.030 & 0.033 & 0.046 & 0.081 & & & & & 0.429 & 0.480 & 0.114 & 0.185 \\
\hline 45C84358 & 0.018 & & & & & & & & & & & \\
\hline
\end{tabular}


Appendix 12. Slope values (mm/year) for the average magnitude of the above threshold events for stations with significant trends during the 1970-2010 time period.

\begin{tabular}{|c|c|c|c|c|c|c|c|c|c|c|c|c|}
\hline Station & 1 hour & 2 hour & 3 hour & 6 hour & 12 hour & 1 day & 2 day & 3 day & 4 day & 5 day & 6 day & 7 day \\
\hline 2C80845 & & & & & & & & & & & & 0.023 \\
\hline 4C89525 & & & & & & 0.318 & & 1.026 & 0.729 & 0.645 & 0.511 & 0.711 \\
\hline 6C89184 & 0.058 & & & & & & & & & & & \\
\hline 7C89176 & & & & 0.084 & 0.152 & & & & & & & \\
\hline 8C82158 & & & & & & & & & & & & 0.023 \\
\hline \multicolumn{13}{|l|}{$10 \mathrm{C} 84273$} \\
\hline 11C85391 & & & & & & & & 0.536 & 0.655 & 0.754 & 0.724 & \\
\hline \multicolumn{13}{|l|}{$12 C 83538$} \\
\hline \multicolumn{13}{|l|}{ 16C80975 } \\
\hline \multicolumn{13}{|l|}{$18 C 87886$} \\
\hline 19C88788 & & & & & & & 0.389 & 1.247 & 1.176 & 0.973 & & \\
\hline 21C88758 & & & 0.064 & 0.127 & & & & & & & & \\
\hline 23C85612 & 0.038 & 0.058 & 0.074 & & & & 0.429 & 0.523 & 0.978 & 0.879 & 0.457 & \\
\hline \multicolumn{13}{|l|}{ 25C81048 } \\
\hline \multicolumn{13}{|l|}{ 26C86628 } \\
\hline 27C83186 & -0.030 & -0.053 & & & & & & & & & & \\
\hline \multicolumn{13}{|c|}{$41 \mathrm{C} 84570$} \\
\hline \multicolumn{13}{|l|}{$42 C 89010$} \\
\hline \multicolumn{13}{|l|}{$43 C 85663$} \\
\hline 44C85076 & & & & & & & & & & 0.592 & 0.325 & 0.287 \\
\hline $45 C 84358$ & 0.041 & 0.056 & 0.069 & & & & & & & & & \\
\hline \multicolumn{13}{|l|}{ 46C82008 } \\
\hline \multicolumn{13}{|l|}{ 48C86842 } \\
\hline 50C89219 & -0.036 & & & & & & & & & & & \\
\hline
\end{tabular}


Appendix 13. Slope values (mm/year) for the average magnitude of the above threshold events for stations with significant trends during the 1980-2010 time period.

\begin{tabular}{|c|c|c|c|c|c|c|c|c|c|c|c|c|}
\hline Station & 1 hour & 2 hour & 3 hour & 6 hour & 12 hour & 1 day & 2 day & 3 day & 4 day & 5 day & 6 day & 7 day \\
\hline $2 \mathrm{C} 80845$ & -0.064 & -0.117 & -0.127 & & & & & & & & \multicolumn{2}{|l|}{0.678} \\
\hline 4C89525 & & & & 0.175 & 0.455 & 0.480 & 1.379 & 1.869 & 1.567 & 1.433 & & 1.326 \\
\hline \multicolumn{13}{|l|}{ 6C89184 } \\
\hline \multicolumn{13}{|l|}{ 7C89176 } \\
\hline 8C82158 & & & & & & & & & & & & 1.326 \\
\hline \multicolumn{13}{|l|}{ 10C84273 } \\
\hline \multicolumn{13}{|l|}{ 11C85391 } \\
\hline 12C83538 & & & 0.074 & & & & & & & & & \\
\hline \multicolumn{13}{|l|}{$16 \mathrm{C} 80975$} \\
\hline \multicolumn{13}{|l|}{$18 \mathrm{C} 87886$} \\
\hline 19C88788 & & & & & & & 0.701 & 1.488 & 1.806 & 1.836 & 1.168 & 0.117 \\
\hline 21C88758 & & & 0.089 & 0.218 & & & & & & & & \\
\hline $23 C 85612$ & 0.046 & 0.109 & 0.140 & 0.170 & 0.361 & 0.554 & 1.750 & 2.413 & 2.654 & 2.540 & 1.796 & 1.758 \\
\hline \multicolumn{13}{|l|}{$25 C 81048$} \\
\hline \multicolumn{13}{|l|}{$26 C 86628$} \\
\hline 27C83186 & -0.053 & -0.102 & & & & & & & & & & \\
\hline $41 C 84570$ & & -0.058 & & & & & & & & & & \\
\hline \multicolumn{13}{|l|}{$42 C 89010$} \\
\hline \multicolumn{13}{|l|}{ 43С 85663} \\
\hline \multicolumn{13}{|l|}{ 44C85076 } \\
\hline $45 C 84358$ & 0.058 & 0.079 & & & 0.315 & 0.772 & 1.270 & & & & & \\
\hline $46 C 82008$ & & & -0.117 & & & & & & -1.295 & -1.509 & -1.679 & -1.473 \\
\hline \multicolumn{13}{|l|}{ 48C86842 } \\
\hline 50C89219 & -0.051 & & & & & & & & & & & \\
\hline
\end{tabular}

